NASA Contractor Report 181708

AN EXPERIMENTAL INVESTIGATION OF THE AERODYNAMIC CHARACTERISTICS OF SLANTED BASE OGIVE CYLINDERS

$$
\begin{array}{r}
1 N-02 \\
234858 \\
290
\end{array}
$$

USING MAGNETIC SUSPENSION TECHNOLOGY

Charles W. Alcorn

OLD DOMINION UNIVERSITY

Norfolk, Virginia

Grant NAG1-716.

November 1988

(NASA-CR-181708) AN EXPERIMENTAL

INVFSTIGATION OF THE AEROOYNAMIC

CHARACTERISTICS OF SLANTEO BASE JGIVE

CYLINDERS USING MAGNETIC SUSPENSION

TECHNOLOGY (OId DOminion Univ.) $90 \mathrm{p}$

N9O-10834

Unclas

$63 / 020234858$

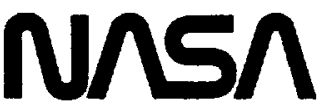

National Aeronautics and

Space Administration

Langley Research Center

Hampton, Virginia 23665 


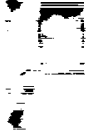




\title{
AN EXPERIMENTAL INVESTIGATION OF THE AERODYMAMIC CHARACTERISTICS OF SLANTED BASE OGIVE CYLINDERS USING MAGNETIC SUSPENSION TECHMOLOGY
}

\author{
By \\ Charles W. Alcorn* \\ Principal Investigator: Colin Britcher
}

\begin{abstract}
An experimental investigation is reported on slanted base ogive cylinders at zero incidence. The Mach number range is 0.05 to 0.3. All flow disturbances associated with wind tunnel supports are eliminiated in this investigation by magnetically suspending the wind tunnel models. The sudden and drastic changes in the lift, pitching moment, and drag for a slight change in base slant angle are reported. Flow visualization with liquid crystals and $0 i 1$ is used to observe base flow patterns, which are responsible for the sudden changes in aerodynamic characteristics. Hysteretic effects in base flow pattern changes are present in this investigation and are reported. The effects of a wire support attachment on the $0^{\circ}$ slanted base mode 1 is studied. Computational drag and transition location results using VSAERO and SANDRAG are presented and compared with experimental results. Base pressure measurements over the slanted bases are made with an onboard pressure transducer using remote data telemetry.
\end{abstract}

*Graduate Research Assistant, Department of Mechanical Engineering and Mechanics, 0ld Dominion University, Norfolk, Virginia 232529. 


\section{ACKNOWLEGMENTS}

The author wishes to thank Dr. Colin P. Britcher for his help and guidance in this research. The author also wishes to thank the members of the Experimental Techniques Branch at Langley Research Center. Further appreciation for support goes to Timothy Schott from the Instrument Research Division at Langley Research Center. Major support for this research provided by NASA Grant NAG1-716, R.P. Boyden, Technical Monitor. Further support provided by the Old Dominion Alumni Association through a fellowship and Meredith Construction Co. through a scholarship. 
TABLE OF CONTENTS

Page

LIST OF TABLES.

$\mathbf{v}$

LIST OF FIGURES.................................................................................. vi

NOMENCLATURE............................................................................................. i i i

Chapter

1. INTRODUCTION........................................................................... 1

1.1 Previous Research........................................................................ 1

1.2 Objectives of the Current Study................................................. 2

1.3 NASA Langley Research Center 13 Inch

Magnetic Suspension and Balance System.................................... 3

1.4 Data Acquisition........................................................................... 4

2. ELECTROMAGNETIC FORCE AND TORQUE EQUATIONS............. 6

2.1 Development of Force and Torque Equations............................... 6

2.2 Field Assumptions.......................................................................... 11

2.3 Determination of Force and Torque Coefficients.......................... 12

3. AERODYNAMIC COEFFICIENTS AND REYNOLDS NUMBER

CALCULATIONS................................................................................. 15

3.1 Aerodynamic Coefficients......................................................... 15

3.2 Reynolds Number Calculations................................................... 16

3.3 Buoyancy Corrections................................................................. 16

3.4 Blockage Corrections.................................................................... 18

3.5 Corrections to Flow Properties.................................................. 19

4. EXPERIMENTAL RESULTS..................................................... 22

4.1 Aerodynamic Characteristics................................................... 22

4.2 Flow Visualization.................................................................. 24

5. COMPUTATIONAL RESULTS.................................................... 25

5.1 Transition Results................................................................... 25

5.2 Drag Results............................................................................ $\quad 26$ 
6. BASE PRESSURE MEASUREMENTS.............................................. 28

6.1 Pressure Telemetry System........................................................ 28

6.2 MSBS Wind Tunnel Pressure Model............................................ 29 29

6.3 Calibration of the Pressure Transducer.......................................... 30

6.4 Experimental Results.................................................................. 31

7. CONCLUSIONS........................................................................................ 33

REFERENCES................................................................................................... 35

\section{APPENDIXES}

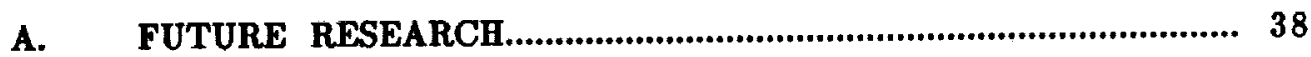

B. CALCULATION METHODS IN SANDRAG AND VSAERO...............40 40 


\section{LIST OF TABLES}

Table

1. Drag, Lift, and Pitching Moment Equations for MSBS Slanted Base Models.... 14

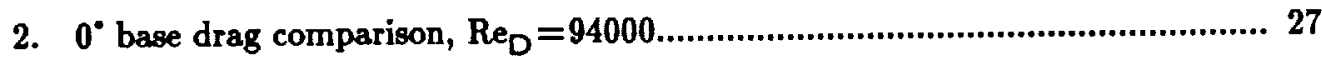




\section{LIST OF FIGURES}

Figure

Page

1. Wake structures behind slanted base models...................................... 41

2. Slanted base drag results................................................................. 41

3. Critical angle of attack for drag overshoot...................................... 42

4. Support systems....................................................................... 42

5. Slanted base ogive cylinder model components................................. 43

6. Magnetic suspension and balance system........................................ 44

7. Demagnetizing factor for a cylinder.............................................. 47

8. Orientation of tunnel axis and body axis system.............................. 48

9. Calibration set-ups to determine force and torque coefficients............ 49

10. Buoyancy effects in a closed throat wind tunnel............................... 50

11. Velocity distribution of $0^{\circ}$ slanted base (VSAERO).......................... 51

12. Pressure tap locations to determine pressure differential.................... 52

13. Blockage effects in a closed throat tunnel......................................... 53

14. Buoyancy and blockage corrections on drag results.......................... 54

15. Experimental results (drag, lift, and pitching moment)..................... 55

16. MSBS/Morel drag results.............................................................. 64

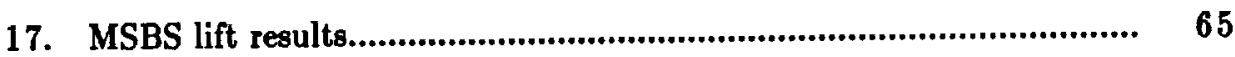

18. MSBS pitching moment results....................................................65

19. Effects of a wire attachment......................................................... 66

20. Base flow patterns using liquid crystals......................................... 67

21. Pressure distribution (VSAERO) and predicted transition locations, $0^{\circ}$ base............................................................................ 69 
22. Details of SANDRAG computations........................................... 69

23. Comparison of SANDRAG and MSBS drag results......................... 70

24. Schematic of pressure telemetry system......................................... 71

25. Details of pressure transducer............................................................ 71

26. Details of pressure telemetry model................................................ 72

27. Schematic of pressure transducer calibration set-up........................... 75

28. Pressure transducer calibration curve............................................ 76

29. Effects of input voltage on output frequency................................ 76

30. MSBS slanted base pressure measurements........................................ 77 


\section{NOMENCLATURE}

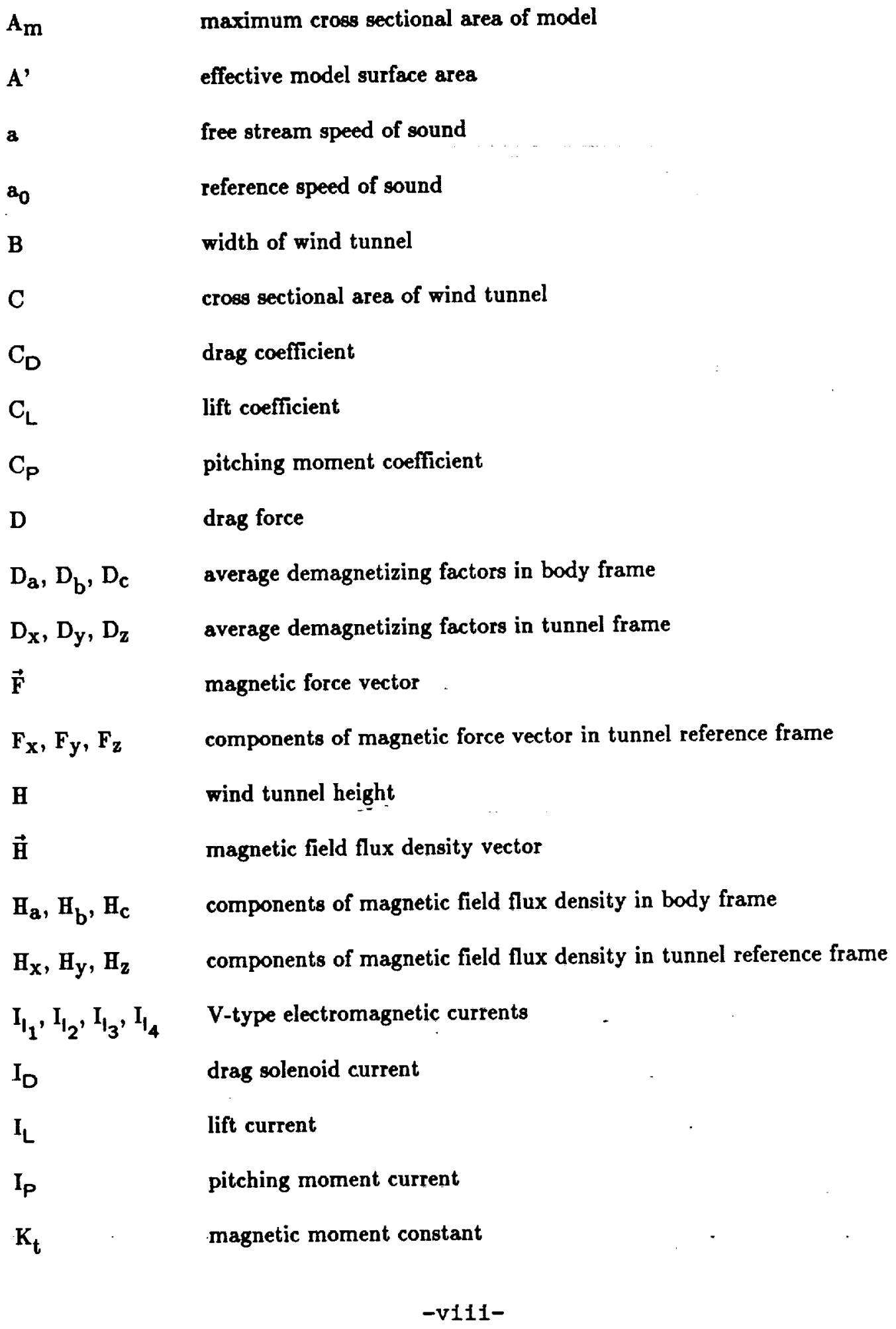




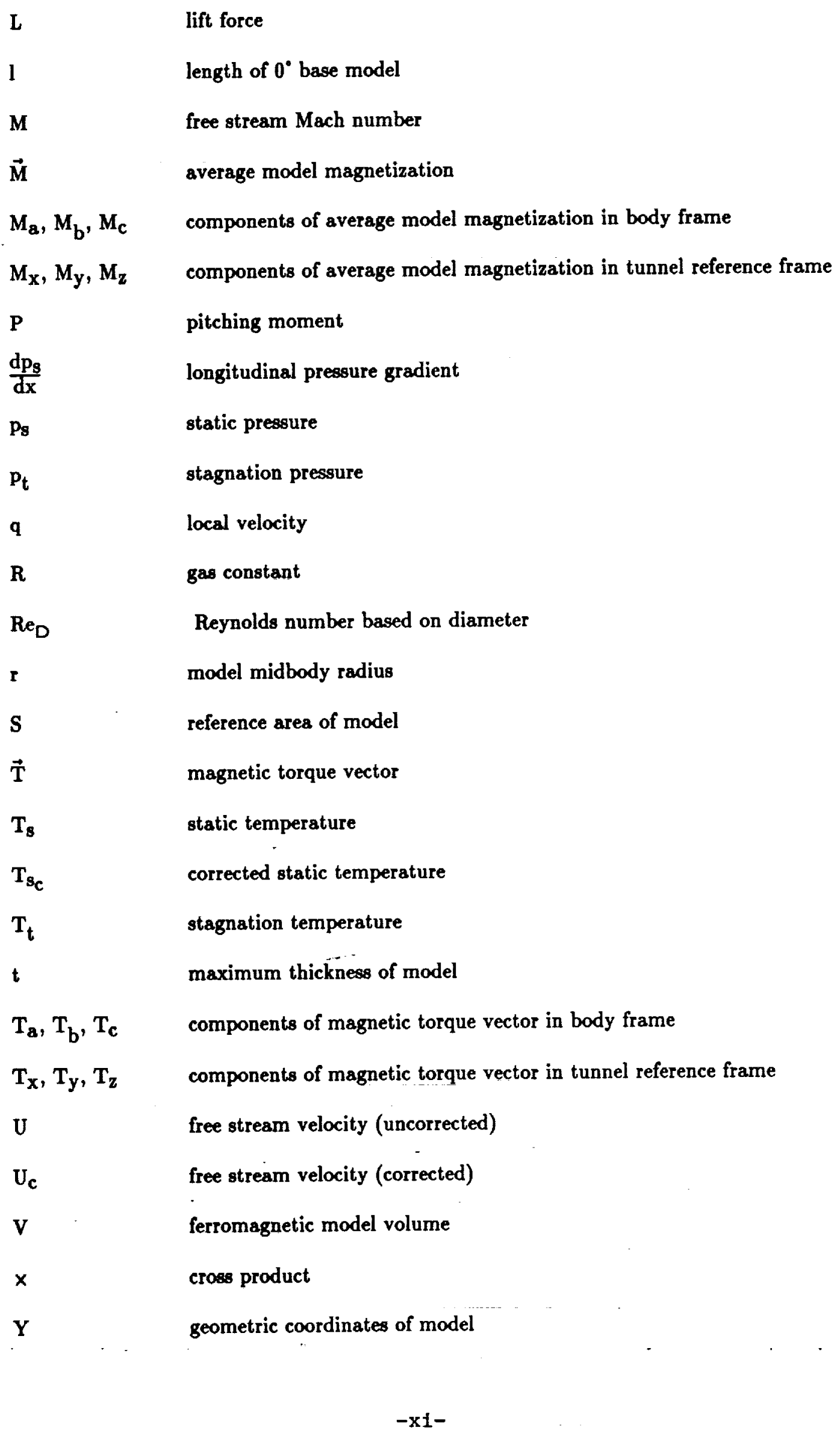




$\begin{array}{ll}\beta & \left(1-\mathrm{M}^{2}\right)^{\frac{1}{2}} \\ \gamma & \text { ratio of specific heats } \\ \epsilon_{\mathrm{s}} & \text { solid body blockage factor } \\ \epsilon_{\mathrm{W}} & \text { wake blockage factor } \\ \Delta \mathrm{U}_{\mathrm{b}} & \text { free stream velocity increment due to blockage } \\ \lambda_{3} & \text { symmetrical body interference factor (dependent on tunnel type) } \\ \mu & \text { magnetic permeability (relative to air) } \\ \mu_{\mathrm{v}} & \text { absolute viscosity } \\ \tau & \text { symmetrical body interference factor (dependent on model shape) } \\ \nabla & \text { gradient operator }\end{array}$




\section{INTRODUCTION}

\subsection{Previous Research}

Applications of this study are in the automotive and aircraft industries. The aftbody of most transport aircraft fuselages and certain car designs, notably hatchback cars, have slant bases. Interest in this research is due to the sudden change in base drag for a small change in slant angle. The sudden change in drag is attributed to the sudden change in separated flow patterns in the near wake. Specifically, the base flow pattern changes from a quasi-symmetric separation pattern to a three-dimensional, longitudinal vortex flow. These vortices produce low pressures and therefore, high base drag.

Jansson and Hucho ${ }^{1}$ discuss early research on this subject. Their paper presents the effects of an automobile rear window on vehicle drag. The study concludes that a small change in rear window angle $\left(55^{\circ}\right.$ to $\left.65^{\circ}\right)$, creates a large drag change and creates changes in the near wake flow pattern. Morel, ${ }^{2,3}$ isolated the effects in the near wake by studying slanted base ogive cylinders. Fig. 1 illustrates the base flow patterns observed by Morel. This investigation involved the study of factors that influence vehicles, such as, rounding the upper slant edge, Reynold's number effects, free stream turbulence, and ground effects. Of these factors, Morel concludes that only rounding the upper slant edge had important modifications on the drag overshoot. The critical slant angle shifts to a higher angle due to rounding. Drag overshoot existed for all factors tested and occurred between $45^{\circ}$ and $46.5^{\circ}$ for the drag runs and $47.25^{\circ}$ and $48^{\circ}$ for the pressure runs. This variation is attributed to differences in the experimental set-up. Fig. 2 shows a typical drag coefficient versus slant angle curve. 
Maull $^{4}$ verified Morel's drag results for slant-based bodies of revolution. Furthermore, drag measurements were made for an incidence range of $-6^{\circ}$ to $6^{\circ}$. Maull shows that the incidence at which the drag overshoot occurs is a linear function of the slant angle. Maull also observed a hysteresis effect in the formation of the base flow patterns when changing the model incidence. Hysteresis effects do not show on drag results since the tunnel was stopped to change incidence for drag measurements.

Xia and Bearman ${ }^{5}$ investigated the effects of incidence on axisymmetric bodies with slanted bases. Their study shows that hysteretic effects exist for the critical incidence for transition between base flow patterns. Furthermore, base pressure measurements with the $45^{\circ}$ base at zero incidence show that the base flow pattern is vortical for all fineness ratios. However, drag measurements for this base at zero incidence indicate that the base flow pattern is a function of the fineness ratio. According to Xia and Bearman, these discrepancies may be due to slight variations in mounting the models and small variations in the approaching flow properties. A further explanation is due to drag measurements being made by increasing the incidence with the tunnel running. The authors compare estimates of the incidence at which the base flow pattern changes with Maull. Fig. 3 shows the comparison. The lack of agreement is attributed to differences in the experimental arrangement (mechanical supports) and. procedures.

These earlier investigations of slanted bases used various arrangements for supporting the models. Morel obtained measurements by suspending the wind tunnel model on thin wires. Maull suspends the wind tunnel model by wires attached to airfoil sections on the model and a wire from the straight section of the body. Xia and Bearman used two support arms attached to the forebody by two tapered rods, and tail wires. Fig. 4 compares these support systems.

\subsection{Objectives of the Current Study}

Research at the NASA Langley Research Center (LaRC) 13 inch Magnetic Suspension and Balance System (MSBS) is intended to validate previous slanted base drag results and to extend 
lift and pitching moment results. Test results will be free of all flow disturbances due to mechanical supports. The slanted base ogive cylinder model in this study is aluminum with interchangeable bases. The nose of the model consists of a 7.1 inch ogive radius, while the cylindrical midbody is 8.323 inches long with a 1.212 inch outer diameter. The aftbody consists of interchangeable bases with $0^{\circ}, 30^{\circ}, 40^{\circ}, 45^{\circ}, 50^{\circ}$, and $60^{\circ}$ slants. A magnetic core of ultra-low carbon iron, 7.225 inches long by 1 inch in diameter is inserted in the model for suspension purposes. Fig. 5 shows the model.

\subsection{NASA Langley Research Center 13 Inch Magnetic Suspension and Balance System}

\subsubsection{Wind Tunnel}

The LaRC 13 inch MSBS wind tunnel is an open circuit design shown schematically in Fig. 6a. Outside air at ambient conditions is drawn into the wind tunnel through a large bellmouth inlet. Air flows through a constant diameter duct from the bellmouth to the first set of turning vanes. A quick diffuser and settling chamber are downstream of the first turn. The settling chamber has several screens to condition the flow for entry into the contraction and test section. A transition section connects the contraction and the test section. The test section cross-section is a modified octagon 12.56 inches from top to bottom wall and 10.69 inches from side wall to side wall. It is 48 inches long and is made of Lexan (brand name Polycarbonate) to permit viewing of the model in flight. Fig. $6 \mathrm{~b}$ shows the inside dimensions of the test section cross-section. Another transition section follows the test section. Both transition sections have the same geometry to minimize costs. A $2 \frac{1}{2}$ inch thick steel honeycomb follows the second transition section to protect the fan from loose objects. Another set of turning vanes follows the honeycomb to direct the flow into the fan. A $200 \mathrm{hp}, 6000 \mathrm{rpm}$ motor drives the fan and is installed in a nacelle. ${ }^{6}$ 


\subsubsection{Electromagnets}

Four copper electromagnets are arranged in a "V-type" configuration to provide the lift force, pitching moment, side force, and yawing moment. An axial solenoid upstream of the test section provides the drag force. Fig. 6c shows the electromagnet configuration. During the tests reported here, the electromagnets were powered by a mix of thyratron, thyristor, and rectified motor-driven variac power supplies. ${ }^{7}$

\subsubsection{Position Sensors}

The position sensors monitor the model's position and orientation in five degrees of freedom. The system uses five linear photodiode arrays shown schematically in Fig. 6d. Each array contains 1024 elements with a 0.001 inch spacing. A laser illuminates a sensor with a vertical light sheet. A model in suspension blocks part of the light sheet, casting a shadow on the array. The spacing of the elements allows the shadow location to be measured to 0.001 inches accuracy. 8

\subsubsection{Control System}

The control system stabilizes and controls the position and attitude of the suspended model. The feedback control system is implemented digitally using a PDP $11 / 23+$ minicomputer. The controller is essentially a digitial simulation of classical analogue MSBS control systems. Programming is almost entirely in assembly language to speed execution. Fig. 6e shows a block diagram of the digitally controlled MSBS. ${ }^{9}$

\subsection{Data Acquisition}

During testing, the data acquisition system measures the wind tunnel parameters, such as, the stagnation and static pressure and the stagnation temperature. Further measurements include the coil currents. These currents are converted into aerodynamic forces through a 
calibration discussed in detail in Chapter 2.

The Hewlett Packard 3497A Data Acquisition/Control Unit, (DACU) reads thermocouple, pressure transducer, and coil voltages. An IBM PC XT runs the software that drives the DACU. Calibrations in the software convert voltage readings into temperature, pressure, and coil current values. A complete scan through all channels of the DACU measures the control and bias currents in the four V-type electromagnets and the control current in the drag solenoid. Further measurements within a complete run include the wind tunnel parameters. The data acquisition software also computes the average of each measurement using values from the present run and from four previous runs. At the completion of each run, the data acquisition software calculates the local Mach number using isentropic flow assumptions.

Modifications to the data acquisition software improve the data retrieval process for future research. The DACU scans the coil voltages twenty times before converting these values to coil currents and printing them to the screen. The previous software printed these values to the screen after every scan which slows the data retrieval process. Pressure transducer voltages are read every five runs to calculate the local Mach number. The local Mach number is then printed to the screen every fifth scan giving the tunnel operator a faster turnaround in local Mach number readings. On the twentieth run, the DACU scans all channels and then prints temperature, pressure, current, and Mach number values to the screen. This software is three to four times faster than the previous version. 


\section{ELECTROMAGNETIC FORCE AND TORQUE EQUATIONS}

\subsection{Development of Force and Torque Equations}

The magnetic force, $\vec{F}$, and torque, $\vec{T}$, on a ferromagnetic body can be determined by regarding the body as a magnetic dipole placed in a magnetic field. The vector equations can be written as follows:

$$
\begin{aligned}
& \mathrm{d} \overrightarrow{\mathrm{F}}=\mathrm{K}_{\mathrm{t}}(\overrightarrow{\mathrm{M}} \cdot \nabla) \overrightarrow{\mathrm{H}} \mathrm{dV} \\
& \mathrm{d} \overrightarrow{\mathrm{T}}=\mathrm{K}_{\mathrm{t}}(\overrightarrow{\mathrm{M}} \times \overrightarrow{\mathrm{H}}) \mathrm{dV}
\end{aligned}
$$

With reasonably uniform fields, the vector equations can be written as follows:*

$$
\begin{aligned}
& \overrightarrow{\mathrm{F}} \simeq \mathrm{K}_{\mathrm{t}} \mathrm{V}(\overrightarrow{\mathrm{M}} \cdot \nabla) \overrightarrow{\mathrm{H}} \\
& \overrightarrow{\mathrm{T}} \simeq \mathrm{K}_{\mathrm{t}} \mathrm{V}(\overrightarrow{\mathrm{M}} \times \overrightarrow{\mathrm{H}}) .
\end{aligned}
$$

Gilliam $^{10}$ applied these equations to a MSBS model at a given incidence, yaw, and roll angle. Writing these equations in matrix form gives,

* For example, see An Introduction to Electromagnetic Theory by P. C. Clemmow 


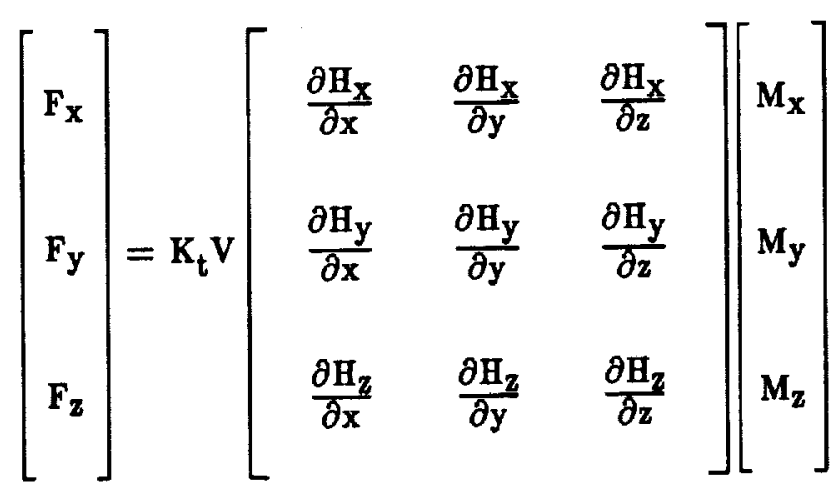

$$
\left[\begin{array}{c}
T_{x} \\
T_{y} \\
T_{z}
\end{array}\right]=K_{t} V\left[\begin{array}{l}
M_{x} \\
M_{y} \\
M_{z}
\end{array}\right] \times\left[\begin{array}{l}
H_{x} \\
H_{y} \\
H_{z}
\end{array}\right]
$$

The components of average magnetization for a soft iron core are,

$$
\begin{aligned}
& \mathrm{M}_{\mathrm{X}}=\frac{\mu}{1+\mu \mathrm{D}_{\mathrm{X}}} \mathrm{H}_{\mathbf{X}} \\
& \mathrm{M}_{\mathrm{y}}=\frac{\mu}{1+\mu \mathrm{D}_{\mathrm{y}}} \mathrm{H}_{\mathbf{y}} \\
& \mathrm{M}_{\mathbf{z}}=\frac{\mu}{1+\mu \mathrm{D}_{\mathbf{z}}} \mathrm{H}_{\mathbf{z}}
\end{aligned}
$$

where $\mu$ is the magnetic permeability of the material (relative to air). The relative permeability for typical materials that are moderately magnetized is in the order of 5000 to 20000 . The demagnetization factors, $D_{i}$, are related as follows.

$$
D_{x}+D_{y}+D_{z}=1 \quad \text { (three dimensional) }
$$




$$
\mathrm{D}_{\mathrm{y}}+\mathrm{D}_{\mathrm{z}}=1 \quad \text { (two-dimensional) }
$$

The demagnetizing factor, $D_{X}$ will decrease as the core slenderness ratio increases as Fig. 7 shows. ${ }^{11}$ The MSBS core is cylindrical and has a slenderness ratio of 7.225. For the permeability range mentioned above, $D_{x} \simeq 0.024$. Since the relative permeability is quite high, the assumption that $\mu D_{i}>1$ is allowed. This simplifies the average magnetization equations.

$$
M_{i} \simeq \lim _{\mu \rightarrow \infty}\left(\frac{\mu}{1+\mu D_{i}}\right) H_{i} \simeq \frac{H_{i}}{D_{i}}
$$

Expressing the average magnetization equations in the body frame gives:

$$
M_{a}=\frac{H_{a}}{D_{a}} \quad M_{b}=\frac{H_{b}}{D_{b}} \quad M_{c}=\frac{H_{c}}{D_{c}}
$$

The average magnetization equations in matrix form gives:

$$
\left[\begin{array}{l}
M_{a} \\
M_{b} \\
M_{c}
\end{array}\right]=\left[\begin{array}{ccc}
\frac{1}{D_{a}} & 0 & 0 \\
0 & \frac{1}{D_{b}} & 0 \\
0 \cdots & 0 & \frac{1}{D_{c}}
\end{array}\right]\left[\begin{array}{l}
H_{a} \\
H_{b} \\
H_{c}
\end{array}\right]
$$

Fig. 8 shows the body frame coordinates $(a, b, c)$ with the tunnel reference frame $(x, y, z)$. The transformation from the tunnel reference frame to the body reference frame is as follows. 


$$
\left[\begin{array}{l}
\mathrm{a} \\
\mathrm{b} \\
\mathrm{c}
\end{array}\right]=\left[\begin{array}{ccc}
1 & 0 & 0 \\
0 & \cos \phi & \sin \phi \\
0 & -\sin \phi & \cos \phi
\end{array}\right]\left[\begin{array}{ccc}
\cos \theta & 0 & \sin \theta \\
0 & 1 & 0 \\
-\sin \theta & 0 & \cos \theta
\end{array}\right]\left[\begin{array}{ccc}
\cos \psi & \sin \psi & 0 \\
-\sin \psi & \cos \psi & 0 \\
0 & 0 & 1
\end{array}\right]\left[\begin{array}{l}
\mathrm{x} \\
y \\
z
\end{array}\right]
$$

To date research at the LaRC 13 inch MSBS involves zero degree yaw, roll, and angle of attack measurements. Therefore, the body frame is aligned with the tunnel reference frame. Under these conditions the transformation matrices reduce to the identity matrix as expected. Future modifications to the MSBS will allow for high angle of attack tests. Therefore, further analysis of the force and torque equations will include the transformation matrix for angles of attack with the remaining matrices equal to the identity matrix.

$$
\left[\begin{array}{l}
\mathrm{a} \\
\mathrm{b} \\
\mathrm{c}
\end{array}\right]=\left[\begin{array}{ccc}
\cos \theta & 0 & \sin \theta \\
0 & 1 & 0 \\
-\sin \theta & 0 & \cos \theta
\end{array}\right]\left[\begin{array}{l}
\mathrm{x} \\
\mathrm{y}
\end{array}\right]=[\mathrm{M}]\left[\begin{array}{l}
\mathrm{x} \\
\mathrm{y} \\
\mathrm{z}
\end{array}\right]
$$

The inverse matrix of a orthogonal matrix is simply the matrix transpose. Therefore,

$$
\left[\begin{array}{l}
\mathrm{x} \\
\mathrm{y} \\
\mathrm{z}
\end{array}\right]=\left[\begin{array}{ccc}
\cos \theta & 0 & -\sin \theta \\
0 & 1 & 0 \\
\sin \theta & 0 & \cos \theta
\end{array}\right]\left[\begin{array}{c}
\mathrm{a} \\
\mathrm{b} \\
\mathrm{c}
\end{array}\right]=[\mathrm{M}]^{\mathrm{T}}\left[\begin{array}{l}
\mathrm{a} \\
\mathrm{b} \\
\mathrm{c}
\end{array}\right]
$$

The transformation matrix allows the average magnetization and the applied magnetic fields to 
be written in the tunnel reference frame.

$$
\left[\begin{array}{l}
M_{x} \\
M_{y} \\
M_{z}
\end{array}\right]=[M]^{T}\left[\begin{array}{l}
M_{a} \\
M_{b} \\
M_{c}
\end{array}\right] \quad(2-15) ; \quad\left[\begin{array}{l}
H_{a} \\
H_{c}
\end{array}\right]=\left[\begin{array}{l}
M \\
H_{y} \\
H_{z}
\end{array}\right]
$$

Combining equations 2-9, 2-13, and 2-14 with equations 2-3 and 2-4 gives the following result for the force and torque vector.

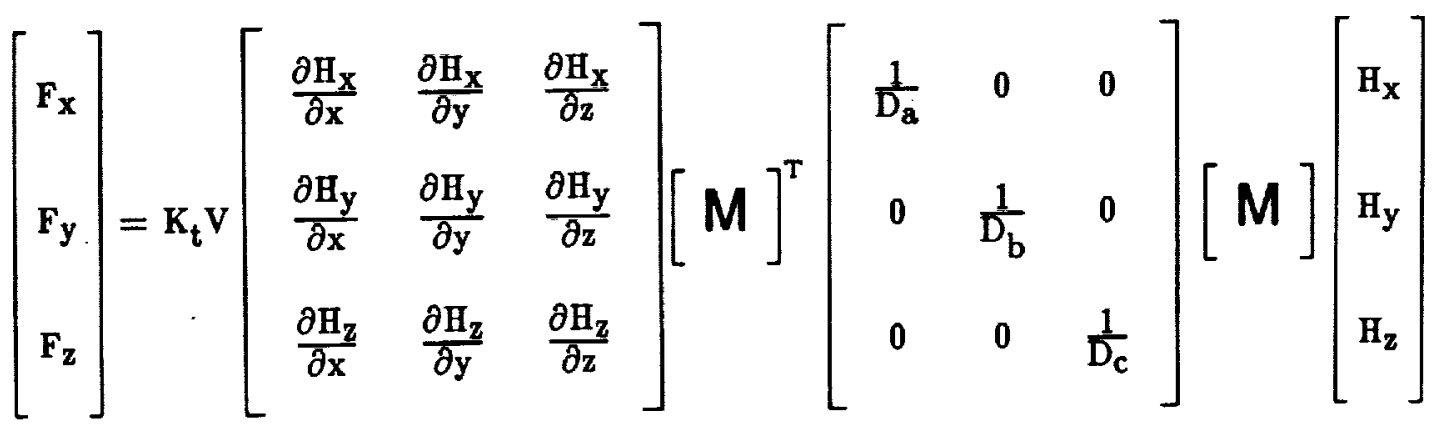

$$
\left[\begin{array}{c}
\mathrm{T}_{\mathrm{x}} \\
\mathrm{T}_{\mathrm{y}} \\
\mathrm{T}_{\mathrm{z}}
\end{array}\right]=\mathrm{K}_{\mathrm{t}} \mathrm{V}[\mathrm{M}]^{\mathrm{T}}\left[\begin{array}{ccc}
\frac{1}{\mathrm{D}_{\mathrm{a}}} & \cdots & 0 \\
0 & \frac{1}{\mathrm{D}_{\mathrm{b}}} & 0 \\
0 & 0 & \frac{1}{\mathrm{D}_{\mathrm{c}}}
\end{array}\right][\mathrm{M}]\left[\begin{array}{c}
\mathrm{H}_{\mathrm{x}} \\
\mathrm{H}_{\mathrm{y}} \\
\mathrm{H}_{\mathrm{z}}
\end{array}\right] \times\left[\begin{array}{c}
\mathrm{H}_{\mathrm{x}} \\
\mathrm{H}_{\mathrm{y}} \\
\mathrm{H}_{\mathrm{z}}
\end{array}\right] .
$$

Side forces, yawing moments, and rolling moments are not present in this research, therefore, simplifying the force and torque matrices give the following equations. 


$$
\begin{gathered}
F_{x}=K_{t} v\left\{\left(\frac{\partial H_{x}}{\partial x} \cos \theta+\frac{\partial H_{x}}{\partial z} \sin \theta\right)\left(H_{x} \cos \theta+H_{z} \sin \theta\right) \frac{1}{D_{a}}+\right. \\
\left.\left(\frac{\partial H_{x}}{\partial x} \sin \theta-\frac{\partial H_{x}}{\partial z} \cos \theta\right)\left(H_{x} \sin \theta-H_{z} \cos \theta\right) \frac{1}{D_{c}}\right\} \\
F_{z}=K_{t} v\left\{\left(\frac{\partial H_{z}}{\partial x} \cos \theta+\frac{\partial H_{z}}{\partial z} \sin \theta\right)\left(H_{x} \cos \theta+H_{z} \sin \theta\right) \frac{1}{D_{a}}+\right. \\
\left.\left(\frac{\partial H_{z}}{\partial x} \sin \theta-\frac{\partial H_{z}}{\partial z} \cos \theta\right)\left(H_{x} \sin \theta-H_{z} \cos \theta\right) \frac{1}{D_{c}}\right\} \\
T_{y}=K_{t} v\left(\frac{1}{D_{a}}-\frac{1}{D_{c}}\right)\left\{\left(\cos ^{2} \theta-\sin ^{2} \theta\right) H_{x} H_{z}+\sin \theta \cos \theta\left(H_{x}^{2}-H_{z}^{2}\right)\right\}
\end{gathered}
$$

Further simplification to the zero incidence case gives:

$$
\begin{aligned}
& \mathrm{F}_{\mathrm{x}}=\mathrm{K}_{\mathrm{t}} \mathrm{V}\left(\frac{\mathrm{H}_{\mathrm{x}}}{\mathrm{D}_{\mathrm{a}}} \frac{\partial \mathrm{H}_{\mathrm{x}}}{\partial \mathrm{x}}+\frac{\mathrm{H}_{\mathrm{z}}}{\mathrm{D}_{\mathrm{c}}} \frac{\partial \mathrm{H}_{\mathrm{x}}}{\partial \mathrm{z}}\right) \\
& \mathrm{F}_{\mathrm{z}}=\mathrm{K}_{\mathrm{t}} \mathrm{V}\left(\frac{\mathrm{H}_{\mathrm{X}}}{\mathrm{D}_{\mathrm{a}}} \frac{\partial \mathrm{H}_{\mathrm{X}}}{\partial \mathrm{z}}+\frac{\mathrm{H}_{\mathrm{z}}}{\mathrm{D}_{\mathrm{c}}} \frac{\partial \mathrm{H}_{\mathrm{z}}}{\partial \mathrm{z}}\right) \\
& \mathrm{T}_{\mathrm{y}}=\mathrm{K}_{\mathrm{t}} \mathrm{V}\left(\frac{1}{\mathrm{D}_{\mathrm{a}}}-\frac{1}{\mathrm{D}_{\mathrm{c}}}\right) \mathrm{H}_{\mathbf{x}} \mathrm{H}_{\mathrm{z}}
\end{aligned}
$$

\subsection{Field Assumptions}

Several assumptions are now necessary to fully develop the force and torque equations. These assumptions are for the magnetic field and magnetic field gradients which depend on the type of magnetic suspension system. The LaRC 13 inch MSBS is a V-type system. The assumptions for a V-type system are developed by Basmajian, Copeland, and Stevens ${ }^{12}$ and are based on magnet symmetry. 


$$
\begin{aligned}
& \frac{\partial \mathrm{H}_{\mathrm{z}}}{\partial \mathrm{x}}=\rho_{1}\left(\mathrm{I}_{\mathrm{I}_{1}}+\mathrm{I}_{\mathrm{I}_{2}}+\mathrm{I}_{\mathrm{I}_{3}}+\mathrm{I}_{\mathrm{I}_{4}}\right) \\
& \frac{\partial \mathrm{H}_{\mathrm{X}}}{\partial \mathrm{x}}=\rho_{2}\left(\mathrm{I}_{\mathrm{I}_{1}}+\mathrm{I}_{\mathrm{I}_{2}}+\mathrm{I}_{\mathrm{I}_{3}}+\mathrm{I}_{\mathrm{I}_{4}}\right)+\rho_{3} \mathrm{I}_{\mathrm{d}} \\
& \frac{\partial \mathrm{H}_{\mathrm{z}}}{\partial \mathrm{z}}=\rho_{4}\left(\mathrm{I}_{\mathrm{I}_{1}}-\mathrm{I}_{\mathrm{I}_{2}}+\mathrm{I}_{\mathrm{I}_{3}}-\mathrm{I}_{\mathrm{I}_{4}}\right)-\rho_{5} \mathrm{I}_{\mathrm{d}} \\
& \mathrm{H}_{\mathrm{X}}=\rho_{6}\left(\mathrm{I}_{\mathrm{I}_{1}}+\mathrm{I}_{\mathrm{I}_{2}}+\mathrm{I}_{\mathrm{I}_{3}}+\mathrm{I}_{\mathrm{I}_{4}}\right)+\rho_{7} \mathrm{I}_{\mathrm{d}} \\
& \mathrm{H}_{2}=-\rho_{8}\left(\mathrm{I}_{\mathrm{I}_{1}}-\mathrm{I}_{\mathrm{I}_{2}}+\mathrm{I}_{\mathrm{I}_{3}}-\mathrm{I}_{\mathrm{I}_{4}}\right)
\end{aligned}
$$

where $\rho_{1}$ through $\rho_{8}$ are constants.

The relative permeability will remain high throughout testing due to the ultra-low carbon iron core, therefore, the demagnetizating factors, $D_{a}, D_{b}$, and $D_{c}$ are constant for a constant volume magnetic core. Substituting equations 2-23a through 2-23e into equations 2-20, 2-21, and 2-22, realizing that $K_{t}$ is a constant, gives the final results.

$$
\begin{aligned}
& F_{X}=\delta_{1} I_{L}{ }^{2}+\delta_{2} I_{L} I_{D}+\delta_{3} I_{D}{ }^{2}-\delta_{4} I_{P} I_{L} \\
& F_{z}=\delta_{5} I_{L}{ }^{2}+\delta_{6} I_{L} I_{D}-\delta_{7} I_{P}{ }^{2}+\delta_{8} I_{P} I_{D} \\
& T_{y}=\delta_{9} I_{P} I_{L}-\delta_{10} I_{P} I_{D} \\
& \text { where, }
\end{aligned}
$$

$I_{L}=I_{I_{1}}+I_{I_{2}}+I_{I_{3}}+I_{I_{4}}$

$I_{P}=I_{I_{1}}-I_{I_{2}}+I_{I_{3}}-I_{I_{4}}$

and $\delta_{1}$ through $\delta_{10}$ are constant coefficients.

\subsection{Determination of Force and Torque Coefficients}

To calculate the coefficients, known forces and torques are applied to the suspended model, and the resulting coil currents are recorded. Fig. 9a shows thẹ proper set-up fọ such a 
calibration. The pulley arrangement provides the known drag force. The weight pans attached to the suspended model inside the test section provide the lift force and pitching moment. This calibration procedure could not be undertaken due to the unexpected down-time of the MSBS for magnet and power supply modifications. Preliminary calibrations only involved axial loads on the $0^{\circ}$ base and the $60^{\circ}$ base models. Due to the discovery of significant lift forces and pitching moments exerted on the slanted base models, more complete calibration data was necessary. Fortunately, the weight and location of the interchangeable bases relative to the magnetic core provided built-in lift forces and pitching moments. An attempt to provide further lift force and pitching moment data was made by positioning brass rings of a known weight on the model. Fig. 9b shows the preliminary calibration set-up. The resulting control and bias currents in each coil are recorded for each force and torque data point.

Following previous analysis, the force and torque coefficients are assumed constant. Therefore, the product terms of the force and torque equations can be combined to give the following equations.

$$
\begin{aligned}
& F_{X}=\delta_{1} X_{1}+\delta_{2} X_{2}+\delta_{3} X_{3}-\delta_{4} X_{4} \\
& F_{z}=\delta_{5} X_{5}+\delta_{6} X_{6}-\delta_{7} X_{7}+\delta_{8} X_{8} \\
& T_{y}=\delta_{9} X_{9}-\delta_{10} X_{10}
\end{aligned}
$$

The coefficients can be estimated using multiple linear regression in which the sum of the squared residuals are minimized. The range of applied forces and torques cover the range of expected aerodynamic forces and torques with limited extrapolation of the data. Table 1. contains the final force and torque equations. 


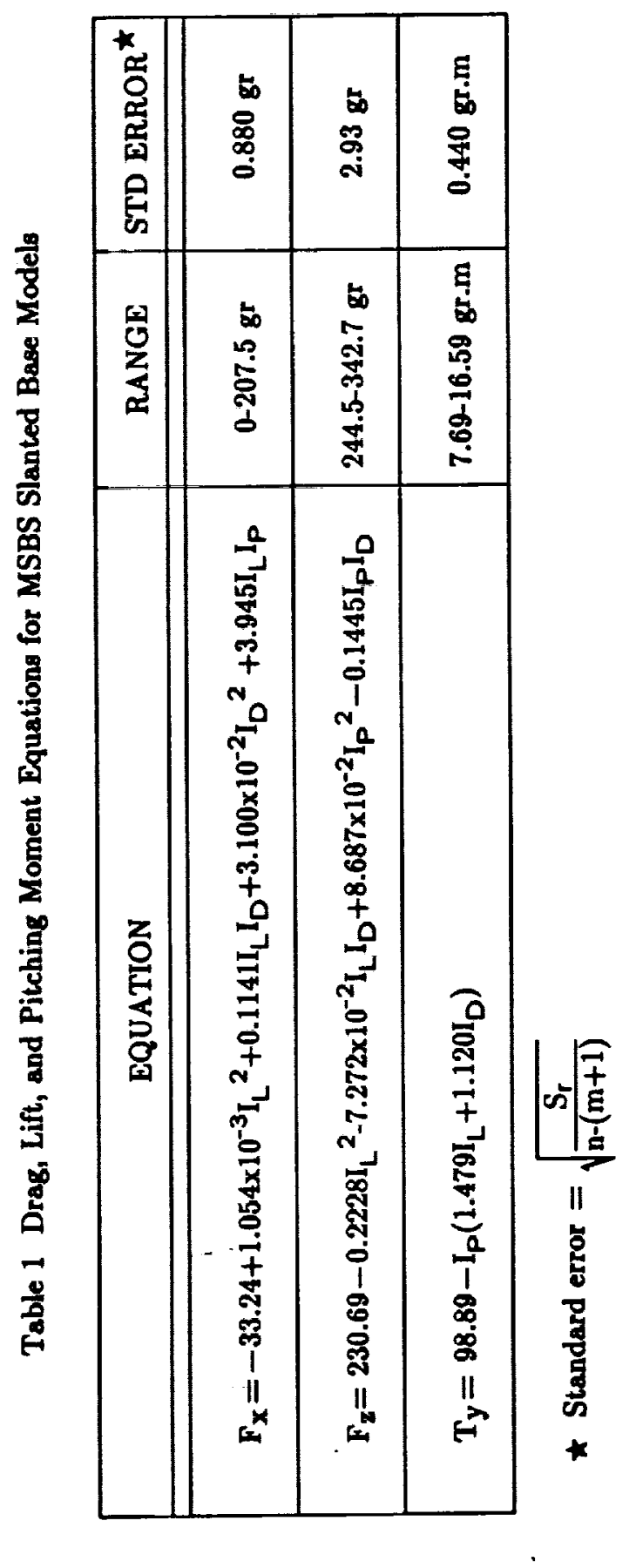




\section{AERODYNAMIC COEFFICIENTS AND REYNOLDS NUMBER CALCULATIONS}

The aerodynamic coefficients and Reynolds numbers are calculated from thermocouple, pressure transducer, and coil current data. Specifically, these measurements are:

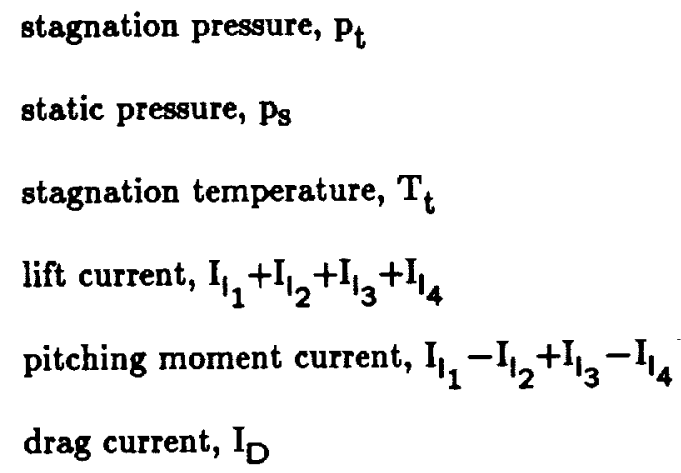

\subsection{Aerodynamic Coefficients}

The forces and torques exerted on the model are found from the calibration equations. The "wind off" lift, pitching moment, and drag currents supporting the suspended model correspond to the no aerodynamic force and torque case. These currents may differ slightly from run to run. This is due to small variations in the model position between runs. A simple correction easily solves this problem. The change in lift, pitching moment, and drag currents from their wind off values are calculated for each data run. These increments are added to the zero force and torque calibration currents to give a corrected current value. For each data run, the corrected currents are substituted into the calibration equations to give the corresponding lift, pitching moment, and drag values. The error in not correcting for the wind off currents is small for intermediate force and torque values, however, it becomes a factor for low values. 
The aerodynamic coefficients are calculated as follows:

$$
\begin{aligned}
& C_{D}=D\left(\frac{2}{\gamma p_{s} \mathrm{M}^{2} \mathrm{~S}}\right) \\
& C_{L}=L\left(\frac{2}{\gamma P_{s} M^{2} S}\right) \\
& C_{P}=P\left(\frac{2}{\gamma P_{s} M^{2} \mathrm{Sl}}\right)
\end{aligned}
$$

The reference area for the coefficients is the maximum cross-sectional area of the model, while the length of the $0^{\circ}$ base is the reference length for the pitching moment coefficient.

\subsection{Reynold's Number Calculations}

The Reynold's number based on the model diameter is,

$$
R e_{D}=\frac{p_{s} M}{\mu_{v}}\left(\frac{\gamma}{R T_{s}}\right)^{\frac{1}{2}} t
$$

The absolute viscosity, $\mu_{\mathrm{v}}$ is found by Sutherland's Law,

$$
\mu_{v}=\frac{1.458 \times 10^{-6} \mathrm{~T}_{\mathrm{s}}^{\frac{1}{2}}}{1+\frac{110.4}{\mathrm{~T}_{\mathrm{s}}^{--}}}
$$

\subsection{Buoyancy Corrections}

The thickening of the boundary layer along the test section walls decreases the effective test section area. This results in a velocity increase due to mass conservation. Velocity and pressure gradients are related by the following equation.

$$
\frac{d p_{s}}{d x}=-\rho_{\infty} U \frac{d U}{d x}
$$


Fig. 10 illustrates this phenomena. The pressure gradient creates an additional force on a model in suspension known as a buoyancy drag. A simplistic equation for calculating buoyancy drag is the product of the model volume and the pressure gradient. Glauert ${ }^{13}$ modified this approach considerably by introducing an effective volume into the correction. Specifically, Glauert shows the effective volume of the model can be calculated if the velocity distribution along the model is known.

$$
\Delta D_{B U O Y}=\pi \frac{d p_{s}}{d x} \int \frac{q}{U} Y^{2} d S=A^{\prime} \frac{d p_{s}}{d x}
$$

A panel method computer code called VSAERO determines the velocity distribution, $\frac{\mathrm{q}}{\mathrm{U}}$, along the model length as Fig. 11 shows. Further results from VSAERO are presented in Chapter 5. The incremental arc length, dS, equals $\operatorname{Rd} \Theta$ for the ogive nose piece and simply equals $\mathrm{dx}$ for the cylindrical section. Numerical integration of the above equation results in an effective volume of $11.54 \mathrm{in}^{3}$. The actual volume of the ogive cylinder model is $11.39 \mathrm{in}^{3}$, which is $1.3 \%$ lower than the effective volume. In all cases examined by Glauert, the effective model volume was greater than the actual model volume.

The MSBS test section walls are parallel and therefore do not account for the boundary layer growth creating a longitudinal pressure gradient. The procedure for determining the pressure gradient in the empty tunnel is as follows.

Two longitudinal pressure tappings are spaced 12 inches apart, centered around the magnetic center. The pressure differential between these tappings are found for various Mach numbers. Mach numbers range from 0.002 to 0.35 in increments of approximately 0.05 and then back to 0.002 with the same increment. A least squares polynomial with the pressure differential as the dependent variable and the Mach number as the independent variable fits the data. Fig. 12 shows the set-up. 


\subsection{Blockage Corrections}

Blockage effects are due to the presence of a body in a closed environment which constricts the flow. Conservation of mass requires a blockage to increase the flow velocities around the body relative to the unconfined case. This is evident in Fig. 13. The velocity increment between confined and unconfined flows is approximately equal along the model length if the body is not "large" compared to the the test section. ${ }^{14}$ A correction for the static pressure, Mach number, and other flow parameters is necessary to account for the constriction. This correction is referred to as "solid body blockage."

Due to the expansion of the wake downstream of the model, the velocity outside the wake will increase. The test section walls act to increase this velocity more than in the unconfined case. Mass conservation requires the velocity around the body to increase to account for this effect. Again, a correction is necessary and is referred to as "wake blockage". Specifically, these blockage corrections are the velocity increment due to constricted flow normalized with respect to the free stream velocity. They are a function of test section and model geometry.

The ratio of the ogive cylinder cross-sectional area to the MSBS test section area is approximately $1 \%$. This ratio is small and blockage effects are minimal. ${ }^{15}$ To achieve as accurate results as possible, blockage corrections are made.

\subsubsection{Solid Body Blockage in an Octagonal Tunnel}

Several methods exist for the calculation of solid body blockage for three-dimensional models in compressible flow depending on the test section geometry. Batchelor ${ }^{16}$ suggests the following formula for octagonal test sections.

$$
\epsilon_{0}=\left[\tau_{0}\left(\frac{\mathrm{C}}{\mathrm{BH}}\right)^{\frac{3}{2}}+\tau_{1}\right]\left(\frac{\mathrm{A}_{m}}{\mathrm{C}}\right)^{\frac{3}{2}}\left(\frac{\lambda_{3}}{\beta^{3}}\right)
$$

where,

$$
\lambda_{3}=\frac{4}{t^{3}} \int \frac{q}{U^{2}} Y^{2} d S
$$


Batchelor estimates $\tau_{1}$ for moderately small fillets to be sufficiently small in comparison to the first term in the squared brackets and is therefore neglected. The MSBS test section fillets are of the same order in size and are therefore classified as being sufficiently small. Neglecting this term results in a solid blockage equation for a rectangular test section with $\tau_{0}$ defined as follows.

$$
\tau_{0}=\frac{1}{2}\left(\frac{C}{*}\right)_{m=-\infty}^{\frac{3}{2}} \sum_{n=-\infty}^{+\infty}\left\{\frac{1}{(m B)^{2}+(n H)^{2}}\right\}^{\frac{3}{2}} ;(m, n) \neq(0,0)
$$

Carrying the summation from 500 to -500 results in a converged solution of $\tau_{0}=0.82$ and a solid body blockage factor of $\epsilon_{\mathrm{s}}=7.576 \times 10^{-3} \beta^{-3}$.

\subsubsection{Wake Blockage in an Octagonal Tunnel}

For bodies of revolution in a rectangular tunnel, Allen and Vincenti and Herriot ${ }^{18}$ suggest the following formula for wake blockage.

$$
\epsilon_{\omega}=\frac{1}{4} \frac{\mathrm{S}}{\mathrm{BH}}\left(\frac{1+0.4 \mathrm{M}^{2}}{\beta^{2}}\right) \mathrm{C}_{\mathrm{D}}
$$

It is further suggested to replace the rectangular area, BH by the octagonal test section area, $\mathrm{C}$.

\subsection{Corrections to Flow Properties}

Corrections to flow properties due to blockage can be made now that the blockage factors, $\epsilon_{\mathrm{W}}$, and $\epsilon_{\mathrm{s}}$ exist. As stated, these factors combine to give the total non-dimensional velocity increment due to constrictions in a closed-throat tunnel. Mathematically, this gives the velocity correction as follows.

$$
\mathrm{U}_{\mathrm{c}}=\mathrm{U}+\Delta \mathrm{U}_{\mathrm{b}}
$$

or, 


$$
\mathrm{U}_{\mathrm{c}}=\left(1+\epsilon_{\mathrm{t}}\right) \mathrm{U} \quad \text { where, } \epsilon_{\mathrm{t}}=\epsilon_{\mathrm{g}}+\epsilon_{\mathrm{w}}
$$

For compressible flow, the Mach number increment is of importance. Differentiation of the isentropic flow equation,

$$
\frac{a_{0}^{2}}{a^{2}}=a_{0} \frac{2 M^{2}}{U^{2}}=1+\frac{\gamma-1}{2} M^{2}
$$

gives the following increment.

$$
a_{0}^{2} \frac{d U}{U^{3}}=\frac{d M}{M^{3}}
$$

But, $\epsilon_{\mathrm{t}}=\frac{\mathrm{dU}}{\mathrm{U}}$ by definition.

Therefore,

$$
\mathrm{a}_{0}{ }^{2} \epsilon_{\mathrm{t}} \mathrm{M}\left(\frac{\mathrm{M}^{2}}{\mathrm{U}^{2}}\right)=\left(\frac{\mathrm{a}_{0}{ }^{2}}{\mathrm{a}^{2}}\right) \epsilon_{\mathrm{t}} \mathrm{M}=\mathrm{d} \mathrm{M}
$$

Substitution of Equation 3-14 into Equation 3-16 gives the final result.

$$
\mathrm{dM}=\left(1+\frac{\gamma-1}{2} \mathrm{M}^{2}\right) \mathrm{M} \epsilon_{\mathrm{t}}
$$

The corrected Mach number becomes,

$$
\mathrm{M}_{\mathrm{c}}=\mathrm{M}+\left(1+\frac{\gamma-1}{2} \mathrm{M}^{2}\right) \mathrm{M} \epsilon_{\mathrm{t}}
$$

A similiar result exists for the static pressure increment upon differentiation of the isentropic flow equation. 


$$
\frac{\mathrm{P}_{\mathrm{t}}}{\mathrm{P}_{\mathrm{g}}}=\left(1+\frac{\gamma-1}{2} \mathrm{M}^{2}\right)^{\frac{\gamma}{\gamma-1}}
$$

The static pressure increment is as follows.

$$
\mathrm{dp} \mathrm{p}_{8}=-\gamma \mathrm{M}^{2} \mathrm{p}_{\mathrm{B}} \epsilon_{\mathrm{t}}
$$

giving,

$$
\mathrm{P}_{\mathrm{B}_{\mathrm{c}}}=\mathrm{P}_{\mathrm{g}}-\gamma \mathrm{M}^{2} \mathrm{Pg}_{\mathrm{g}} \epsilon_{\mathrm{t}}
$$

Similarly, the corrected static temperature is as follows.

$$
T_{s_{c}}=\frac{T_{t}}{1+\frac{\gamma-1}{2} M_{c}^{2}}
$$

Fig. 14 compares buoyancy and blockage drag corrections with uncorrected values. Buoyancy corrections are between $1.5 \%$ and $6 \%$ of the uncorrected drag and are the largest corrections to the drag data. Blockage corrections are between $1 \%$ and $2 \%$ of the uncorrected drag. 


\section{EXPERIMENTAL RESULTS}

\subsection{Aerodynamic Characteristics}

Experimental results from the LaRC MSBS are presented in Figs. 15a through 15r. MSBS results are corrected for buoyancy and blockage by the methods presented in the previous chapter. Scatter exists at the lower Reynolds numbers due to the inability to accurately resolve current and pressure readings at very low speeds. This is evident in most of the results presented. The reference area for the drag, lift, and pitching moment coefficients is the maximum cross-sectional area of the model. The reference length of the pitching moment coefficient is the length of the $0^{\circ}$ base model.

Several runs with the $0^{*}$ base exhibit fair repeatability of drag results. Lift and pitching moment data are not well resolved due in part to the imperfect calibration data available. Available computational results presented in Chapter 6. and flow visualization results discussed at the end of this chapter indicate the boundary layer is laminar over the entire body for these lower Reynolds numbers. It is therefore reasonable that runs with transition fixed just downstream of the nose piece indicate a substantial rise in drag due to the higher stresses associated with a turbulent boundary layer.

Free transition on the $30^{\circ}$ and $40^{\circ}$ bases show that lift and pitching moment results increase proportionally with drag. This is thought to be evidence of low pressures on the base as illustrated in the sketch below.

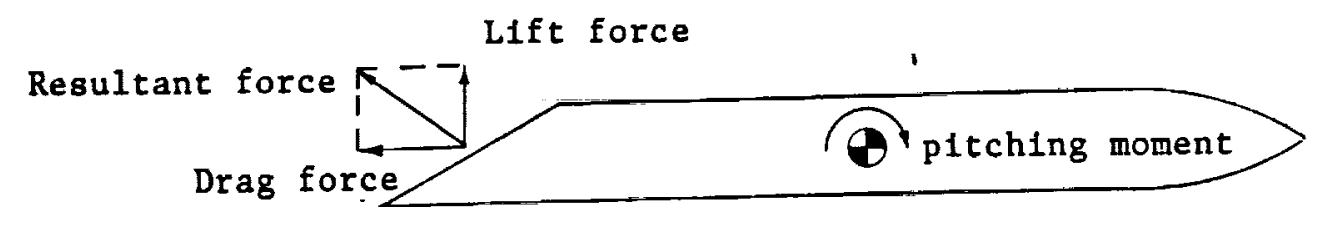


An unexpected drag increase occurred with the $45^{\circ}$ base with increasing Reynolds number. This increase still exists upon lowering the Reynolds number past its critical value implying a hysteretic effect. A similiar lift and pitching moment increase is coincident with drag results. The sudden change in aerodynamic forces and torques appear to be due to sudden changes in base flow patterns. A repeat run was made to more closely approximate the critical Reynolds number where the increase occurred. The critical Reynolds number $\left(R e_{D}\right)$ is approximately 60,000 . An attempt to explore the effects of fixing transition on the $45^{\circ}$ base was then made with transition fixed just downstream of the nose piece. It was found that the sudden drag increase did not occur for Reynolds numbers greater than the critical value with fixed transition. Similiar results apply to the lift and pitching moment. Previous research by Page $^{18}$ on axisymmetric body base flow patterns concludes that base flow patterns are a strong function of the incoming boundary layer. Differences in the base flow pattern exist on the $45^{\circ}$ base due to fixed and free transition. This implies that this conclusion may be extended to nonsymmetric bases.

Data for the $50^{\circ}$ and $60^{\circ}$ bases could not be taken at higher speeds due to some stability problems (uncontrolled rolling of the $60^{\circ}$ model) and large vertical loads on the rear of the model (reducing the rear electromagnet currents).

Fig. 16 illustrates a comparison of drag results between Morel and MSBS results interpolated from experimental data for $R e_{D}=94000$. Morel's results for the lower base slant models lie between fixed and free transition MSBS results. The wire supports used by Morel are likely to have caused partial turbulent boundary layers responsible for these drag discrepancies. Existing measurements and computational results indicate the boundary layer is laminar over the entire body for $\mathrm{Re}_{\mathrm{D}}=94000$. Morel measured the drag overshoot at a slightly higher slant angle of 46.5 (for the drag runs), while MSBS data indicate that the drag overshoot is Reynolds number dependent and exists for the $45^{\circ}$ base. Time limitations prevented the testing of a cluster of bases around $45^{\circ}$ to further resolve the overshoots. There is good agreement between MSBS data and results by Morel for the $50^{\circ}$ and the $60^{\circ}$ bases. Fig. 17 and Fig. 18 show the 
corresponding lift and pitching moment results versus base slant angle for $\operatorname{Re}_{D}=94000$ respectively.

\subsection{Flow Visualization}

The effects of a wire attachment on an ogive cylinder model was made. A piece of grit (approximately $0.5 \mathrm{~mm}$ in diameter) was placed just downstream of the nose piece to represent the wire attachment. Flow visualization liquid crystals were applied to the midbody. Liquid crystals selectively reflect discrete wavelengths (color) of light in response to a shear stress. ${ }^{19}$ Liquid crystals can therefore distinguish between laminar and turbulent boundary layers. Fig. 19 shows flow visualization results for the modeled wire attachment. The spotted areas on the nose piece are color changes representing areas of high stresses. A region of high stresses also develops downstream of the grit representing a turbulent wedge. This result further explains why Morel's drag results lie between fixed and free transition MSBS results.

An attempt at flow visualization using liquid crystals and oil flow was made over the slanted bases. Fig. 20a shows the quasi-symmetric flow pattern over the $30^{\circ}$ base and shows pressure distributions by Xia and Bearman..$^{5}$ A very distinct horseshoe pattern exists over the $50^{\circ}$ base representing the vortical flow pattern. Fig. 20b illustrates this pattern along with pressure distributions. The line surrounding the horseshoe corresponds to the region of minimum pressure, or the vortex center. The darker colored region inside this line appears to be a region of reattachment. Oil flow over the $45^{\circ}$ base revealed the change in base flow patterns at the critical Reynolds number. The flow pattern remains vortical for decreasing Reynolds numbers past its critical value confirming the hysteretic effect.

Further attempts at flow visualization using liquid crystals over the cylindrical midbody was made for fixed transition just downstream of the nose piece. The characteristic liquid crystal color change occurred, representing a high stress region (turbulent boundary layer) not present on the clean midbody. 


\section{COMPUTATIONAL RESULTS}

Two codes are used for predicting transition locations and drag for the $0^{\circ}$ slanted base model. SANDRAG ${ }^{20}$, predicts drag of bodies of revolution at zero angle of attack in incompressible flow. VSAERO ${ }^{21}$, a surface panel method for predicting subsonic aerodynamic characteristics of arbitrary configurations is also used.

\subsection{Transition}

Fig. 21 shows predicted boundary layer transition and surface pressure distributions for the $0^{\circ}$ slanted base. The transition locations predicted by VSAERO and SANDRAG are in poor agreement. VSAERO predicts transition far forward of SANDRAG predictions. Present experimental results using flow visualization agree with SANDRAG results in that transition starts at the back end and moves forward with increasing Reynolds number.

To understand the reasons for these results, the factors that influence transition need to be analyzed. VSAERO predicts transition in the region of adverse pressure gradient for the Reynolds numbers tested. In this region Tollmien-Schlichting instability grows rapidly. In this case VSAERO predicts the instability is sufficiently large to cause transition. It is of interest that a large portion of the body has a flat pressure gradient. This may cause a rapid growth in the Tollmien-Schlichting instability creating a considerable amount of uncertainity in the prediction of transition location in this region. VSAERO can predict accurately the transition location of bodies with strong favorable pressure gradients in which Tollmien-Schlichting waves are dampened. 22

SANDRAG relies on built-in empirical correlations to predict transition on axisymmetric bodies. This code is able to consider surface roughness in its calculations. Computed transition 
locations on the configuration vary considerably with the surface roughness.

\subsection{Drag Results}

Most of the drag on this configuration is due to base pressure drag. SANDRAG predictions use empirical results to determine the base pressure drag component. VSAERO is able to determine base pressure drag by attaching a wake to the base. Base pressures computed by VSAERO are a strong function of the tangential velocities inside and outside the vortex sheet wake. There is considerable difficulty in choosing a good approximation of these parameters and for this reason, a drag comparison between VSAERO and SANDRAG is excluded.

Fig. 22 shows drag variations with Reynolds numbers using SANDRAG. Predictions indicate that a majority of the drag on this configuration is due to base pressure drag which is presumed constant $\left(C_{D} B A S E=0.13\right)$ for all Reynolds numbers tested. The drag increases for $R e_{D}$ greater than $2.6 \times 10^{5}$ due to transition moving forward from the model base. Flow visualization results show that transition does occur at the model base and moves forward with increasing Reynolds number. Table 2 compares experimental and computational results for $\operatorname{Re}_{\mathrm{D}}=94000$.

Fig. 23 compares SANDRAG predictions with MSBS results for the $0^{\circ}$ base. There is good agreement between MSBS wind tunnel results and SANDRAG predictions for the lower Reynolds numbers, however, MSBS results indicate that transition occurs sooner than SANDRAG predictions. Differences in transition locations can be attributed to variations in surface roughness and differences in turbulence intensities between MSBS wind tunnel values and the values of the empirical correlations used in SANDRAG. The slanted base models have a standard machine surface roughness of $10 \mu$ in which lies between the two surface roughness cases of Fig. 22. The 13" MSBS wind tunnel has a turbulence intensity $\leq 0.1 \%$. The Appendix compares calculation methods between SANDRAG and VSAERO. 
Table $20^{*}$ base drag comparison, $R e_{D}=94000$

\begin{tabular}{|c|c|c|c|}
\hline \multirow{2}{*}{ Morel } & \multicolumn{2}{|c|}{ MSBS } & SANDRAG \\
\hline \multirow{2}{*}{0.237} & clean & fixed & \\
\cline { 2 - 3 } & 0.181 & 0.263 & 0.186 \\
\hline
\end{tabular}




\section{BASE PRESSURE MEASUREMENTS}

MSBS's eliminate the need for mechanical supports, therefore, another method of retrieving base pressure measurements is necessary. Wireless data acquisition using an infrared pressure telemetry system solves this problem. The telemetry system contains a pressure transducer, a signal conditioning circut, an infrared LED (Light Emitting Diode), and a power source. This system was developed for base pressure measurements by Tcheng, Schott, and Bryant ${ }^{23}$, and is installed in the wind tunnel model.

\subsection{Pressure Telemetry System}

Fig. 24 shows a schematic of the pressure telemetry system. The pressure transducer is an Endevco 8510B 2 psid piezoresistive differential pressure transducer. The vent tube of the transducer is filled with argon gas at atmospheric pressure and is sealed with epoxy. This is a reference pressure. The transducer contains a four-arm strain gage bridge diffused in a silicon diaphram for maximum sensitivity. Fig. 25 shows the dimensions of the pressure transducer.

The signal conditioner converts the analog output of the pressure transducer into a pulsed optical signal. It contains a LM124 quad operational amplifier for signal conditioning. Three of the operational amplifiers differentially amplify the transducer signal which operates on very low power. An AD537 voltage to frequency converter is used to produce a square wave output from its DC voltage input. The input stage of the AD537 converts the input voltage into a drive current. The drive current charges a timing capacitor which controls the astable multivibrator frequency. The square wave output of the AD537 drives a NPN transistor (2N2222) which charges another capacitor. This capacitor discharges through the LED (OP160W) when the square wave is high. The LED has a flat window providing a wide radiation angle. This allows 
for ease in data transmission. The pulsed optical signal from the LED is received by a silicon photodiode located outside the test section and the frequency is read by a digital frequency counter.

The power supplies for the pressure telemetry system are hearing-aid batteries (E41E) which are rated at $1.4 \mathrm{~V}$ each. Five batteries in series provide the power requirements.

\subsection{Wind Tunnel Pressure Model}

A slanted base pressure model was developed to house the telemetry package. The major problem in installing the pressure telemetry system in the model is space restriction.

\subsubsection{Installation of the Pressure Telemetry System}

The signal conditioner flies in the nose piece of the model due to size limitations of its components. It is housed in a 0.75 inch diameter hole drilled to a depth of 1.6 inches. The signal conditioner is built on both sides of a circut board in order to minimize its length. The battery pack flies forward of the signal conditioner in a 0.5 inch diameter hole drilled to a depth of 0.96 inches. Fig. 26a shows the model nose piece for pressure measurements.

The pressure transducer and the LED are housed in the model aftbody. A 0.125 inch diameter hole is drilled through the magnetic core to run connections between the signal conditioner, the pressure transducer, and the LED. Fig. 26b shows the magnetic core used for pressure measurements. A 0.17 inch diameter hole through the side of the aftbody houses the LED. The LED is epoxied in place with its window flush against the outside of the aftbody. The pressure transducer has a 10-32 mounting thread which screws into the rear of the aftbody. The face of the transducer is flush with the rear of the aftbody after installation. Fig. 26c shows the aftbody which houses the pressure transducer and the LED. The slanted bases fit onto a shaft located on the rear of the aftbody. A RC1 fit is specified to join the aftbody and the slanted bases. Rubber cement is applied at the joint to ensure an air-tight fit. Fig. 26d shows 
the slanted base design for pressure measurements. Notice that a cylindrical pocket 1.131 inches in diameter and 0.025 inches long exists between the aftbody and the slanted bases. The need for this pocket will be discussed later.

Pressure taps are drilled on the $0^{\circ}, 40^{\circ}, 45^{\circ}$, and $50^{\circ}$ bases. Flow visualization results from Chapter 4. show the longitudinal vortex is centered near a distance of $\frac{3}{4}$ the radius (r) from the base center. A horizontal pressure tap pattern on the slanted bases is chosen with a geometric spacing of $0 \mathrm{r}, \frac{1}{2} \mathrm{r}, \frac{3}{4} \mathrm{r}$, and $\frac{7}{8} \mathrm{r}$ to show the horizontal pressure gradient. A similiar pressure tap pattern is chosen to measure the vertical pressure gradient. Fig. $26 \mathrm{~d}$ also shows the pressure tap pattern.

\subsubsection{How the Pressure Telemetry System Works}

To measure the pressure at a specific station, all pressure stations not in use are sealed. The pocket between the aftbody and the slanted base is open to the outside by the unsealed pressure tap. At steady state, the pocket will reach the pressure at the unsealed station. The pressure transducer actually measures the pressure in this pocket that corresponds to this station.

\subsection{Calibration of the Pressure Transducer}

Fig. 27 shows a schematic of the pressure calibration set-up. The calibration procedure involves applying known pressures to the pressure transducer at constant temperature and measuring the resulting frequency output across the LED. The pressure is varied by a pressure regulator attached to the pressure transducer. A manometer is in line with the pressure regulator to measure the resulting pressures. The LED signal is measured by a photodiode in line with a frequency counter. Gage pressures are varied between 0.0 and 20.0 in. $\mathrm{H}_{2} \mathrm{O}$ and the resulting LED signal is recorded. Fig. 28 shows that pressure is a linear function of the square wave frequency at constant temperature. Fig. 28 also shows the pressure transducer is extremely sensitive to temperature changes. The pressure transducer is in good thermal contact with the aluminum model shell, and the transducer face is exposed to tunnel conditions through the 
pressure taps. The approximation is therefore made that the pressure transducer temperature is equal to the tunnel stagnation temperature.

Fig. 29 shows the effects of varying the input voltage on the frequency output for two limiting temperatures. The telemetry system does not have a voltage regulator, and therefore, the battery voltage will decrease with operation. Battery voltages were measured before and after operation to determine the operational range. The output frequency is shown to be independent of the input voltage over the entire operational range of the batteries.

\subsection{Experimental Results}

Base pressure coefficients are determined by the following equations:

$$
C_{p} \text { (base) }=\frac{2\left\{p_{\text {(base) }}-\mathrm{P}_{s}\right\}}{\gamma \mathrm{ps}_{\mathrm{s}} M^{2}}
$$

where,

$$
P_{(\text {base })}=P_{t}(M=0)-P_{\text {transducer }}
$$

Ptransducer is found from the calibration curves for a given output frequency and transducer temperature. Pressure measurements were made on the $40^{\circ}$ and $50^{\circ}$ base along a horizontal line passing through the centerline. Results for the $40^{\circ}$ and $50^{\circ}$ base are shown in Fig. 30. Scatter exists in MSBS measurements due to the sensitivity of the pressure transducer to temperature changes.

There is good agreement between MSBS $\left(\mathrm{Re}_{D}=100,000\right)$ and Morel's ${ }^{24}$ results $\left(R e_{D}=94,000\right)$ on the $40^{\circ}$ base for the centerline pressure station. Xia and Bearman's ${ }^{5}$ results $\left(\operatorname{Re}_{D}=180,000-290,000\right)$ consistently lie above MSBS results implying there may be a Reynolds number effect on base pressure. The pressure gradient trends between MSBS and Xia and Bearman's results are similiar, showing the flow pattern for the $40^{\circ}$ base is quasi-symmetric. Morel only documents the centerline pressure value for the $40^{\circ}$ base, therefore, a pressure gradient cannot be deduced. 
There is good agreement between MSBS and Morel's results on the $50^{\circ}$ base. As with the $40^{\circ}$ base, Xia and Bearman's base pressure measurements consistently lie above MSBS results implying a Reynolds number effect. Large pressure gradients exist for all results, showing the vortical flow pattern is present on the $50^{\circ}$ base. MSBS results show the pressure maxima occurs near $2 \frac{r}{b}=\frac{3}{4}$. This agrees with MSBS flow visualization results and Xia and Bearman's results. Morel only documents three pressure values, therefore, a horizontal pressure maxima cannot be accurately deduced.

A source of error in MSBS base pressure measurements is due to the inability to accurately resolve the pressure transducer temperature during operation. The transducer temperature is assumed to be equal to the wind tunnel stagnation temperature during operation. When not in use, the base pressure model was stored at room temperature, which was 5 to $10^{\circ} \mathrm{F}$ below the wind tunnel stagnation temperature. The pressure model was suspended in the wind tunnel at low Reynolds numbers for 10-15 minutes before measurements were taken in order to stabilize the pressure transducer temperature. Thermal effects of the iron core and the aluminum model may still be present after this time, causing the pressure transducer temperature to be less than the stagnation temperature. Electrical heating may also be present during operation which will tend to increase the transducer temperature. The magnitudes of these thermal effects are not known. Inaccuracies in the transducer temperature measurement can be minimized by direct measurement with a thermocouple, however, this creates the need for temperature telemetry.

Further problems develop in determining the pressure differential, $\mathrm{p}_{\text {(base) }}-\mathrm{p}_{\mathrm{s}}$. This quantity is not measured directly, therefore, the pressure differential is found by subtracting two large numbers. The pressure differential is between $.1 \%$ and $2 \%$ of these pressure values. Solving this problem involves referencing the wind tunnel stagnation pressure instead of the pressure of the sealed argon gas. This will also eliminate the temperature assumption necessary in this study. 


\section{CONCLUSIONS}

The sudden change from a quasi-symmetric base flow pattern to a vortical base flow pattern has been shown to be responsible for the large drag increase on slanted base ogive cylinders at zero incidence. Flow visualization using liquid crystals and oil flow shows the base flow pattern change which further validates MSBS drag results. Lift forces and pitching moments acting on the slanted base configurations were also measured revealing large increases similiar to the drag results.

Previous research" 2 shows that the change in base flow patterns is not "too dependent" on Reynolds number, however, this research shows the base flow pattern change occurs suddenly with increasing Reynolds number $\left(R e_{D} \simeq 60,000\right)$ on the $45^{\circ}$ base. Hysteresis is present in base flow pattern changes on the $45^{\circ}$ base with decreasing Reynolds number. Tripping the boundary layer far forward on the $45^{\circ}$ base prevents the formation of the vortical flow pattern and therefore prevents any hysteretic effects. A summary of MSBS drag results with Morel's drag results shows that Morel's results lie between MSBS fixed and free transition results. Flow visualization with liquid crystals reveals that partial turbulent boundary layers form due to wire support attachments on the model.

Computational results are difficult to achieve for the $0^{\circ}$ slanted base configuration unless empirical results are used. This is primarily due to the large contribution of base drag, responsible for more than $\mathbf{5 0 \%}$ of the total drag, which is not easily modeled computationally. Transition locations are not easily modeled computationally due to the flat pressure gradient over most of this configuration. In order to achieve computational results for the slanted base configurations a three-dimensional Navier Stokes solution is needed.

Base pressure measurements on the $40^{\circ}$ and $50^{\circ}$ bases using remote data telemetry show the 
two flow patterns present in this research. In conclusion, Magnetic Suspension and Balance Systems can retrieve interference-free data on aerodynamically complex configurations not available in conventional wind tunnels. 


\section{REFERENCES}

1. Jansson, L. J.; and Hucho, W. H.: "Aerodynamische Formoptimerung der Type VW-Golf and VW-Scirocco," Kolloquium ueber Industrie-Aerodynamik, Aachen, Part 3, 1974, pp. 46-49.

2. Morel, T.: “Aerodynamic Drag of Bluff Body Shapes Characteristic of Hatch-Back Cars," SAE Paper-780267, Feb. 1978.

3. Morel, T.: "The Effect of Base Slant on the Flow Patterns and Drag of Three -Dimensional Bodies with Blunt Ends," Symposium of Aerodynamic Drag Mechanisms of Bluff Bodies and Road Vehicles, Warren, MI, Sept. 1976, pp. 191-226.

4. Maull, D. J.: "The Drag of Slant-Based Bodies of Revolution," Aeronautical Journal, June 1980, pp. 164-166.

5. Xia, X. J.; and Bearman, P. W.: "An Experimental Investigation of the Wake of an Axisymmetric Body with a Slanted Base," Aeronautical Quarterly, Feb. 1983, pp. 24-45.

6. Johnson, W. G., Jr.; and Dress, D. A.: "The 13-inch Magnetic Suspension and Balance System Wind Tunnel," NASA TM-4090, 1989.

7. Kilgore, R. A.; Dress, D. A.; Wolf, W. D.; and Britcher, C. P.: "Test Techniques - A Survey Paper on Cryogenic Tunnels, Adaptive Wall Test Sections, and Magnetic Suspension and Balance Systems," LaRC Transonic Symposium, Apr. 1988.

8. Tcheng, P.; and Schott, T. D.: "A Five Component Electro-Optical Positioning System," 12th ICIASF Conference, Williamsburg, VA, Aug. 1985.

9. Britcher, C. P.; Goodyer, M. J.; Eskins, J.; Parker, D.; and Halford, R. J.: "Digital Control of Wind Tunnel Magnetic Suspension and Balance Systems," 12th ICIASF Conference, Williamsburg, VA, June 1987.

10. Gilliam, G. D.: "Data Reduction Techniques for Use with a Wind Tunnel Magnetic Suspension and Balance System," MIT-TR-168, June 1970. 
11. Bozorth, R. M.; and Chapin, D. M.: "Demagnetizing Factors of Rods," Journal of Applied Physics, Vol. 13, Mar. 1942.

12. Basmajian, V. V.; Copeland, A. B.; and Stephens,T.: "Studies Related to the Design of a Magnetic Suspension and Balance System," MIT-TR-128, Feb. 1966.

13. Glauert, H.: Wind Tunnel Interference on Wings, Bodies, and Airscrews, ARC R\&M 1566, Sept. 1933.

14. Herriot, J. G.: "Blockage Corrections for Three-Dimensional Flow Closed Throat Wind Tunnels with the Consideration of the Effect of Compressibility," NACA Report 995, 1950.

15. "Blockage Corrections for Bluff Bodies in Confined Flows," ESDU-80024, Nov, 1980.

16. Batchelor, G. K.: "Interference on Wings, Bodies and Airscrews in a Closed Octagonal Section," Report ACA-5 (Australia), Mar. 1944.

17. Garner, H. C.; Rogers, E. W. E.; Acum, W. E. A.; and Maskell, E. C.: "Subsonic Wind Tunnel Wall Corrections," AGARDograph 109, Oct. 1966.

18. Page, R. H.: "Compressible, Subsonic, Axisymmetric Base Flows," Symposium on Rocket/Plume Fluid Dynamic Interactions, Apr, 1983.

19. Gall, P. D.; and Holmes, B. J.: "Liquid Crystals for High-Altitude In-Flight Boundary Layer Flow Visualization," AIAA paper 86-2592, Sept. 1986.

20. Wolfe, W. P.; and Oberkampf, W. L.: "SANDRAG - A Computer Program for Predicting Drag of Bodies of Revolution at Zero Angle of Attack in Incompressible Flow," SAND85-0515, Apr. 1985, Sandia National Laboratories.

21. Maskew, B.: "Program VSAERO, A Computer Program for Calculating the Non-linear Aerodynamic Characteristics of Arbitrary Configurations," NASA CR-166476, Dec. 1982.

22. Dodbele, S. S.; van Dam, C. P.; and Vijgen, P.: "Shaping of Airplane Fuselages for Minimum Drag," AIAA Paper 86-0316, Jan. 1986.

23. Tcheng, P.; and Schott, T. D.: “A Miniature, Infrared Pressure Telemetry System," 34th International Instrumentation Symposium, Albuquerque, NM, May 1988. 
24. Morel, T.: "Effect of Base Slant on Flow in the Near Wake of an Axisymmetric Cylinder," Aeronautical Quarterly, May 1980.

25. Dress, D. A.: "Drag Measurements on a Body of Revolution in Langley's 13" Magnetic Suspension and Balance System," AIAA Paper 88-2010, May 1988. 


\section{APPENDIX A: FUTURE RESEARCH}

\section{Aerodynamic Testing}

Previous research at the LaRC 13 inch MSBS by Dress ${ }^{25}$ showed the ability of the system to take force measurements. This research involved drag measurements on bodies of revolution at zero incidence. No lift forces or pitching moments occurred for this test case, therefore, no interactions between coil currents developed. The drag force is a function of the current in the drag solenoid, $I_{D}$.

Large lift forces and pitching moments were shown to act on slanted base ogive cylinders at zero incidence creating significant coil current interactions. The development of the zero incidence equations for drag, lift, and pitching moment in Chapter 2. account for these interactions. These equations allow for complex configurations to be tested at zero incidence.

The next step in MSBS research will be the aerodynamic testing of complex configurations at arbitrary angles of attack. Lift, pitching moment, and drag measurements for a fighter configuration at a given angle of attack is an example of such research. The governing equations for this research are determined by substituting the field assumptions (2-23a through 2-23e) into the angle of attack equations (2-17 through 2-19). The coefficients are constant for a constant angle of attack and can be determined by the calibration precedure outlined in Chapter 2.

\section{Pressure Measurements}

Chapter 6. shows how pressure measurements are possible for magnetically suspended models using remote data telemetry. The calibration shows that the pressure transducer is extremely sensitive to temperature. An onboard thermocouple with temperature telemetry is necessary to 
accurately determine the pressure transducer temperature and will eliminate the temperature approximation necessary in this research. Furthermore, the pressure differential, $\left.P_{(\text {base }}\right)^{-P_{8}}$, needs to be measured directly for accurate results. Some barriers still exist preventing multiple pressure measurements. This research has shown how multiple pressure measurements can be made over a small surface area (in this case the slanted bases) with a single channel pressure transducer. However, before multiple pressure measurements over large surface areas can be made, a miniature multi-channel pressure transducer needs to be developed. 


\section{APPENDIX B: CALCULATION METHODS IN SANDRAG AND VSAERO}

The two codes used in this research, VSAERO and SANDRAG, implement various methods to solve for the flow fields. SANDRAG results are restricted to axisymmetric bodies at zero incidence in incompressible flow, however, this code is "user-friendly". VSAERO can predict subsonic flow fields for general configurations at any orientation, however, this code is not userfriendly.

The effects of viscosity in VSAERO are determined in an iterative loop which couples the potential flow and boundary layer solutions. VSAERO is a panel method code in which doublet and source singularities are piecewise constant over the panels. ${ }^{21}$ Thwaites' method with Curle's modifications is used in VSAERO for laminar boundary layer calculations, while Granville's criterion is used for transition predictions. Nash and Hicks method is used for turbulent boundary layer calculations. Wake calculations in VSAERO determine base pressure estimates. $^{22}$

As with VSAERO, viscous effects are determined by coupling the potential flow and boundary layer solutions. SANDRAG uses an axial distribution of source and sink elements to determine the potential flow solution. These strengths vary linearly with length. Laminar boundary layer solutions in SANDRAG are determined by Thwaites' one parameter solution of the momentum integral equation for steady flow over axisymmetric bodies. Transition calculations in SANDRAG are determined by an approximate method by Schlichting and Ulrich, and by combining surface roughness effects using Kluck's empirical results. Turbulent boundary layer calculations are made by a modification of White's Karman-type method which includes surface roughness effects. Base pressure estimates in SANDRAG are found by empirical results by Payne, Hartley, and Taylor for various axisymmetric afterbodies. ${ }^{20}$ 
(a) Quasi-axisymmetric Separation Pattern

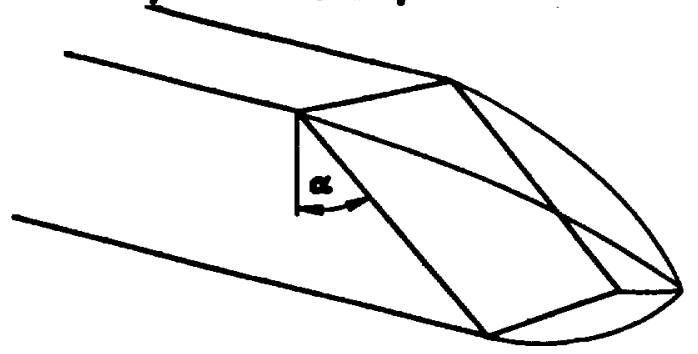

(b) 3-D Separation Pattern

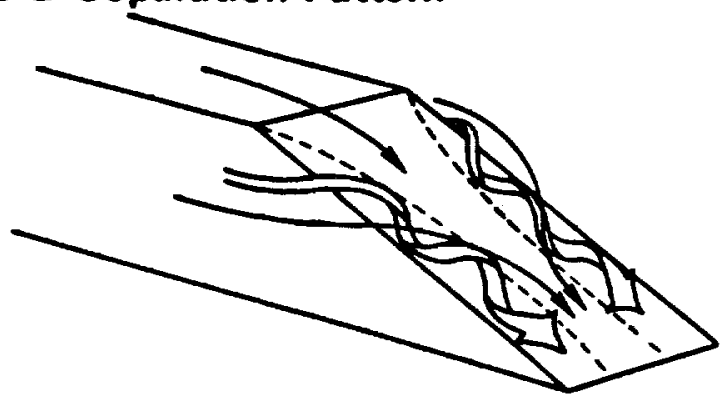

F1g. 1 Wake structures behind slanted base models.

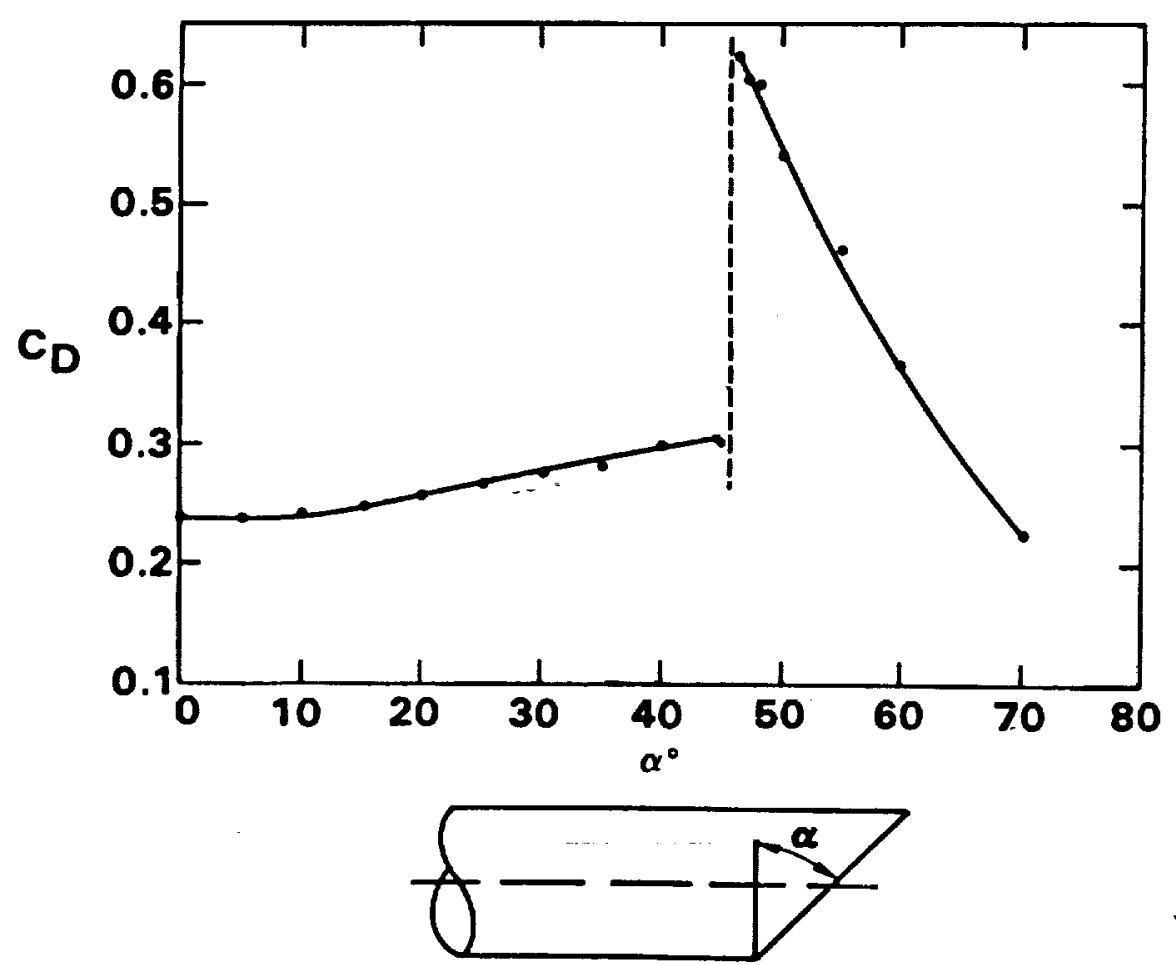

Fig. 2 Slanted base drag results (Morel). 


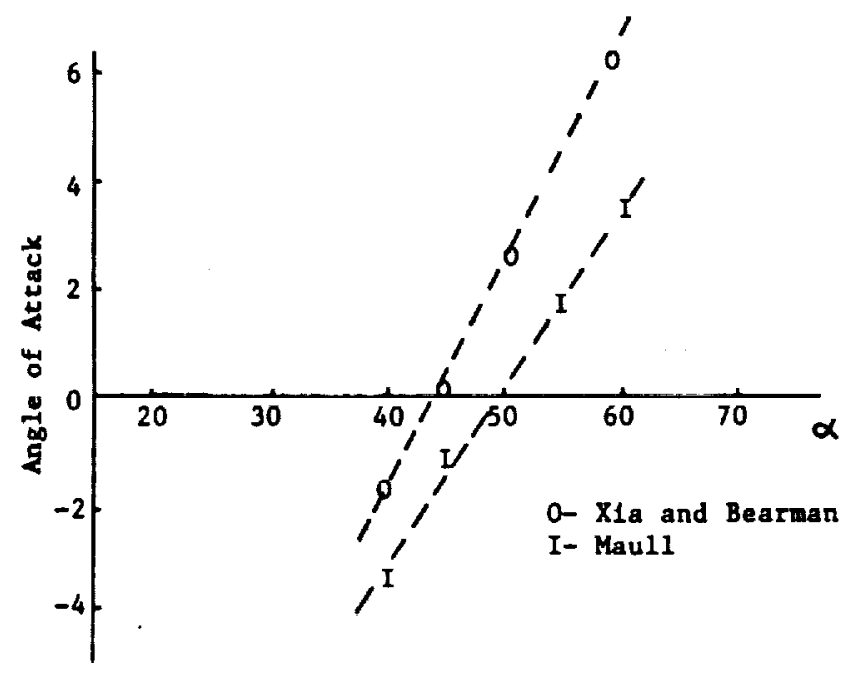

Fig. 3 Critical angle of attack for drag overshoot.
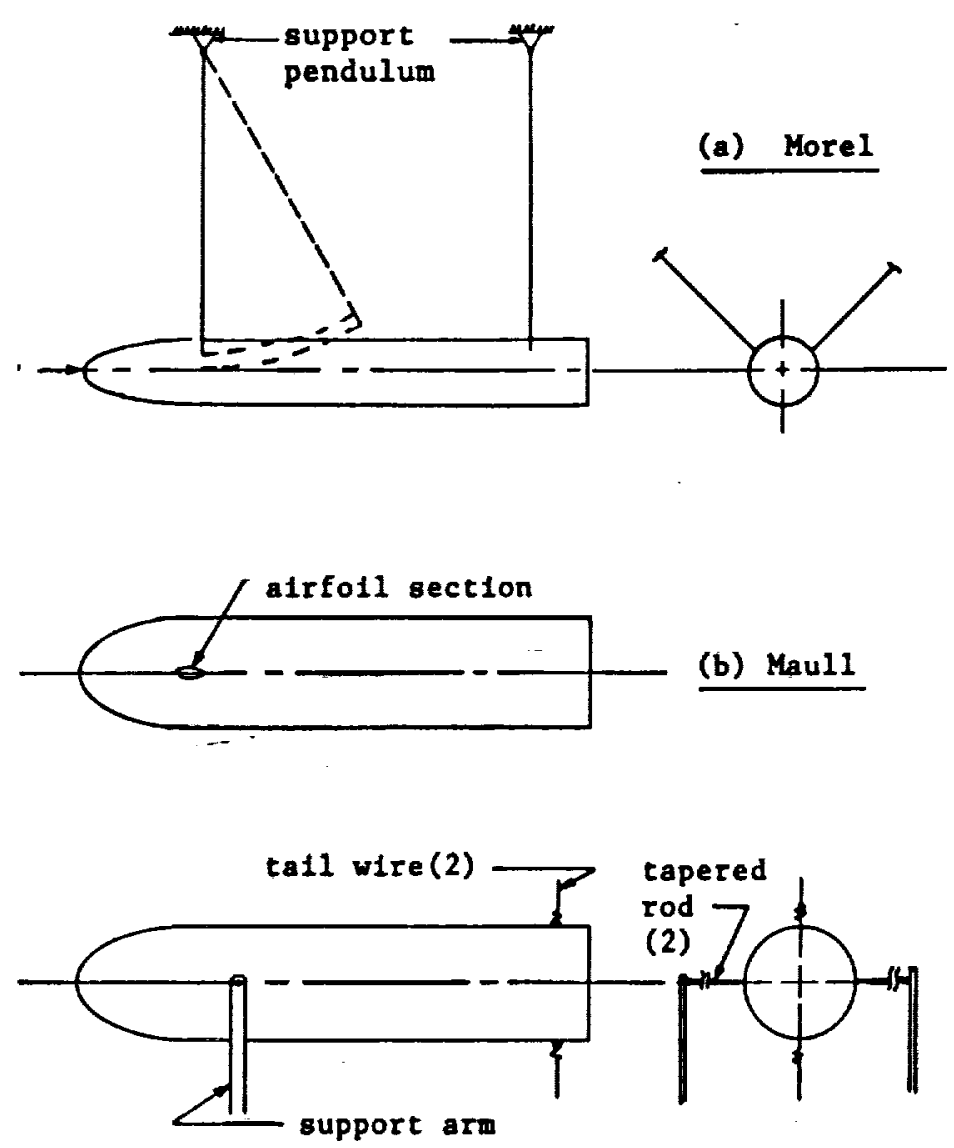

(c) X1a and Bearman

Fig. 4 Support systems (not to scale). 


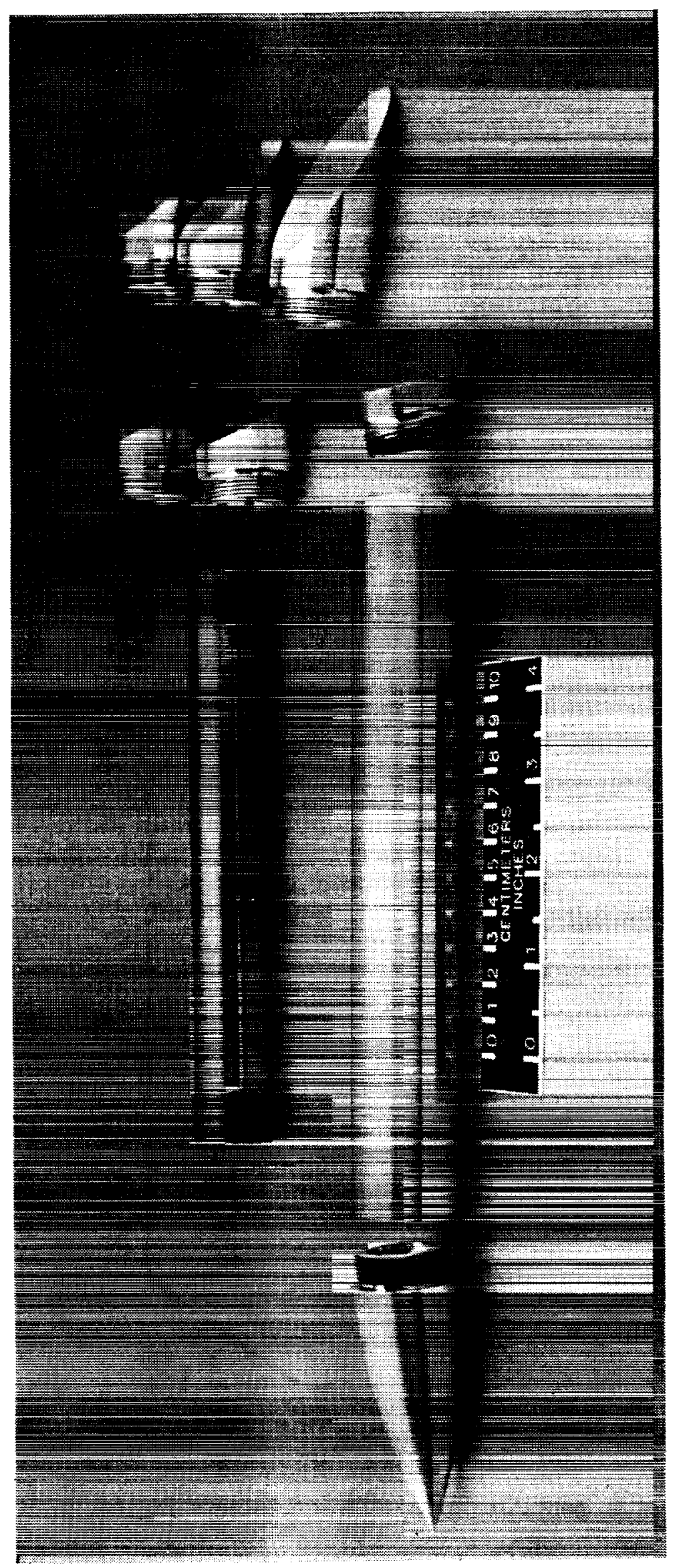

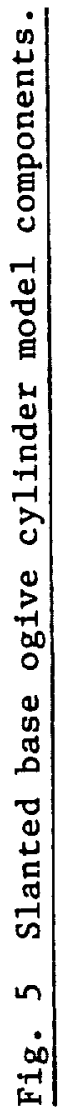

ORIGINAL PAGE

-43- BLACK AND WHITE PHOTOGRAPH 


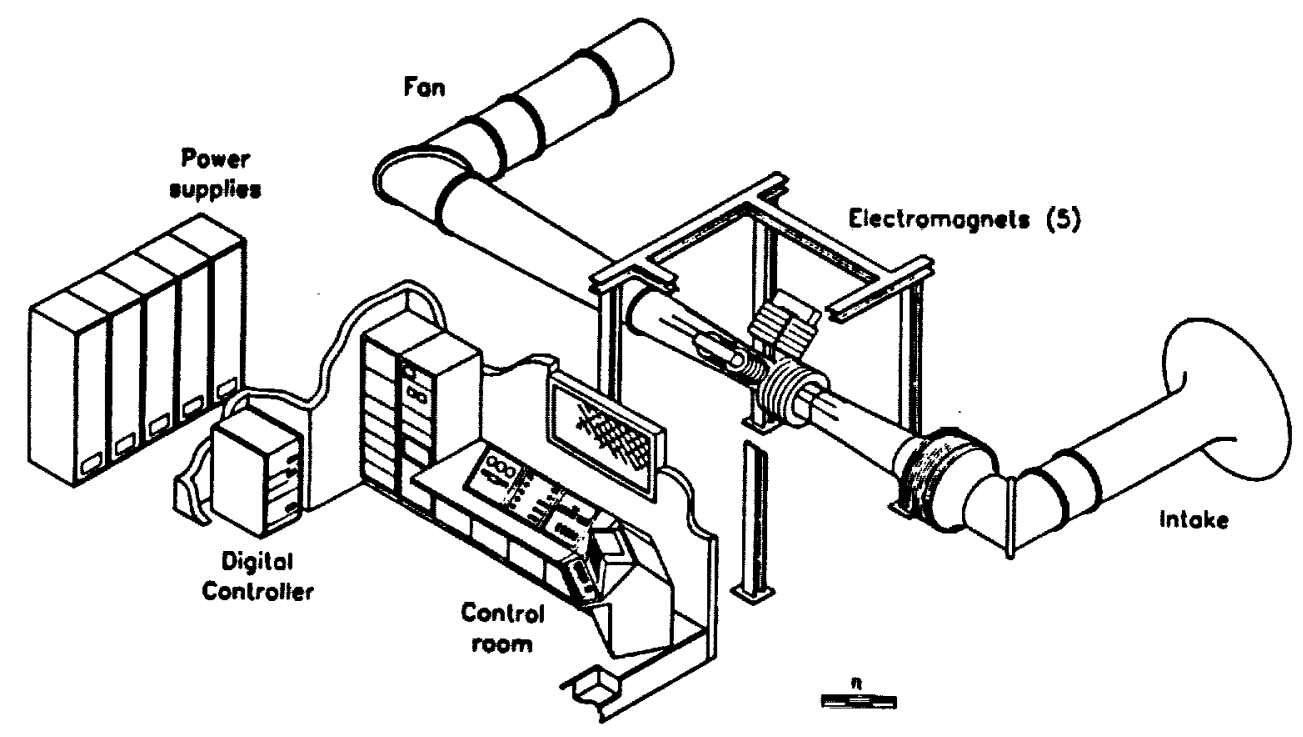

(a) Magnetic suspension laboratory (LaRC)

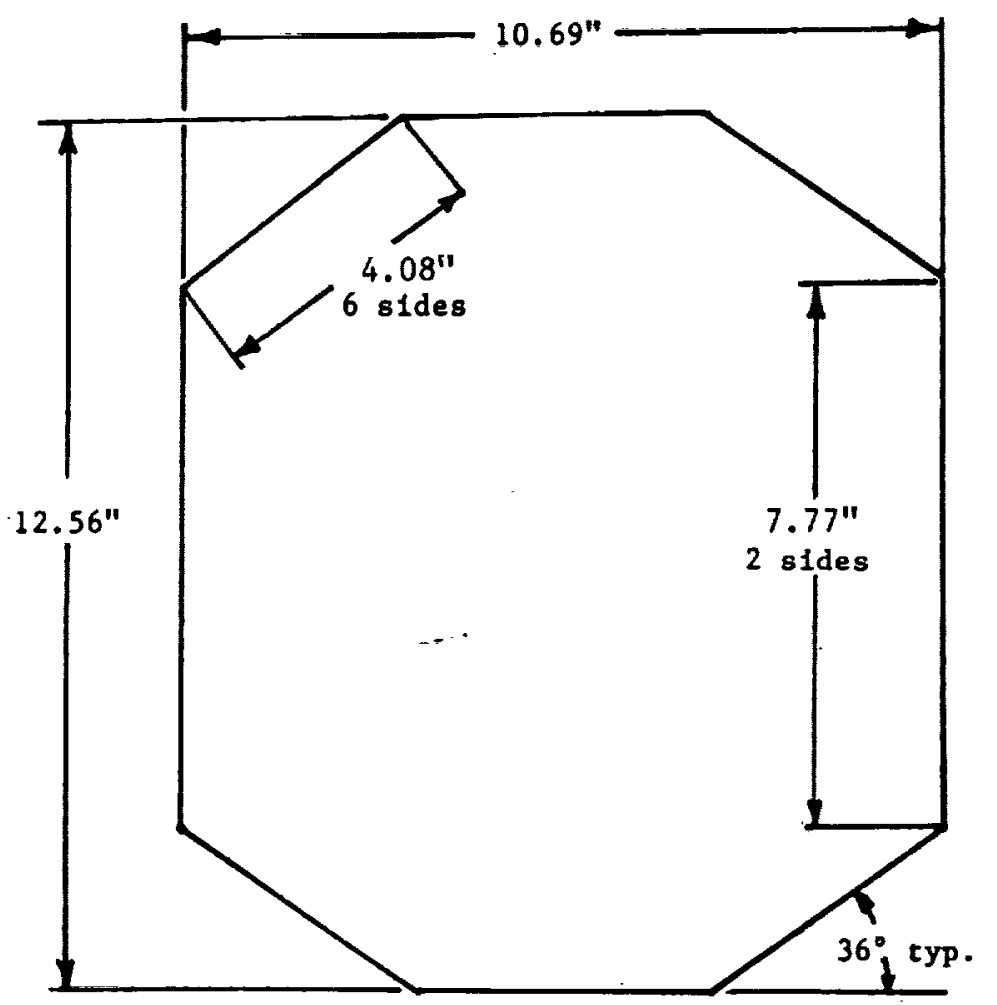

(b) Test section dimensions

Fig. 6 Magnetic Suspension and Balance System. 


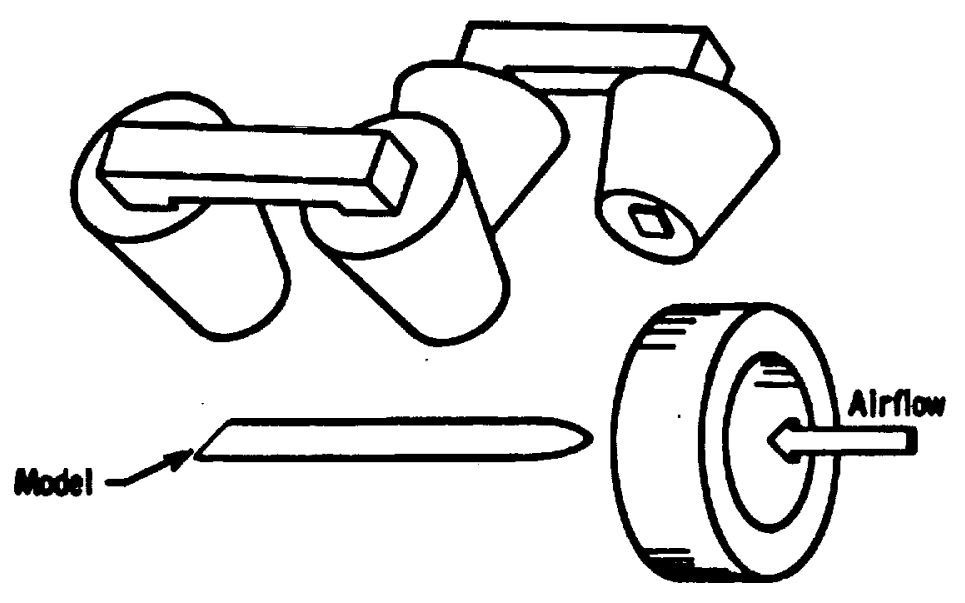

\section{(c) Electromagnet configuration}

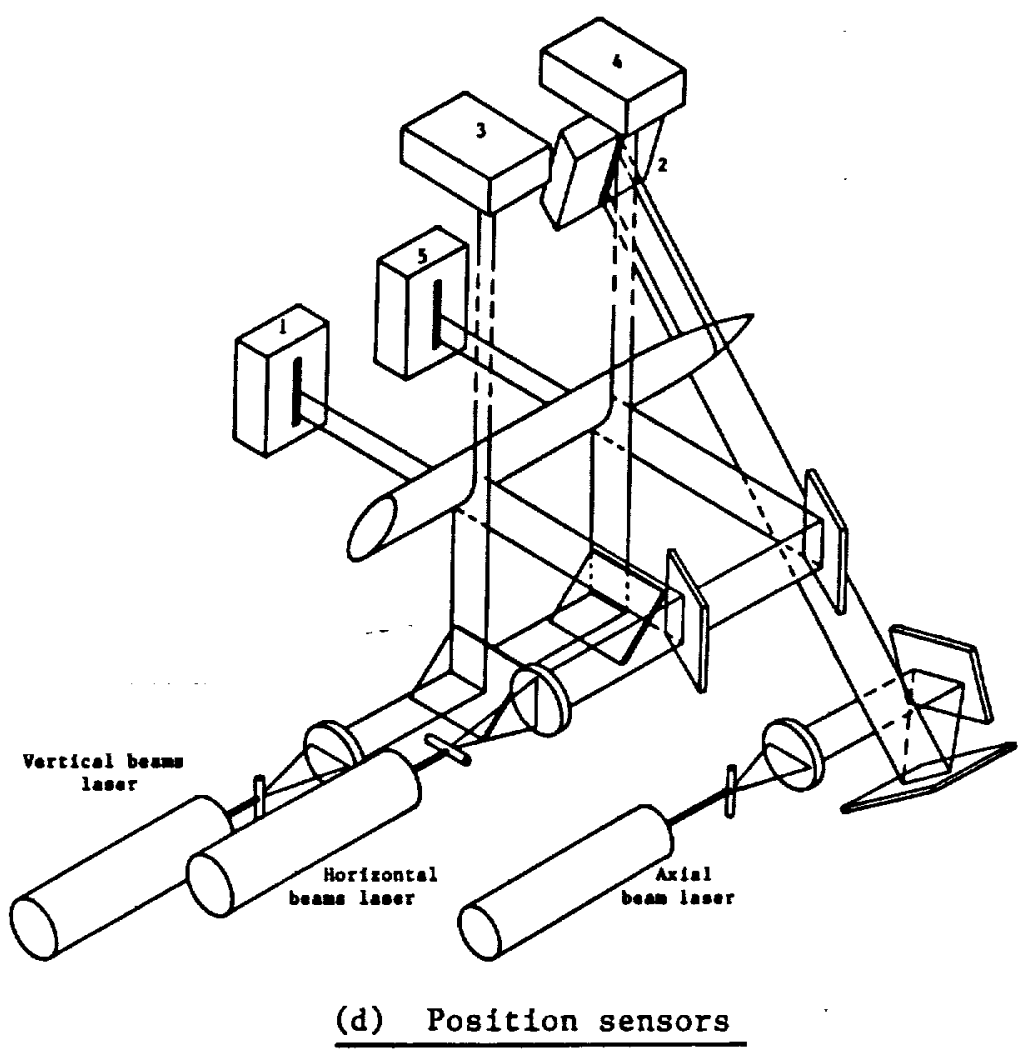

Fig. 6 cont'd 


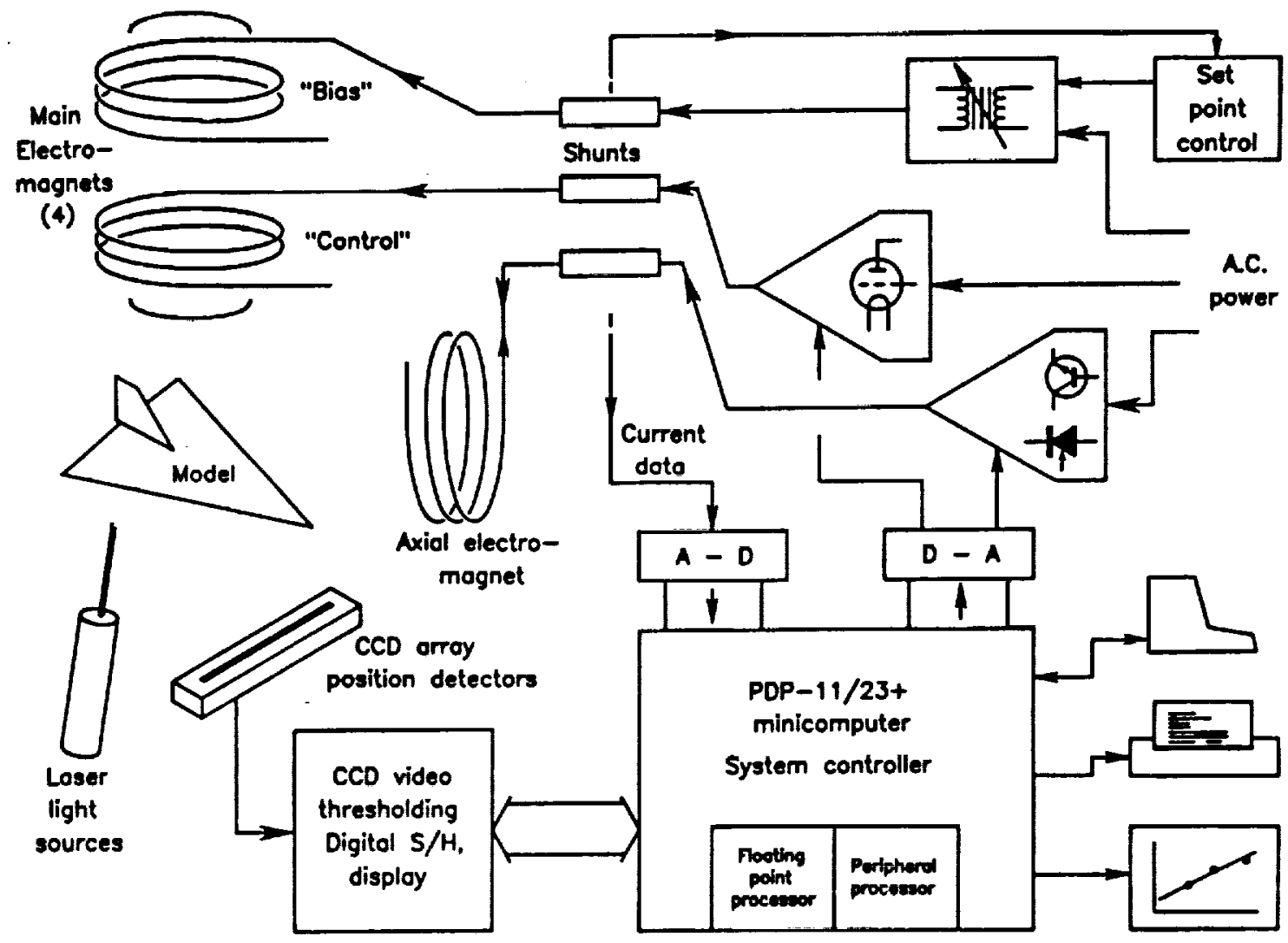

(e) Block diagram of 13" MSBS hardware

Fig. 6 cont'd 


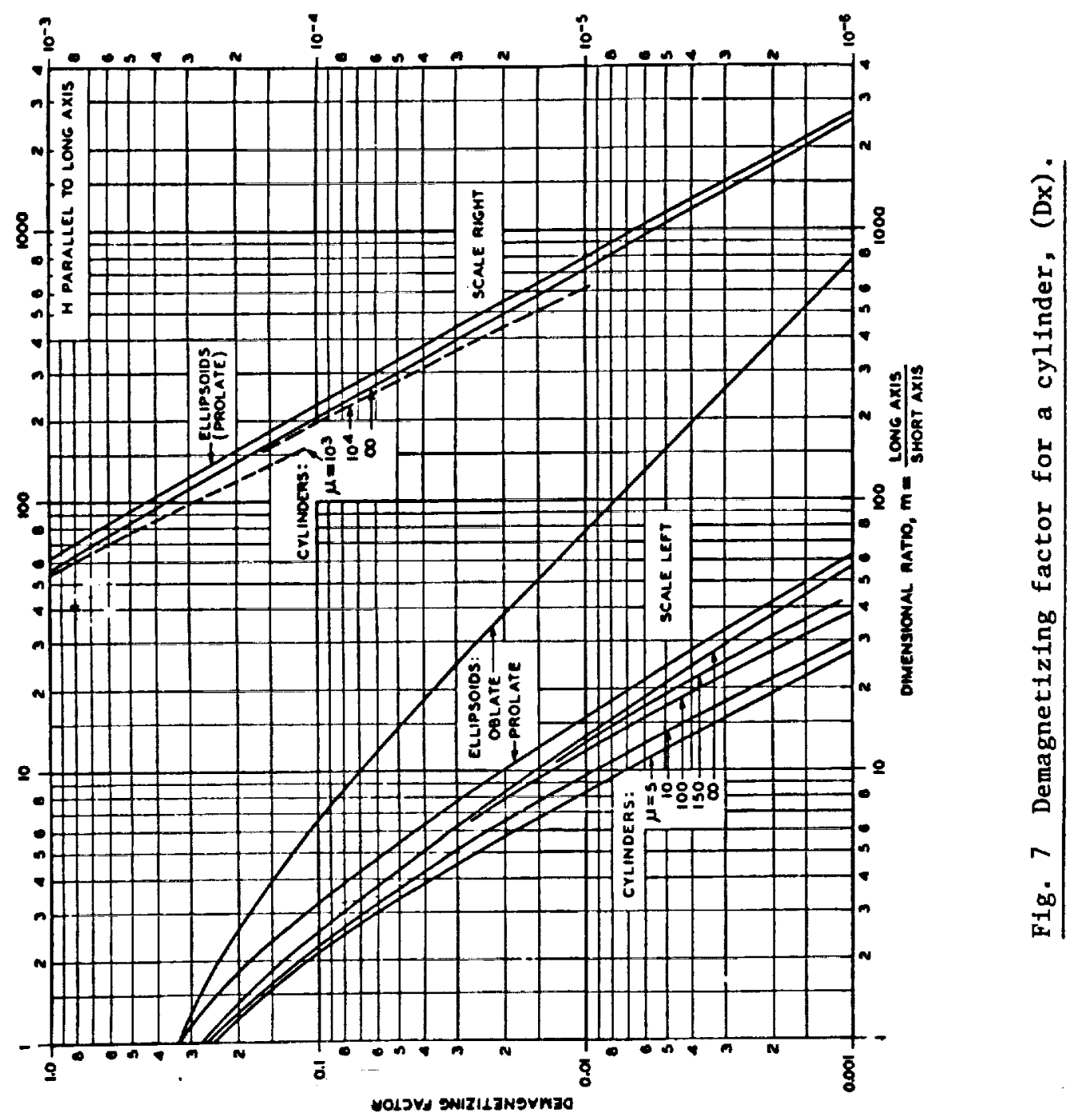




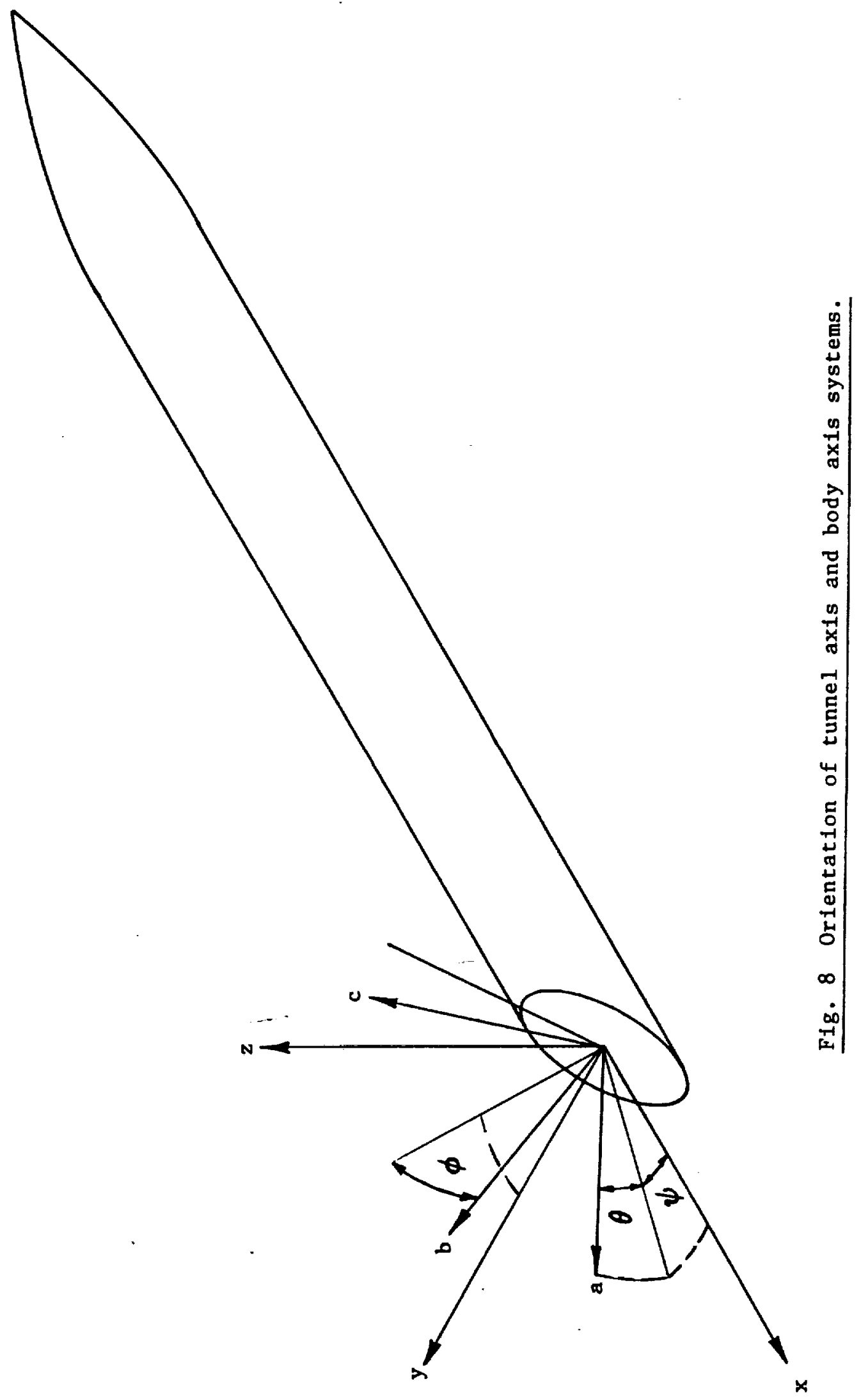




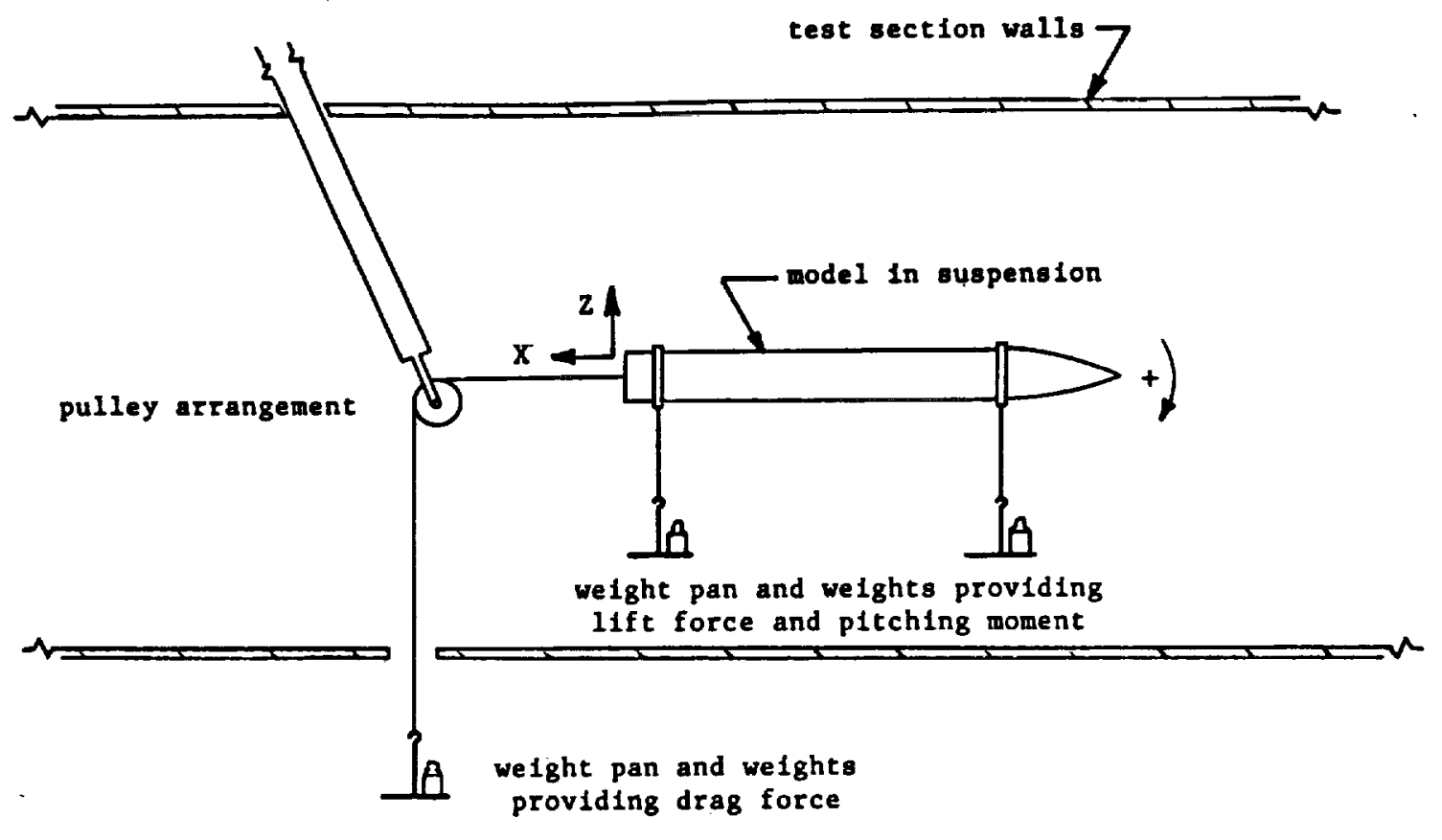

(a) Proper calibration set-up

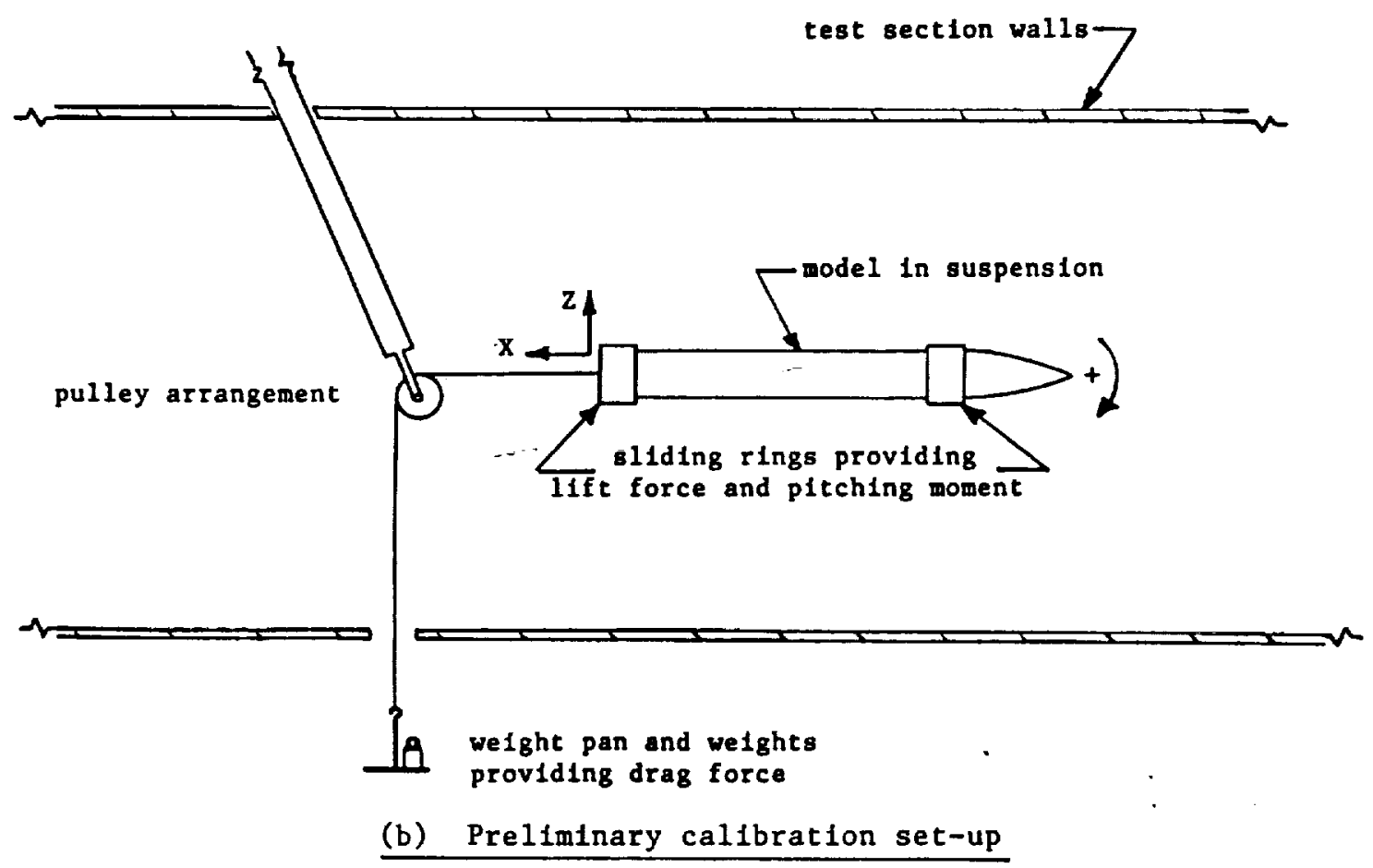

Fig. 9 Calibration set-ups to determine force and torque coefficlents. 


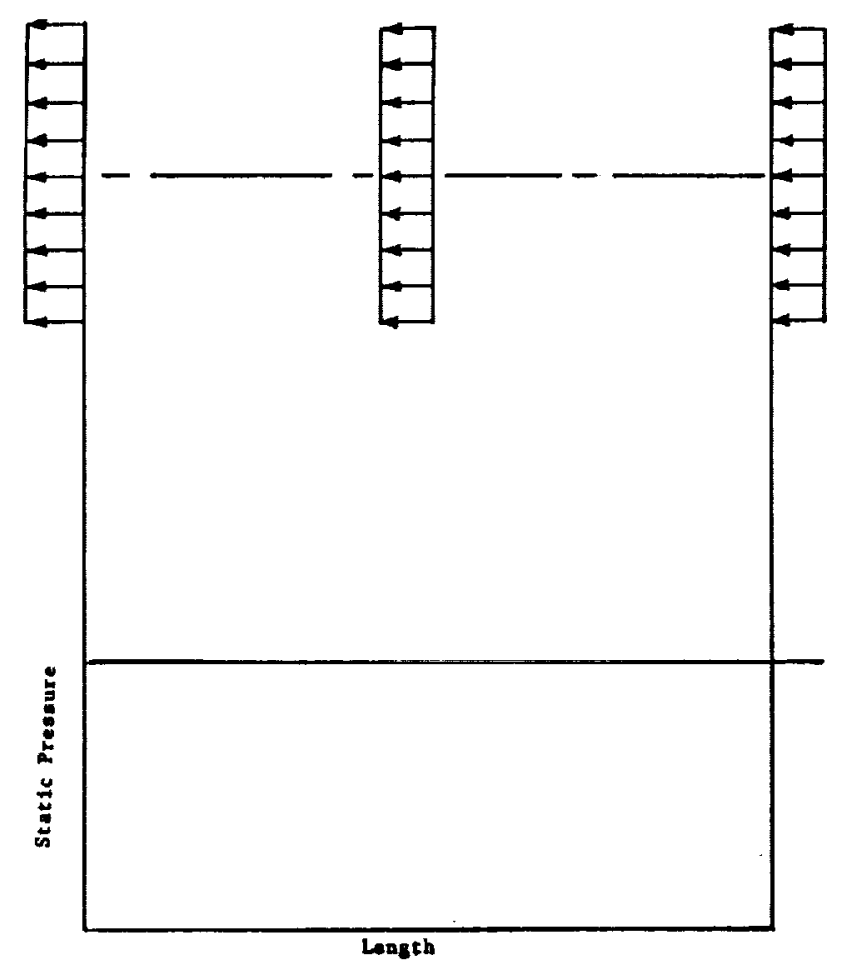

(a) Free stream conditions

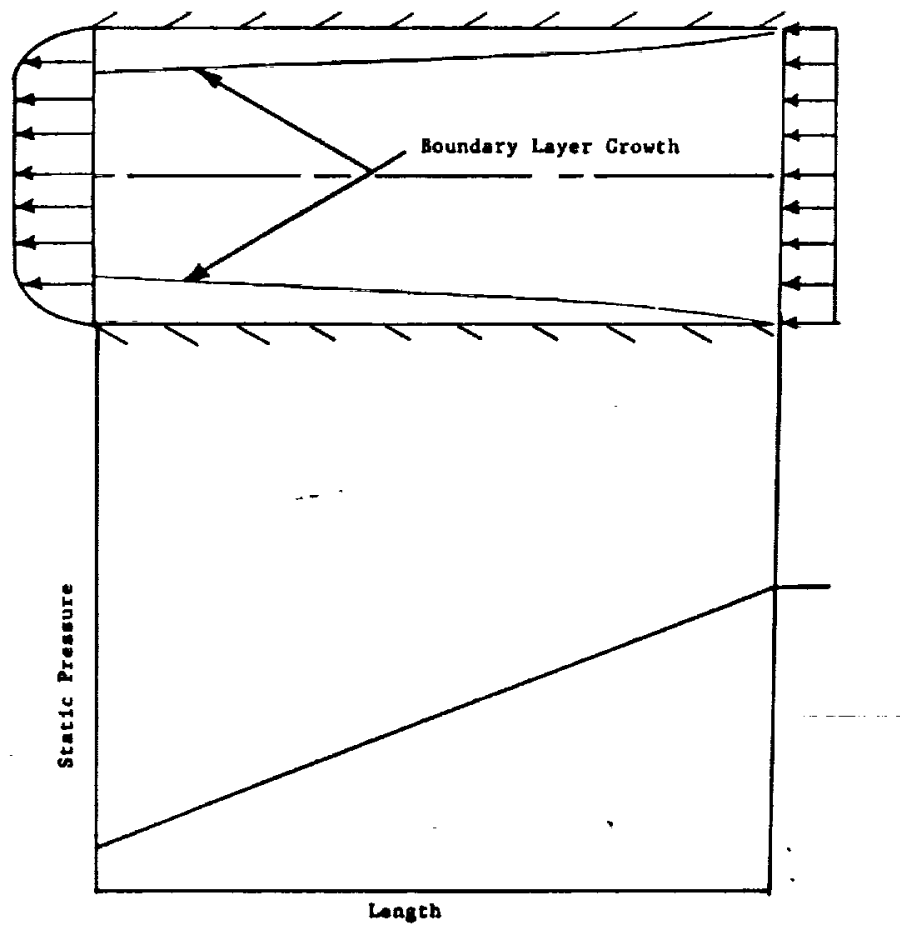

(b) Flow with boundaries.

Fig. 10 Buoyancy effects in a closed throat wind tunnel. 

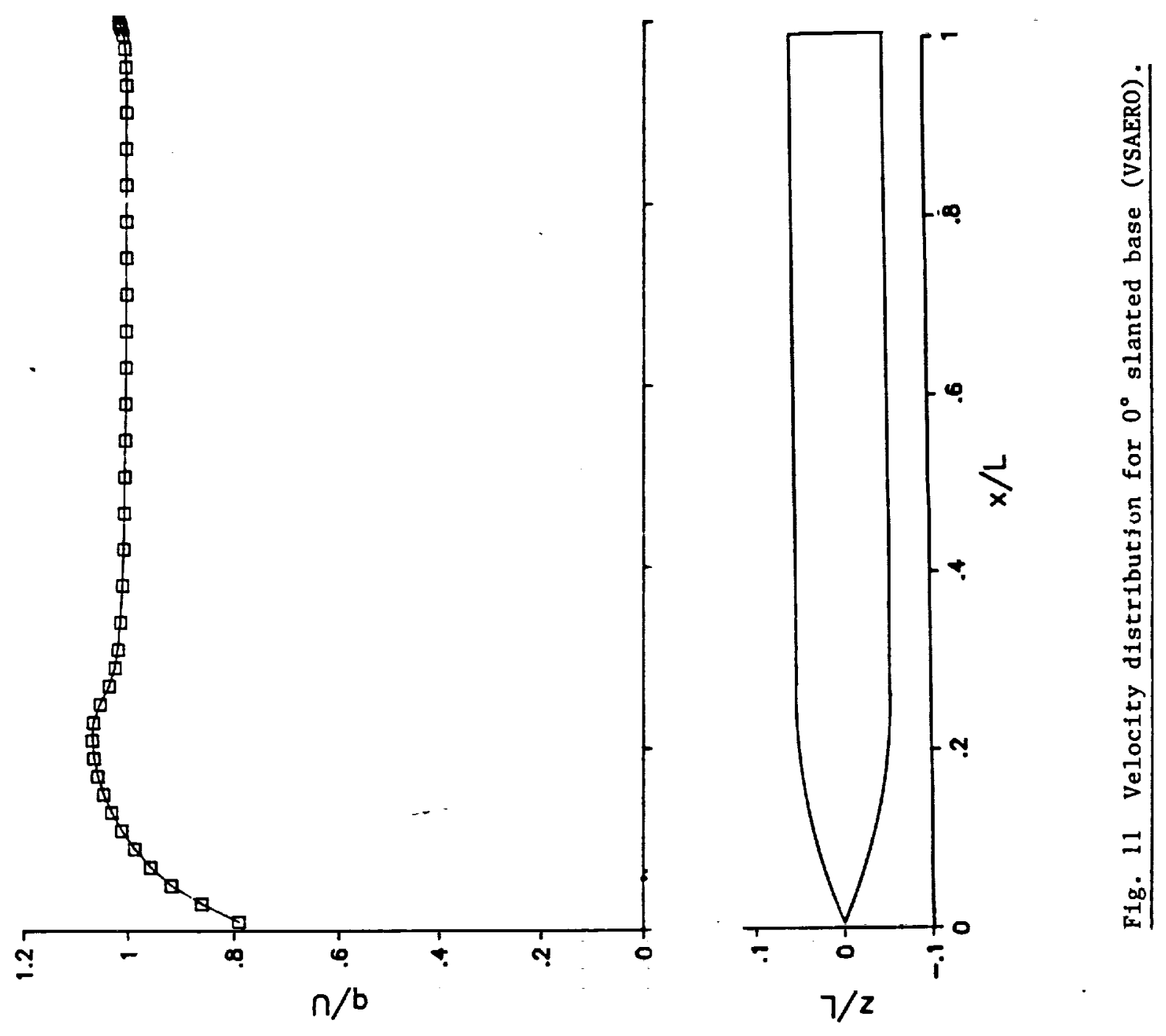


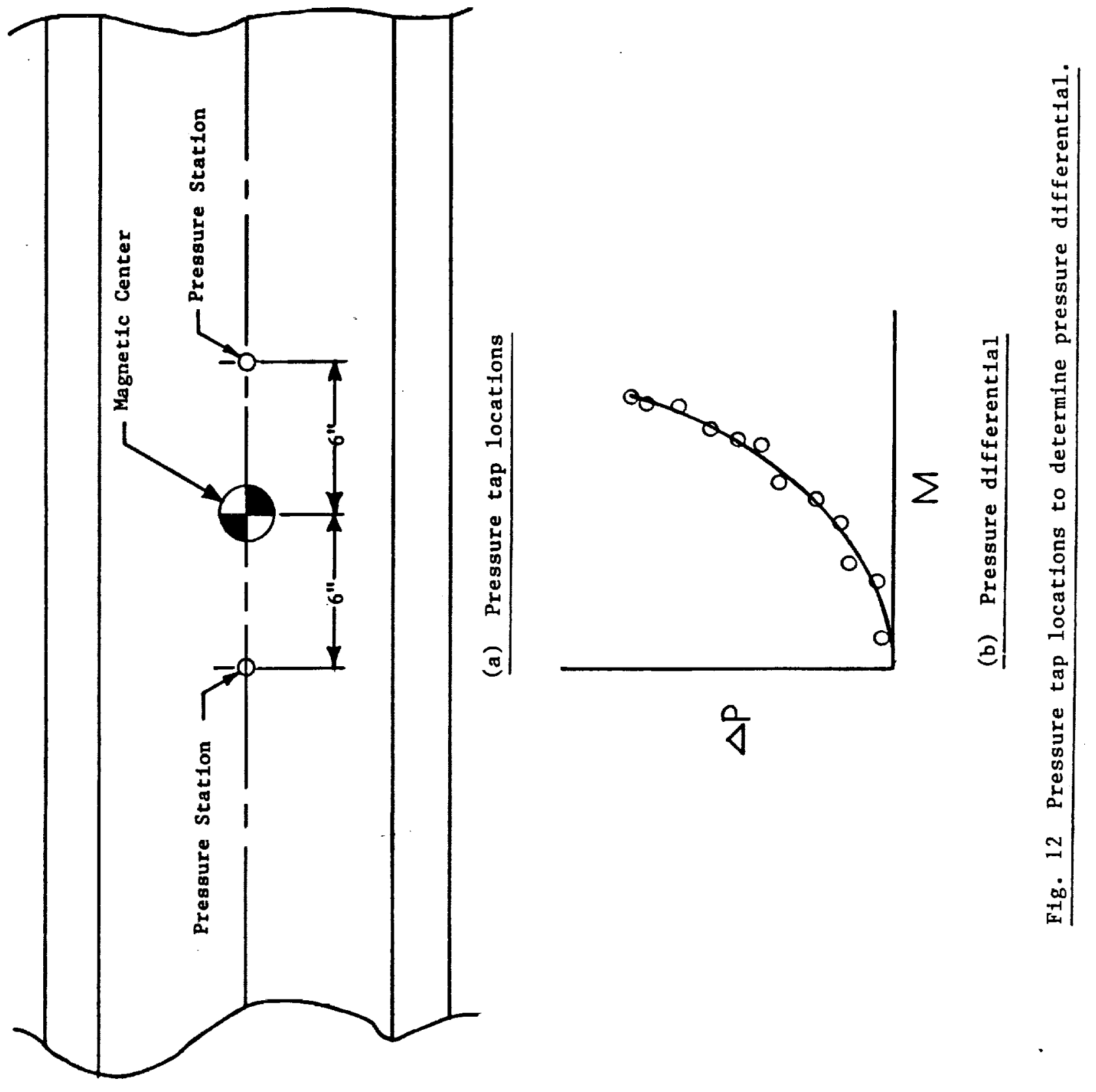




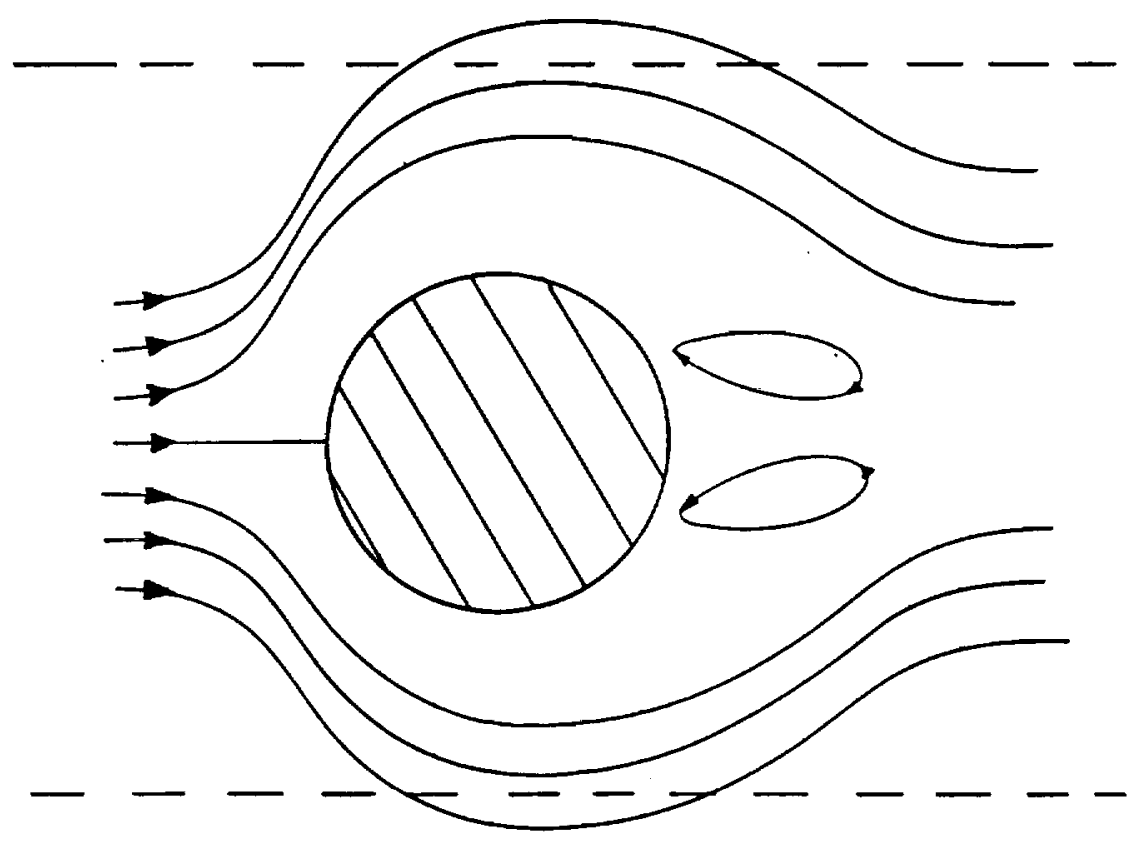

(a) Unconfined flow
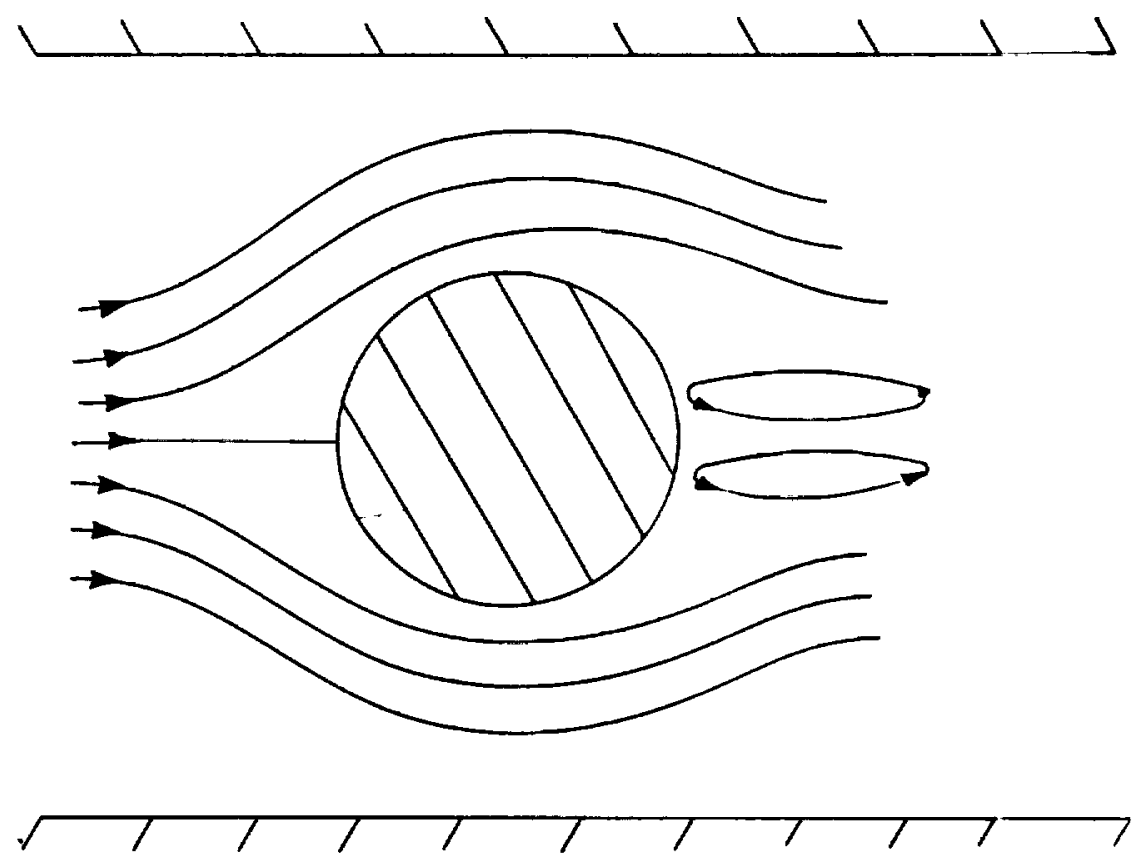

(b) Confined flow

Fig. 13 Blockage effects in a closed throat wind tunnel. 

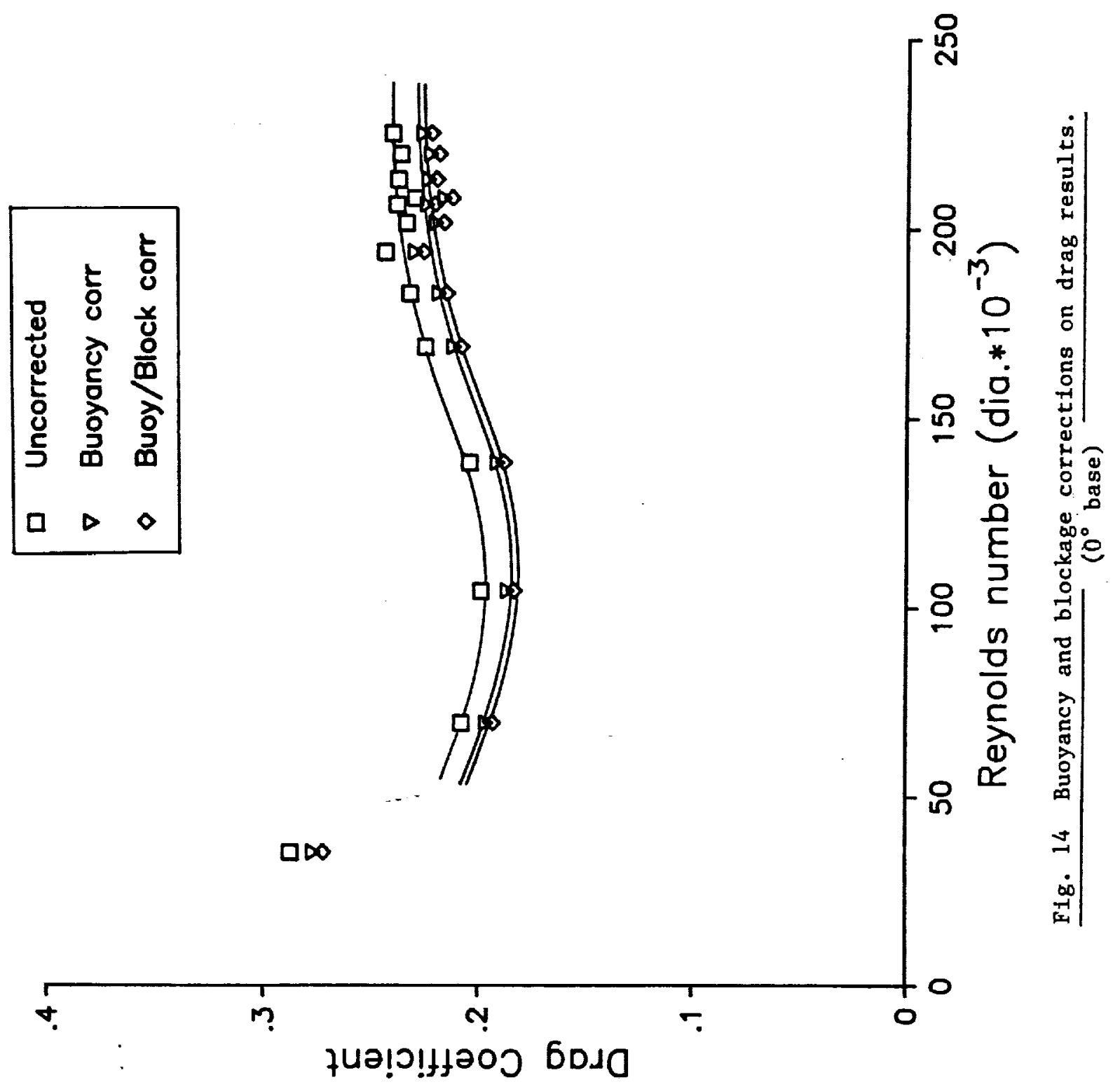


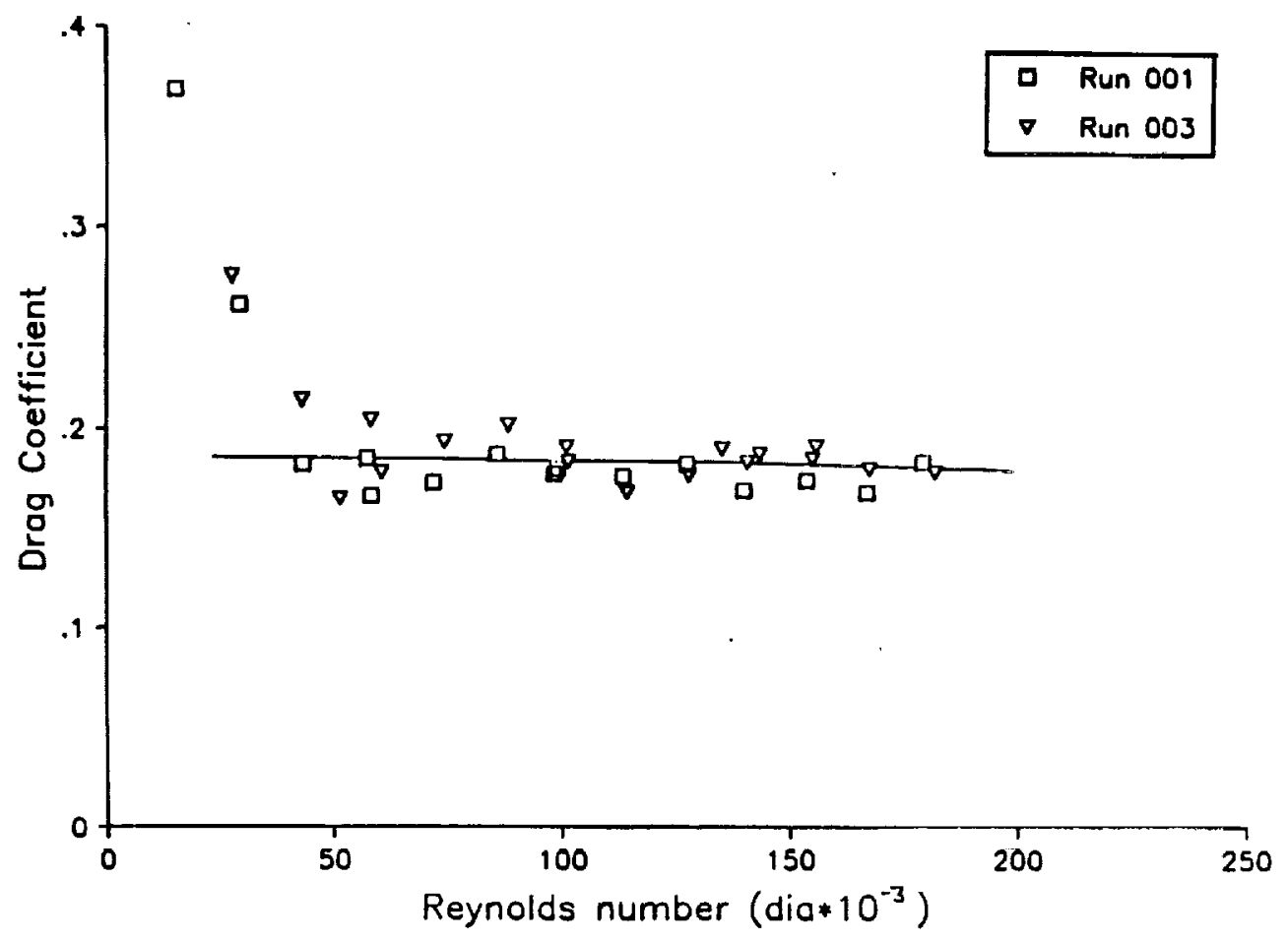

(a) Drag, $0^{\circ}$ base, Run $001 / 003$, free transition

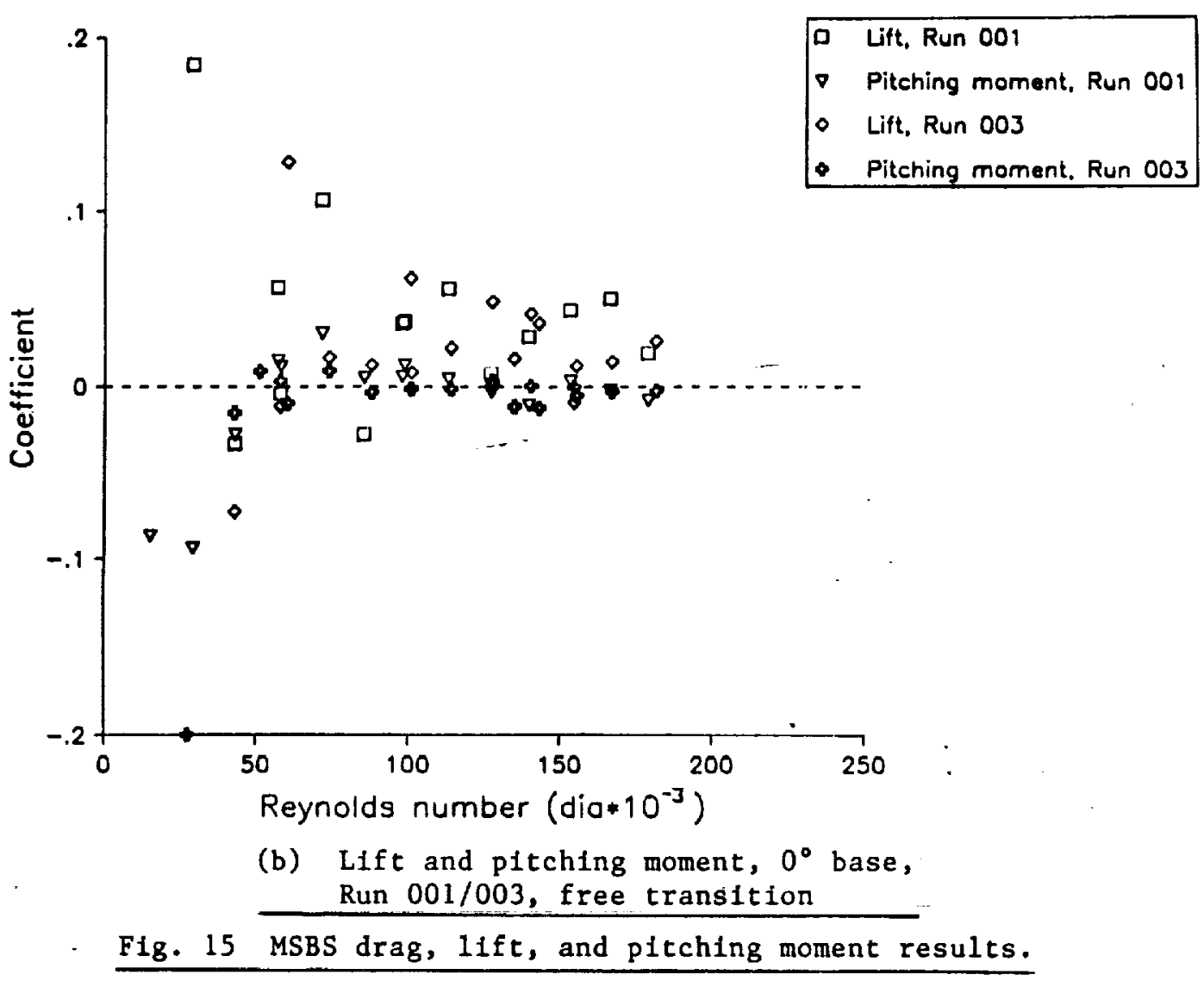




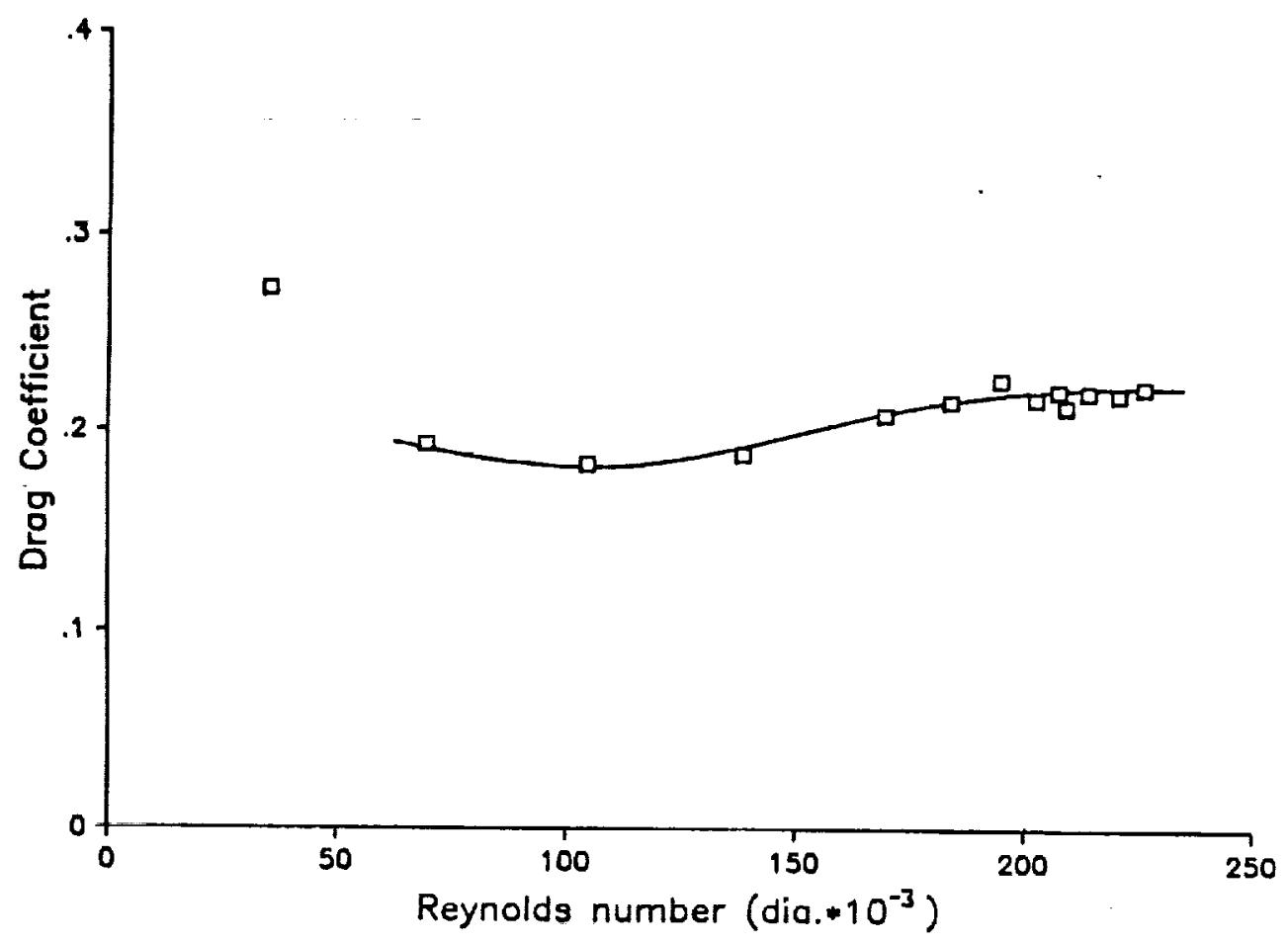

(c) Drag, $0^{\circ}$ base, Run 006, free transition

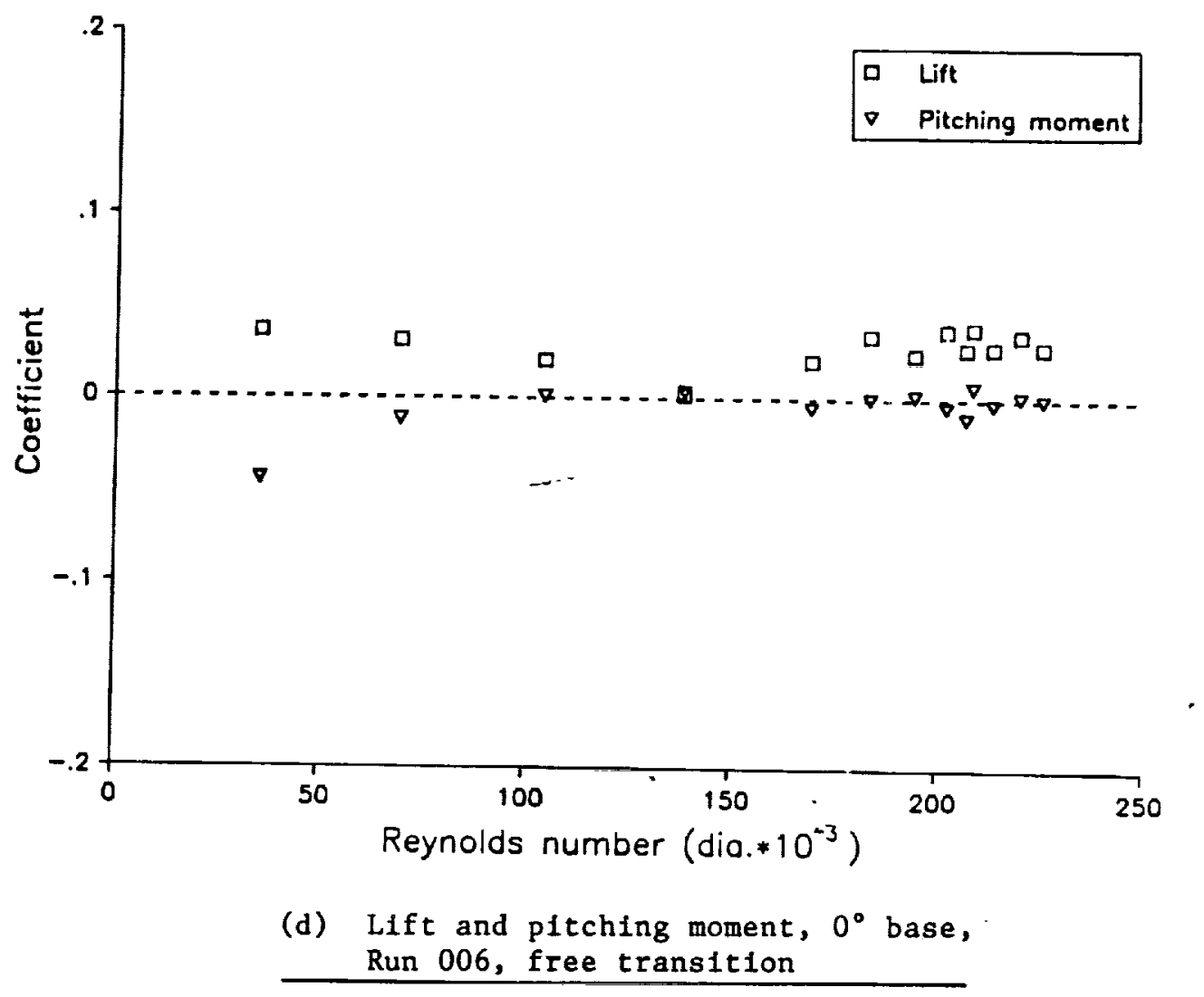

Fig. 15 cont'd 


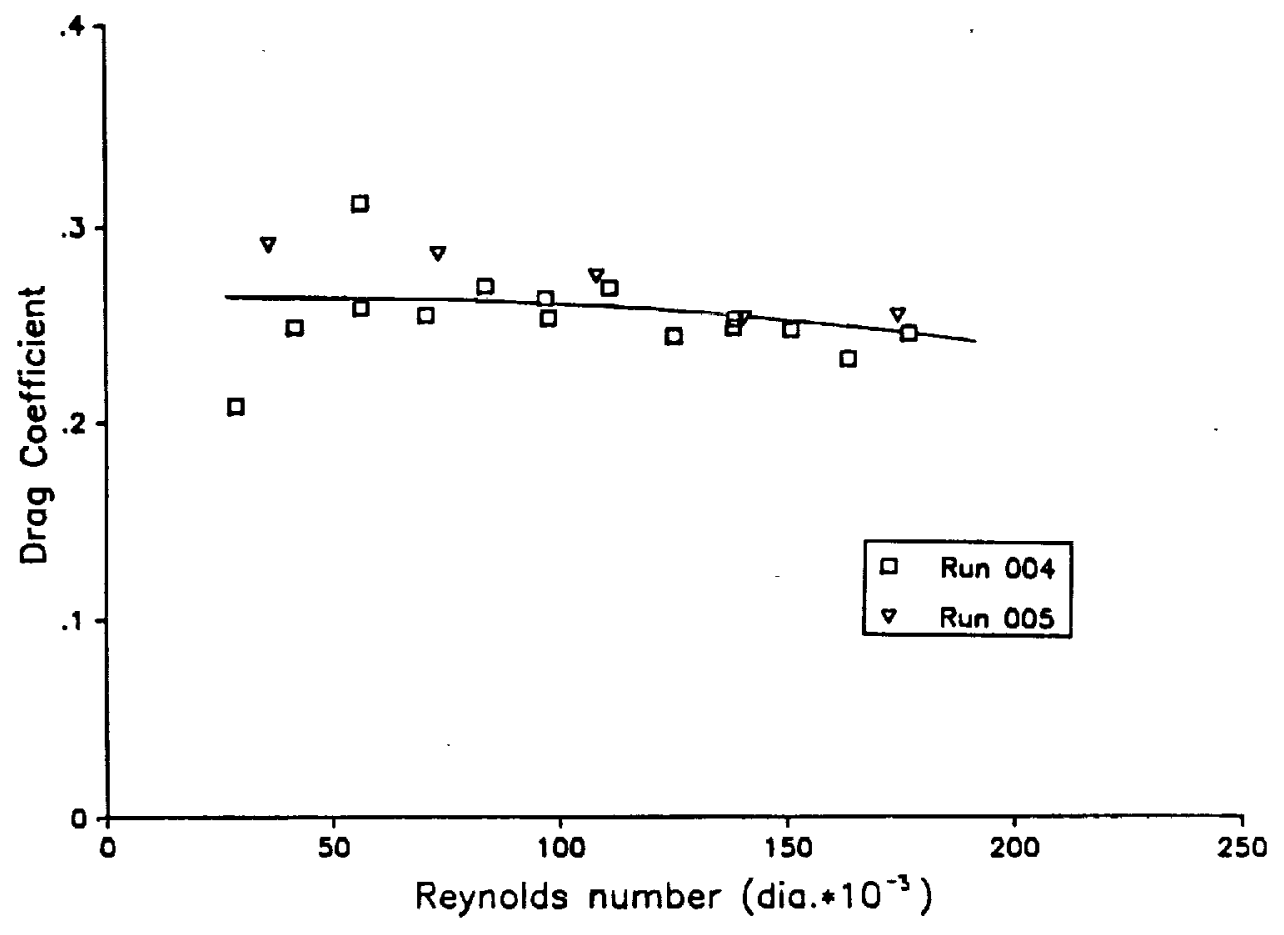

(e) Drag, $0^{\circ}$ base, Run 004/005, fixed transition

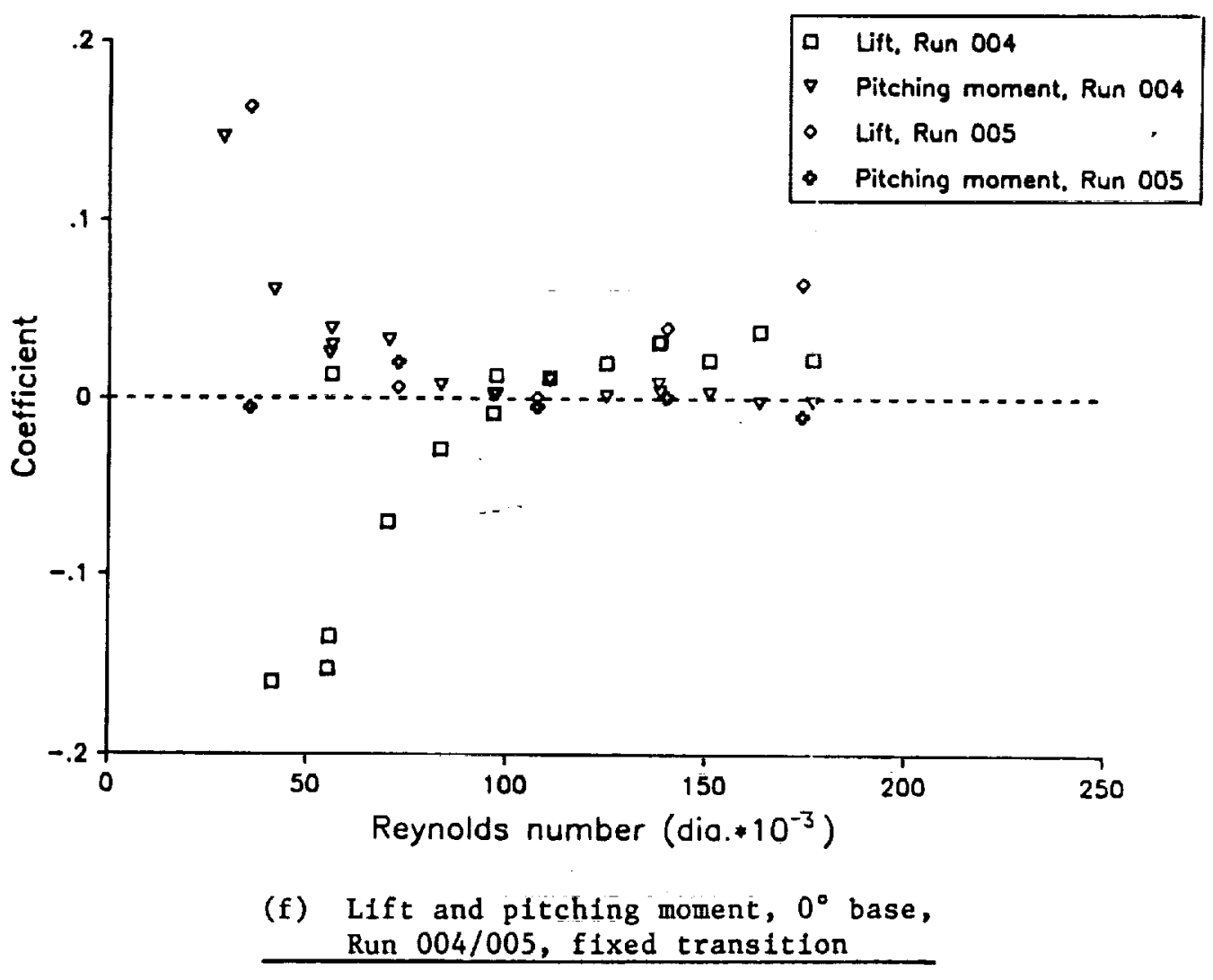

F1g. 15 cont'd 


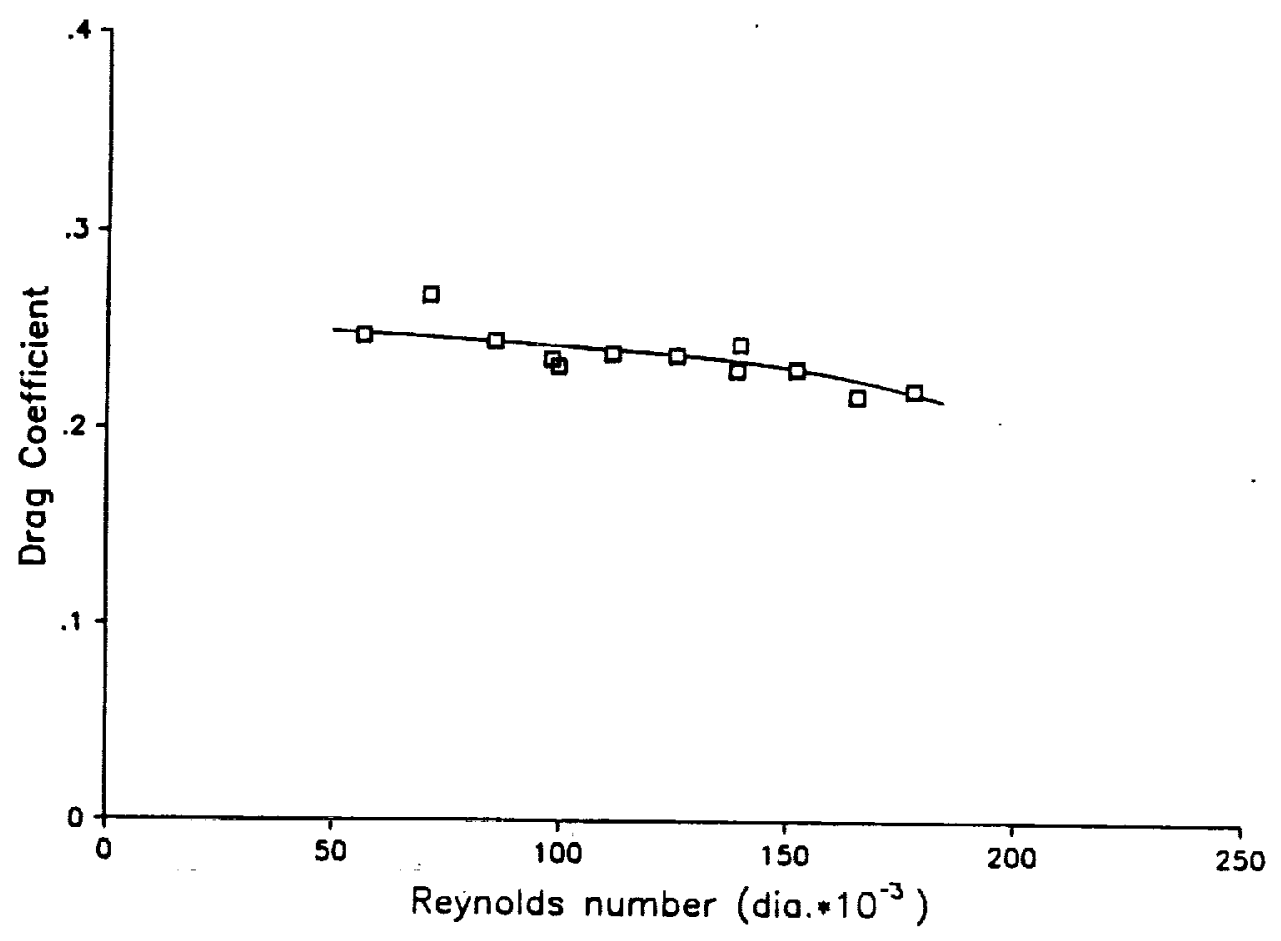

(g) Drag, $30^{\circ}$ base, Run 302 , free transition

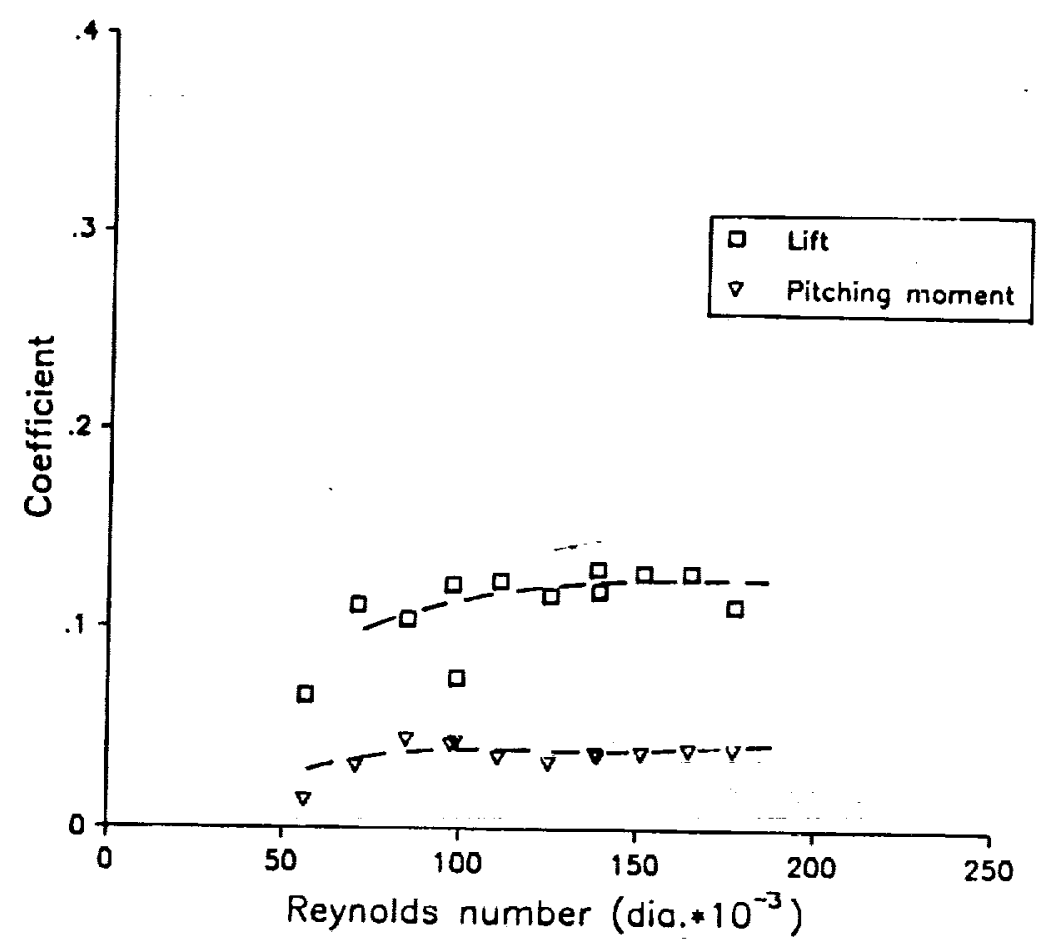

(h) Lift and pitching moment, $30^{\circ}$ base, Run 302 , free transition

Fig. 15 cont'd 


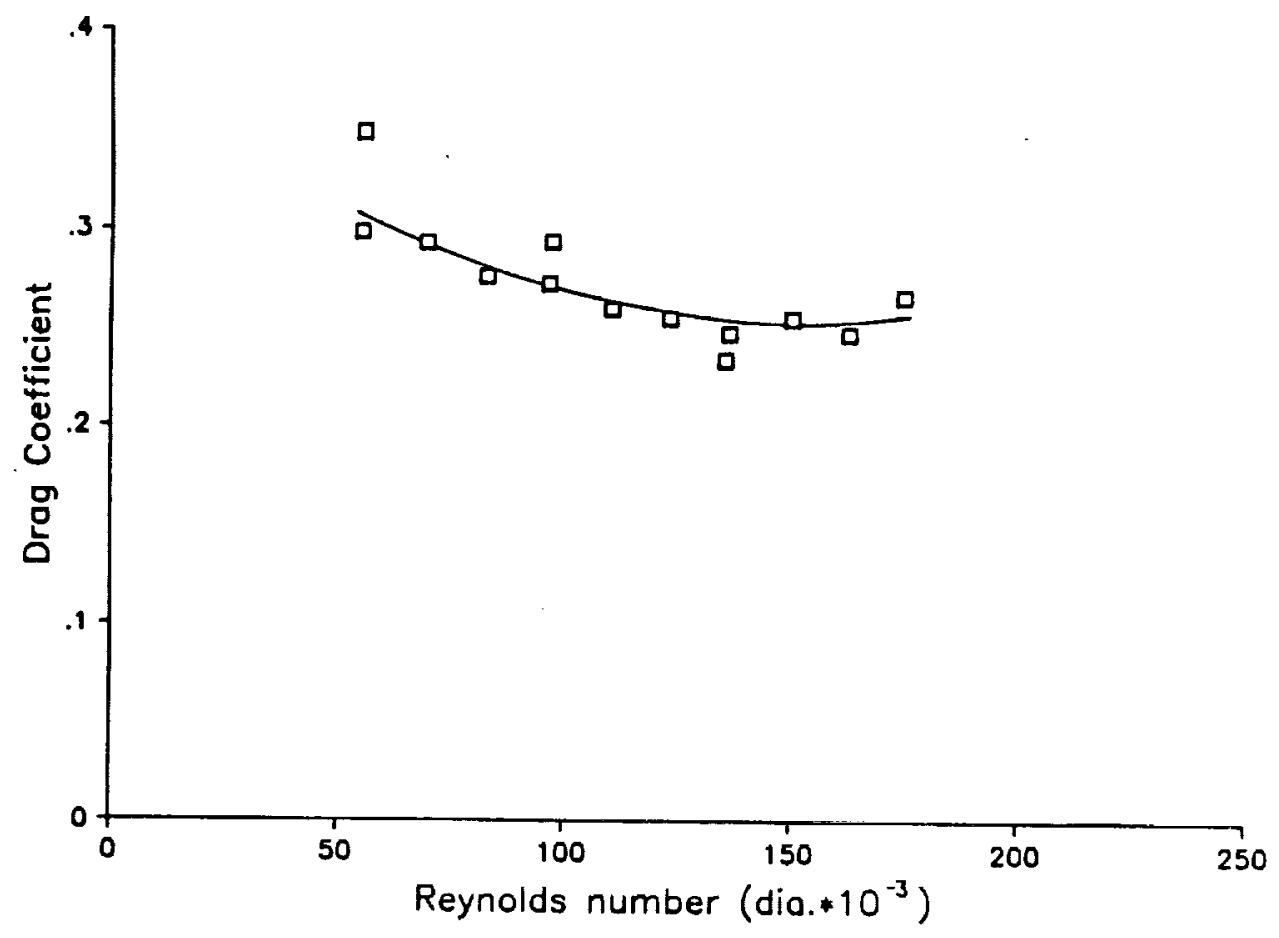

(i) Drag, $40^{\circ}$ base, Run 401 , free transition

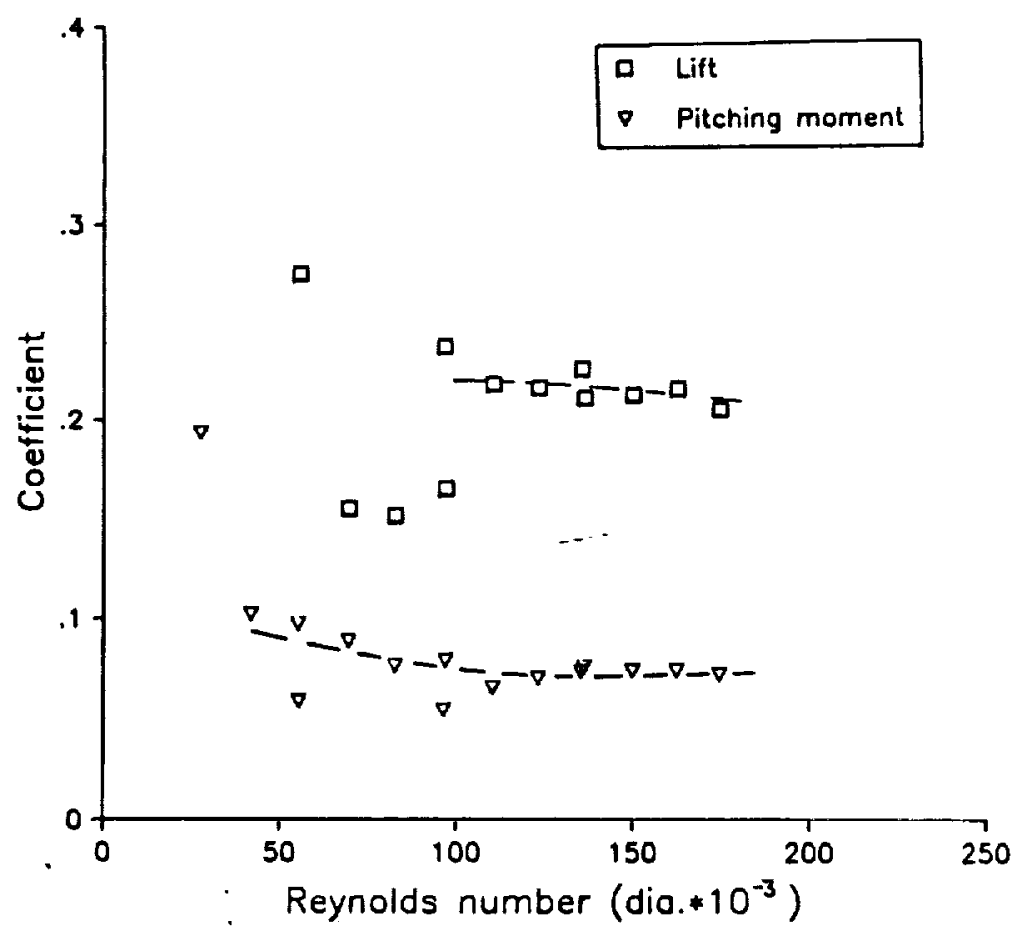

(j) Lift and pitching moment, $40^{\circ}$ base, Run 401 , free transition

Fig. 15 cont'd 


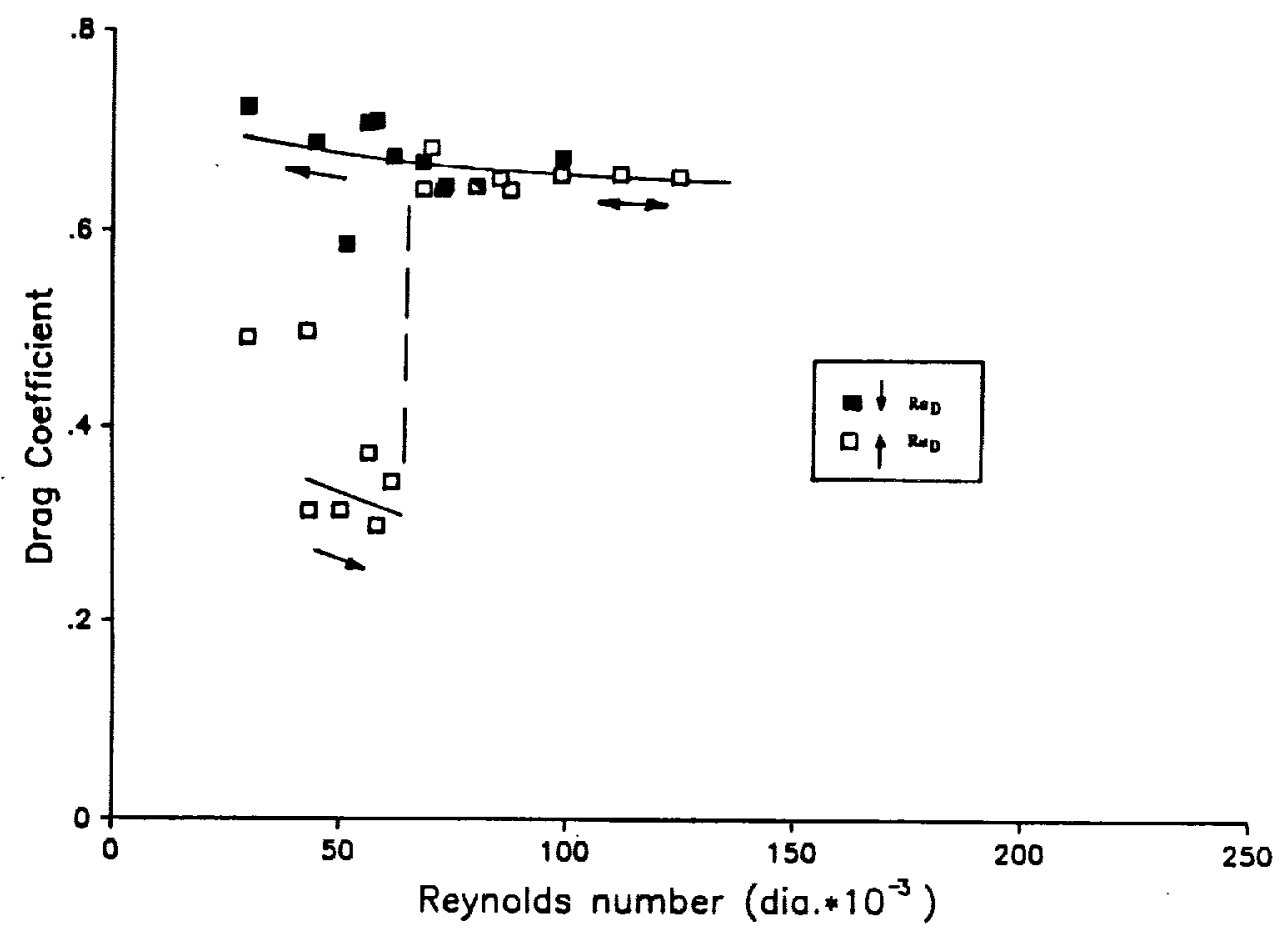

(k) Drag, $45^{\circ}$ base, Run 451/453, free transition

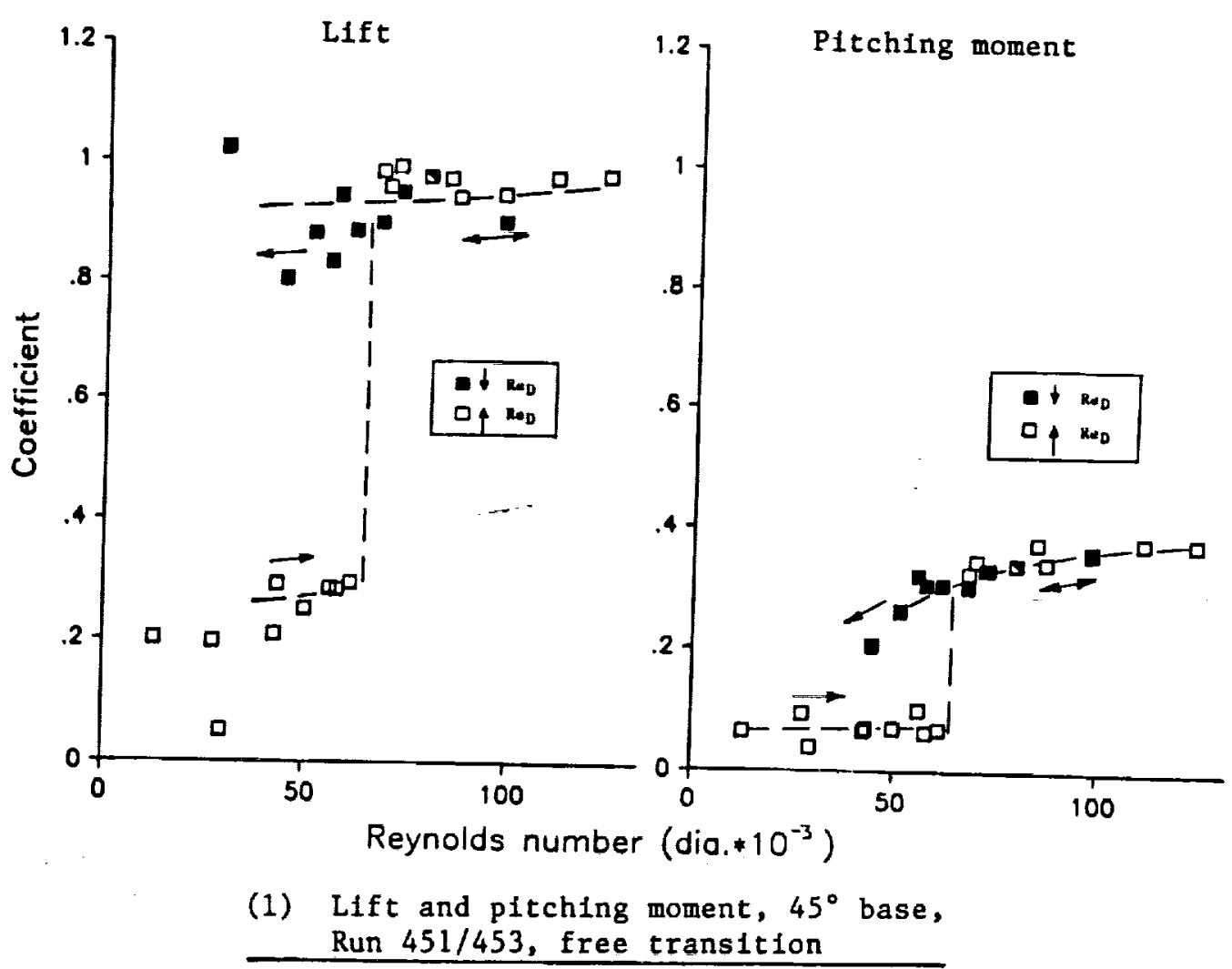

Fig. 15. cont'd 


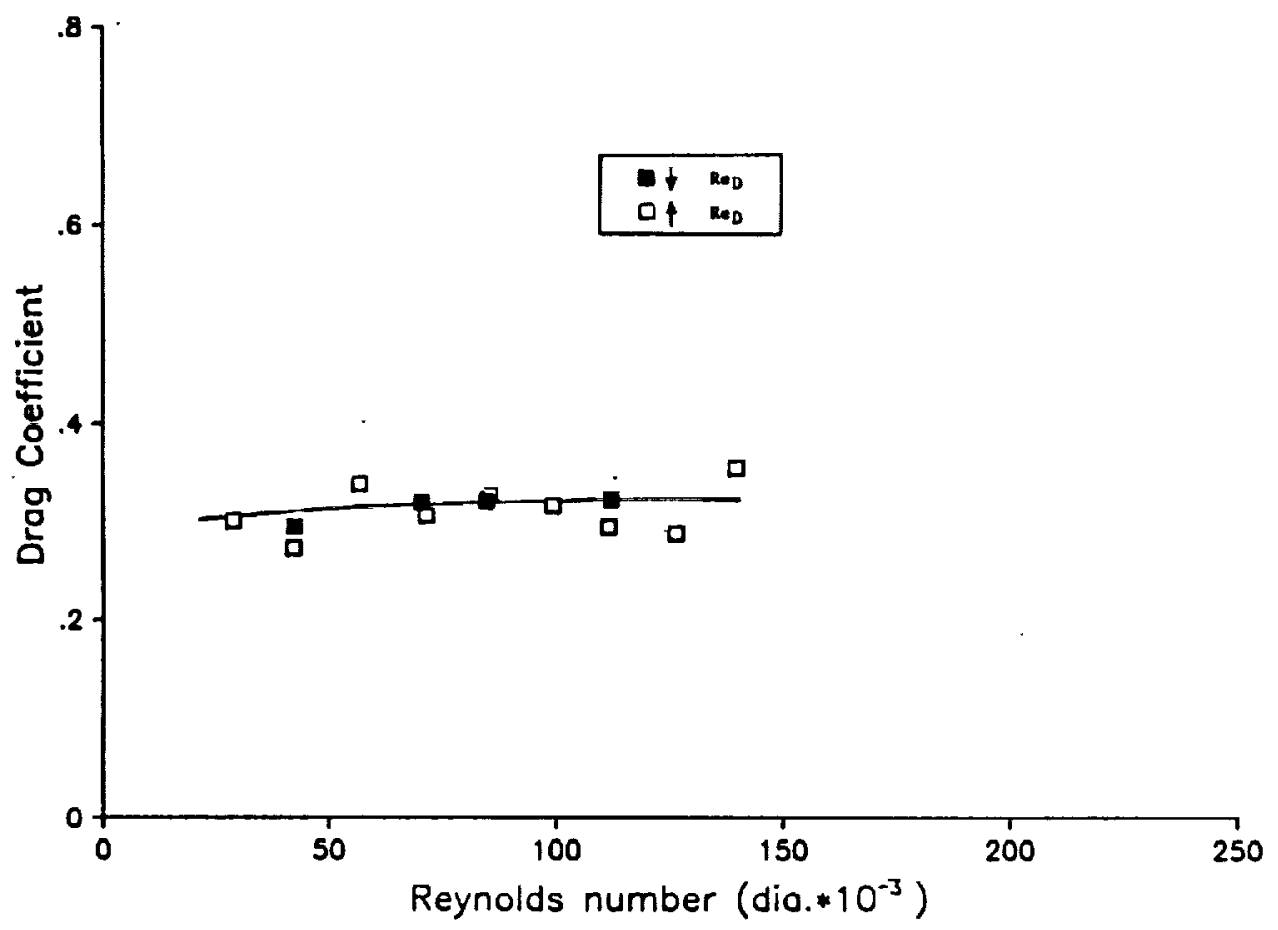

(m) Drag, $45^{\circ}$ base, Run 454, fixed transition

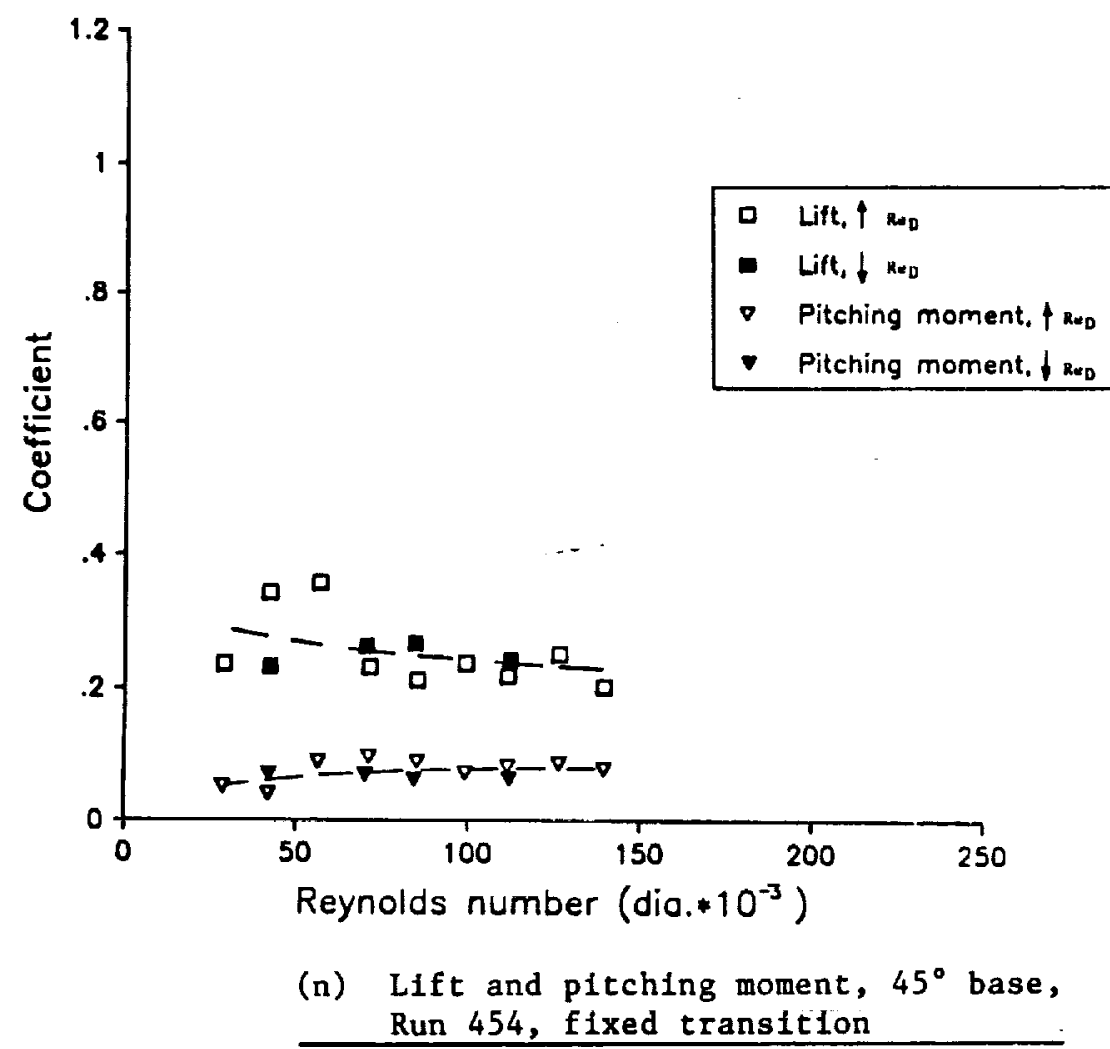

Fig. 15 cont'd 


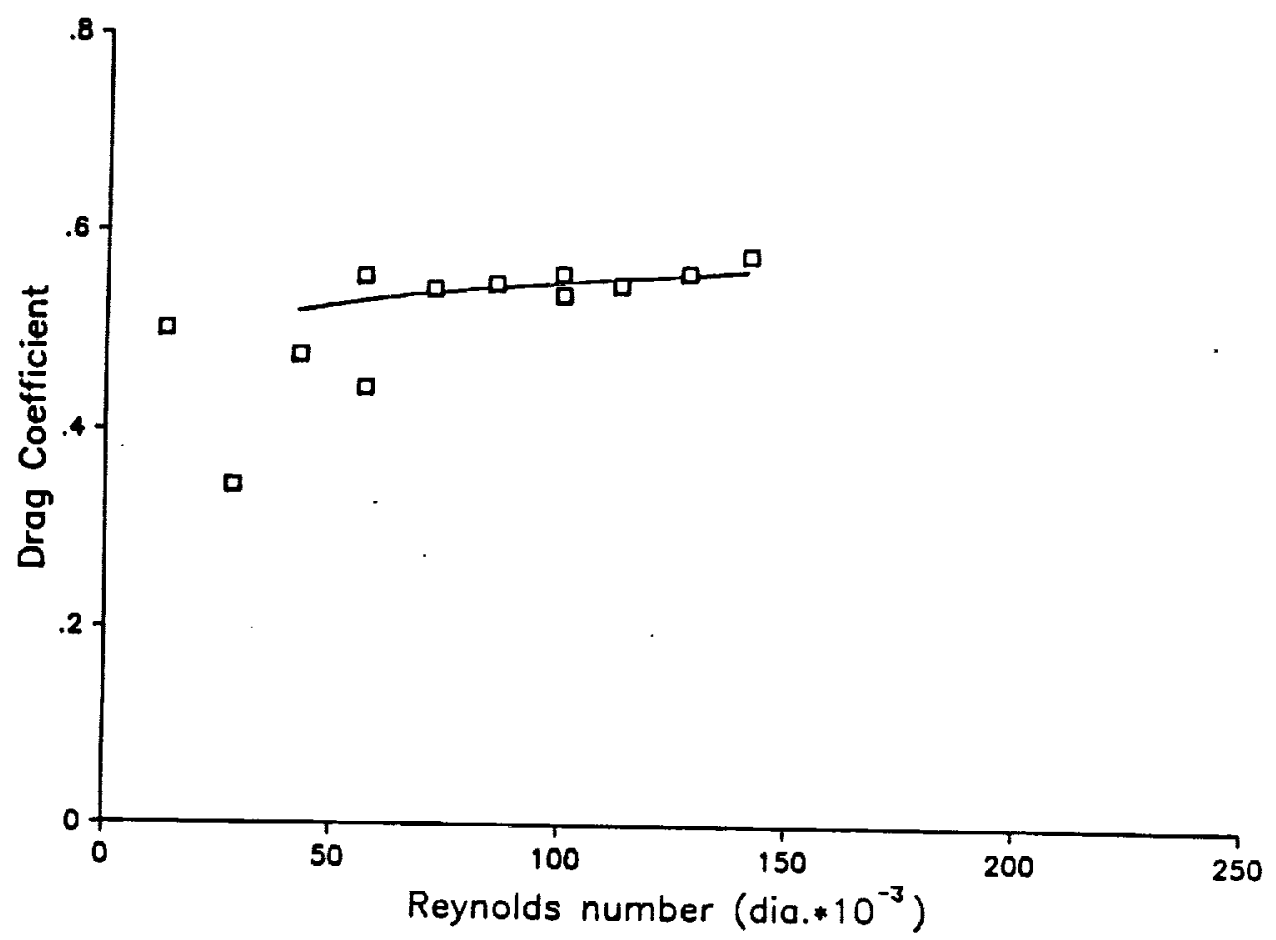

(o) Drag, $50^{\circ}$ base, Run 501, free transition

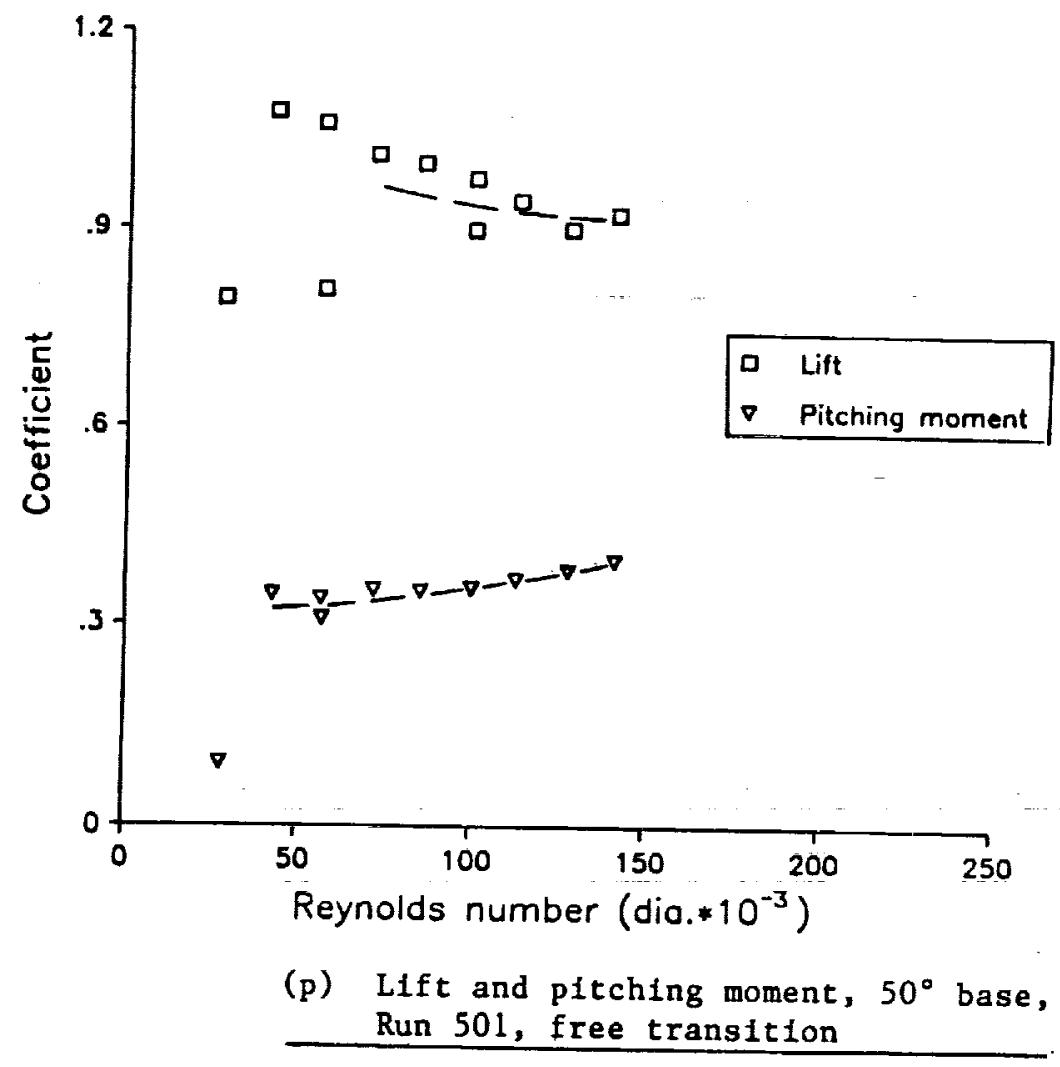

Fig. 15 cont'd 


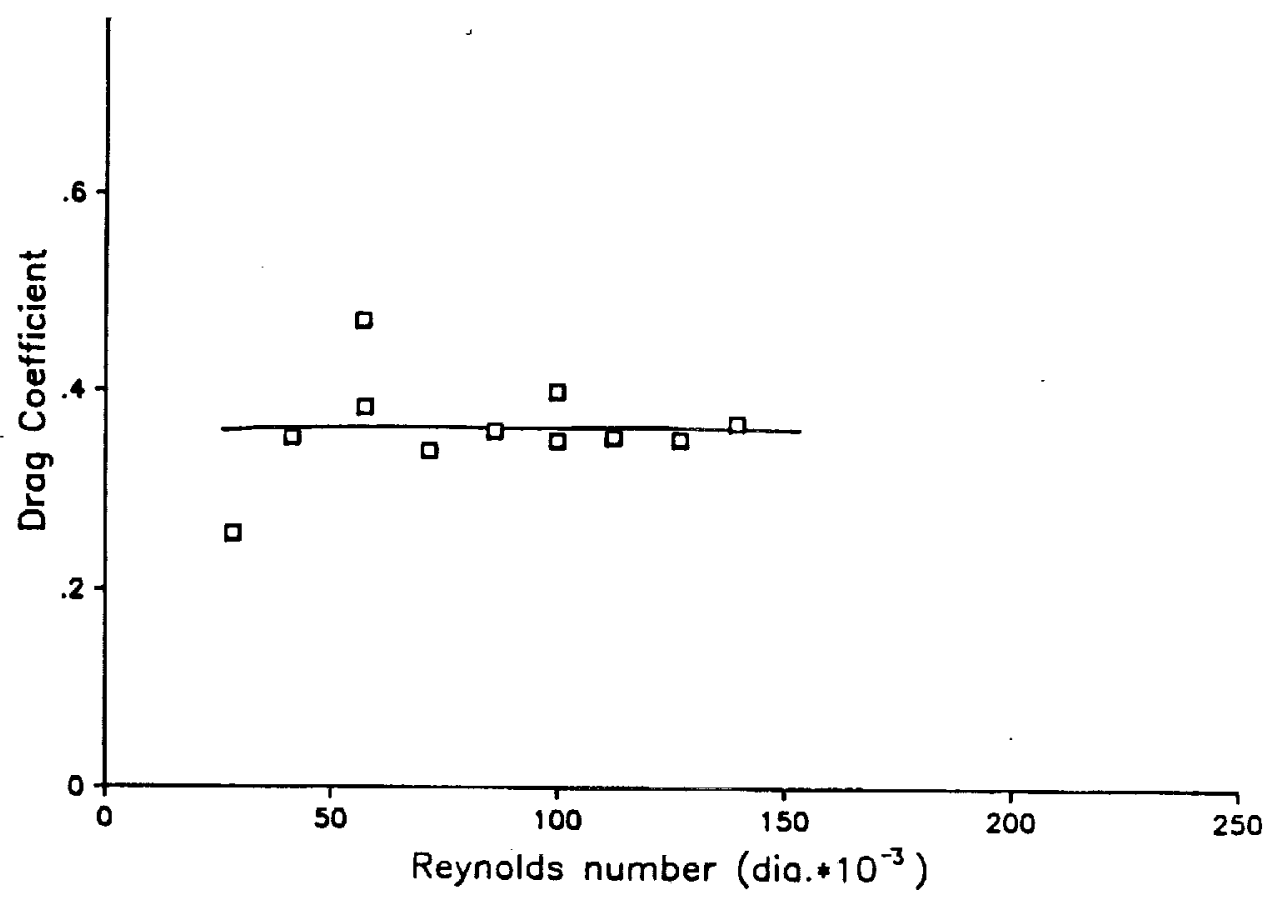

(q) Drag, $60^{\circ}$ base, Run 601 , free transition

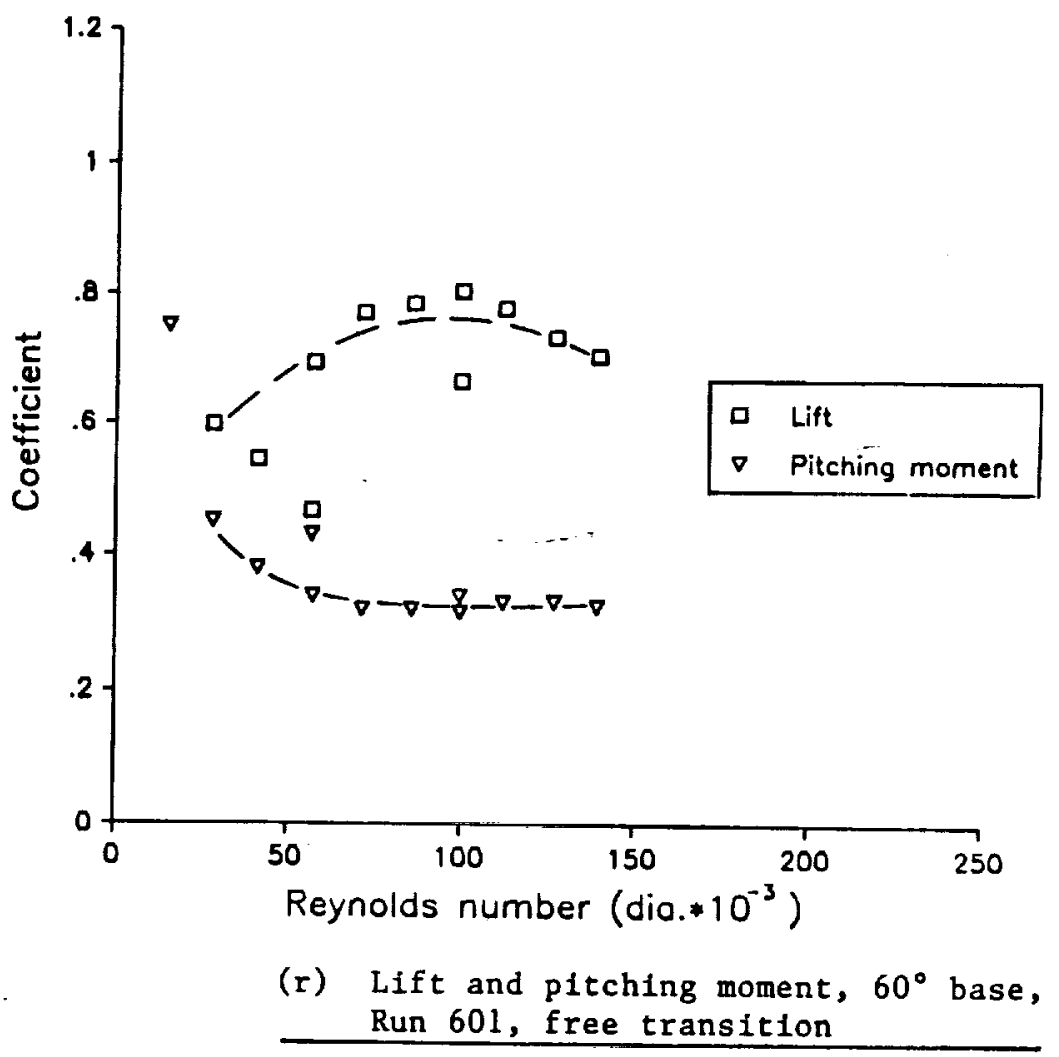

Fig. 15 cont'd 


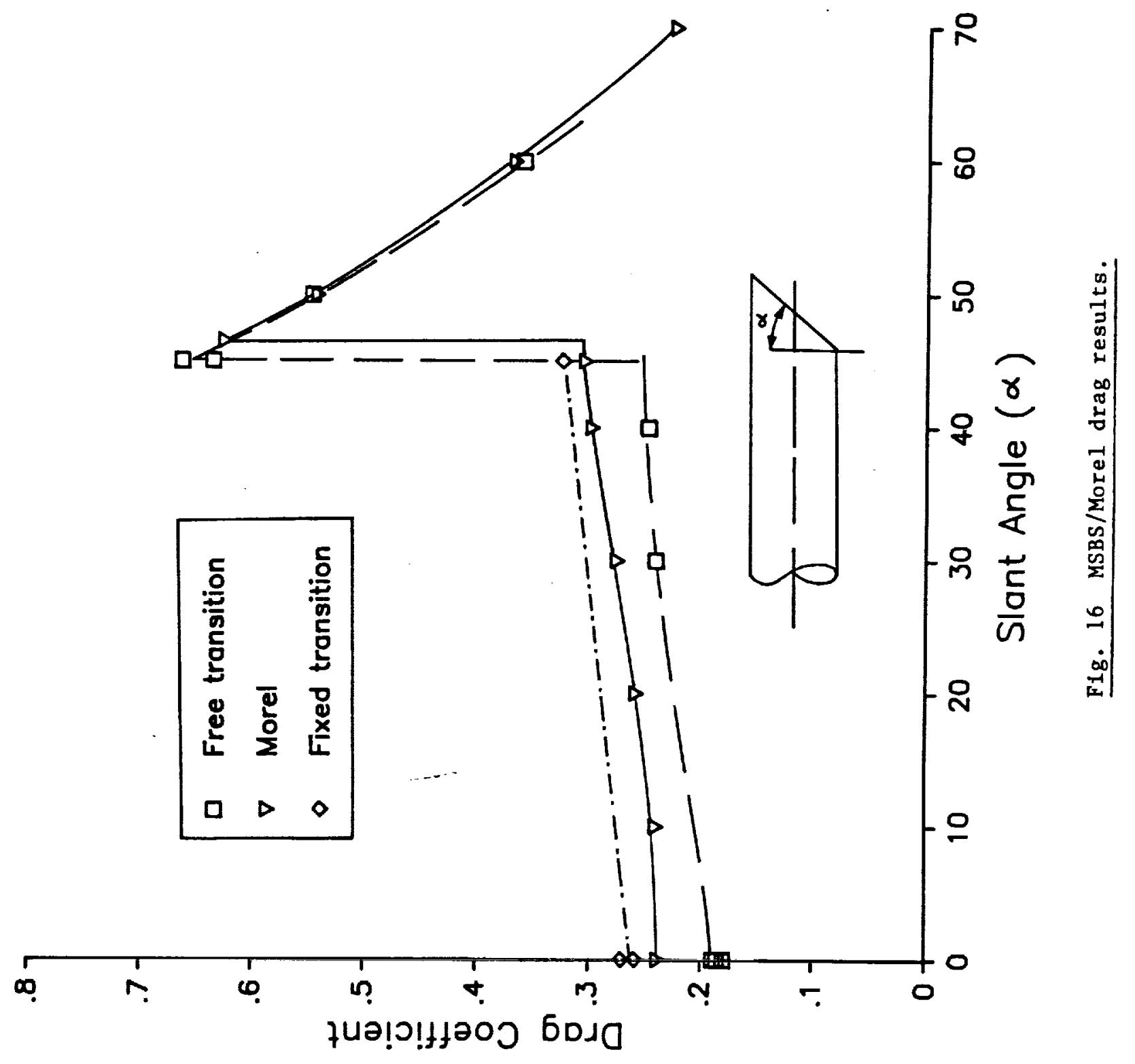




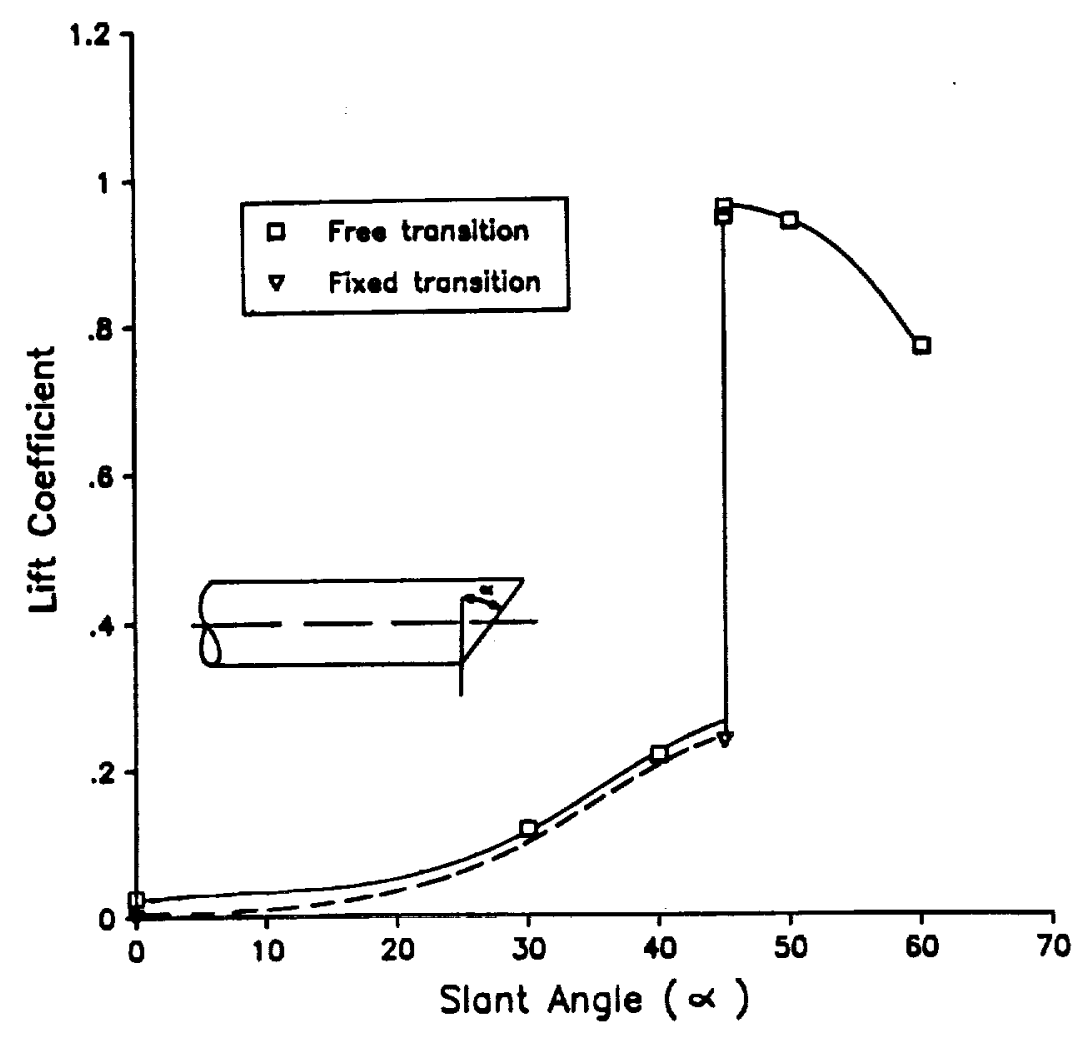

F1g. 17 MSBS Ifft results.

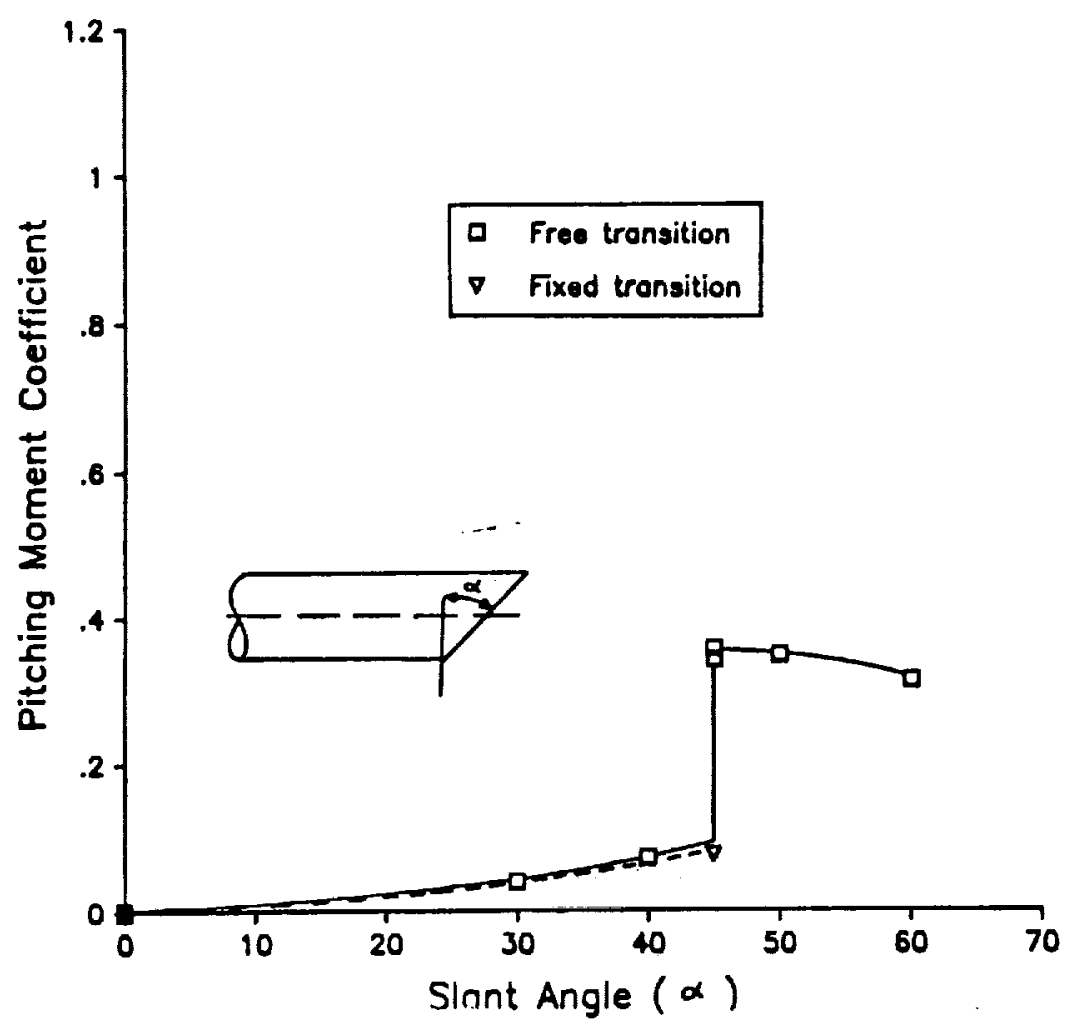

Fig. 18 MSBS pitching moment results. 


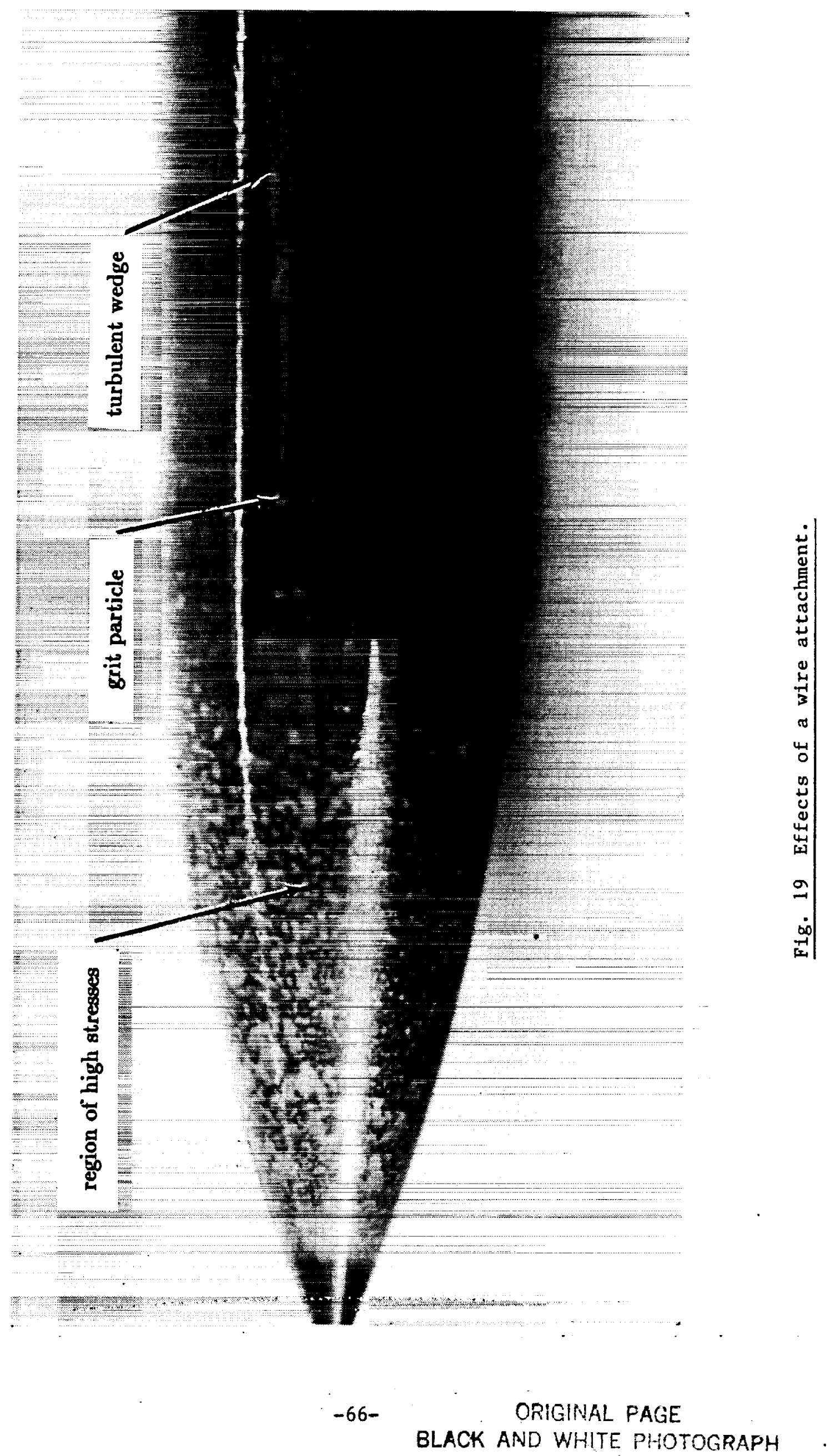




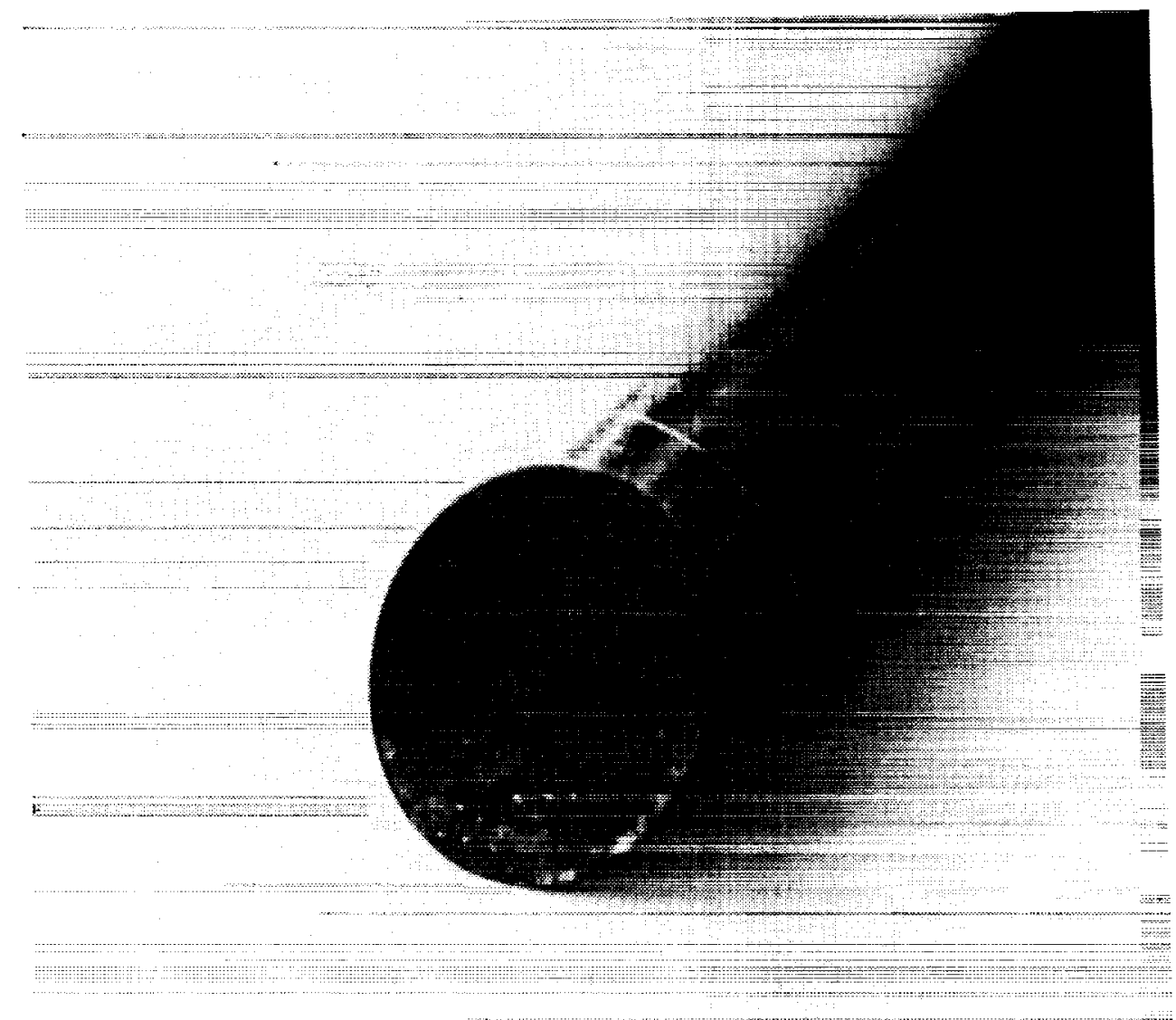

1. Quas1-symetric flow pattern $\left(30^{\circ}\right.$ base).

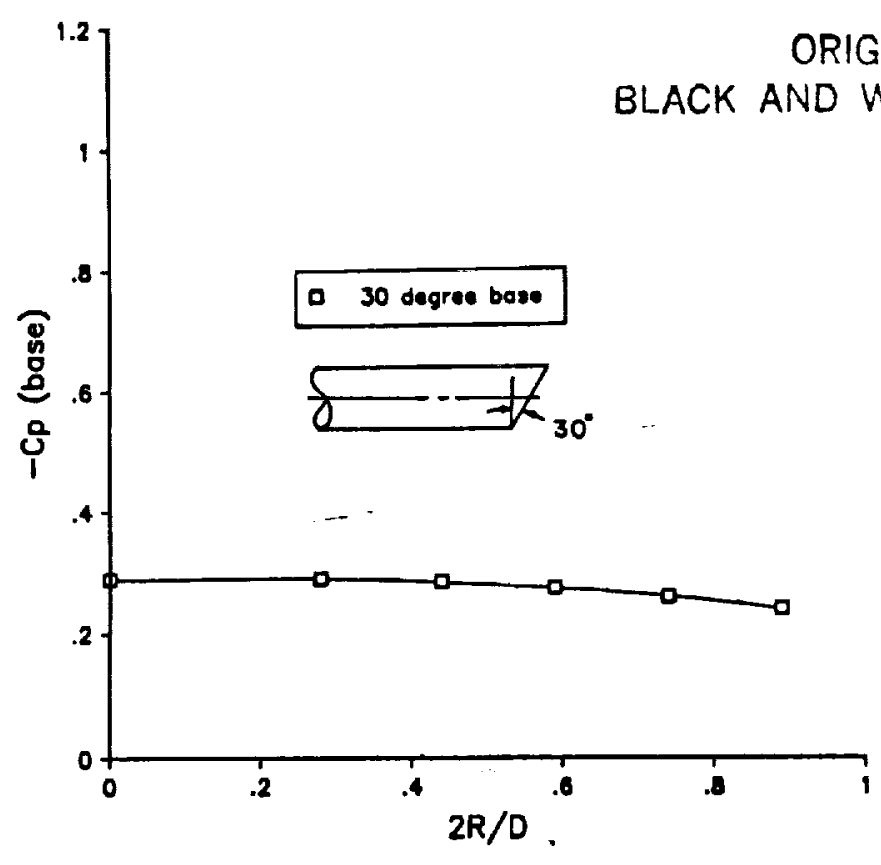

2. Pressure distribution $\left(30^{\circ}\right.$ base).

Fig. 20a Flow visualization on the $30^{\circ}$ base (Liquid crystals). 


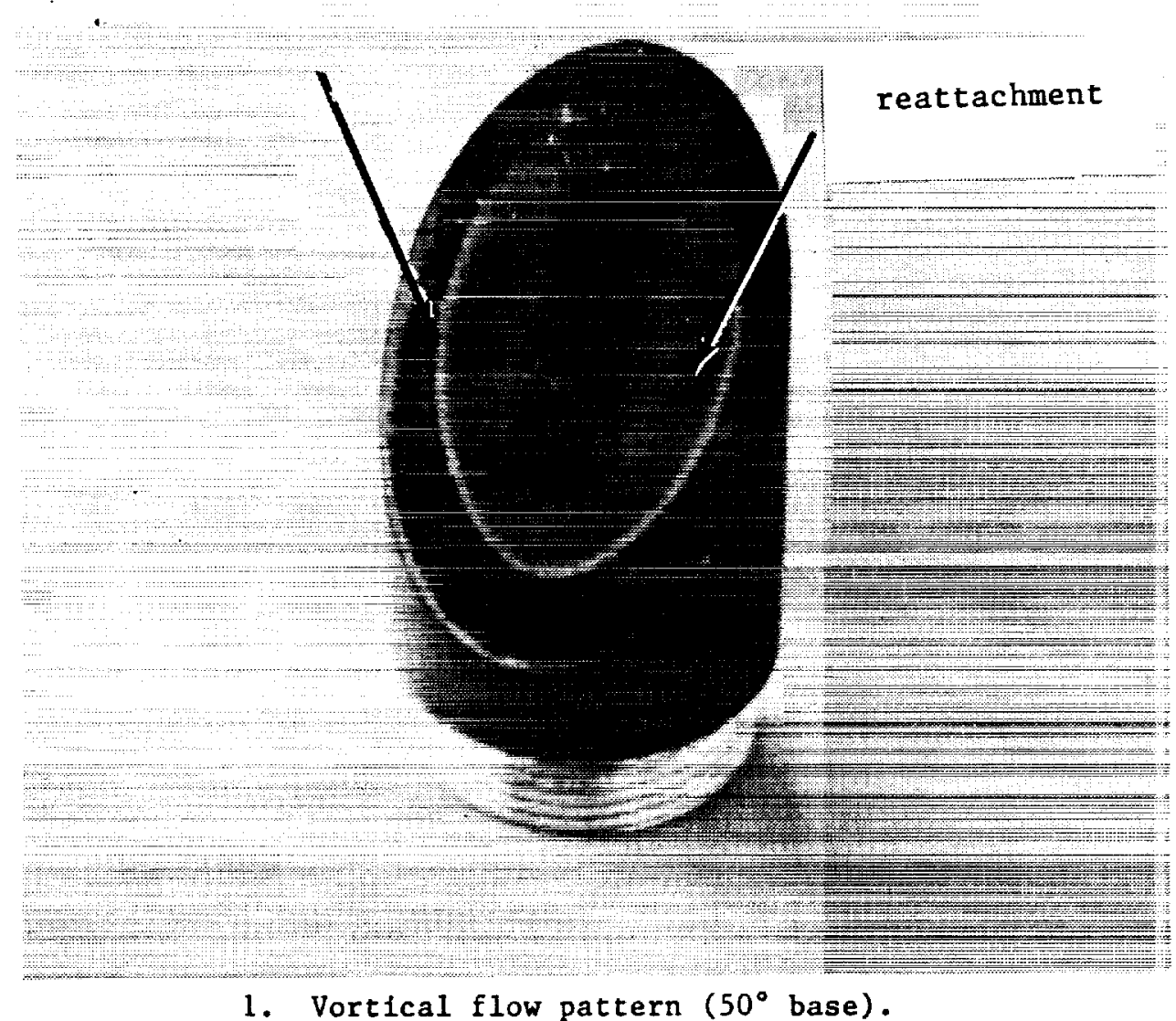

1. Vortical flow pattern $\left(50^{\circ}\right.$ base).

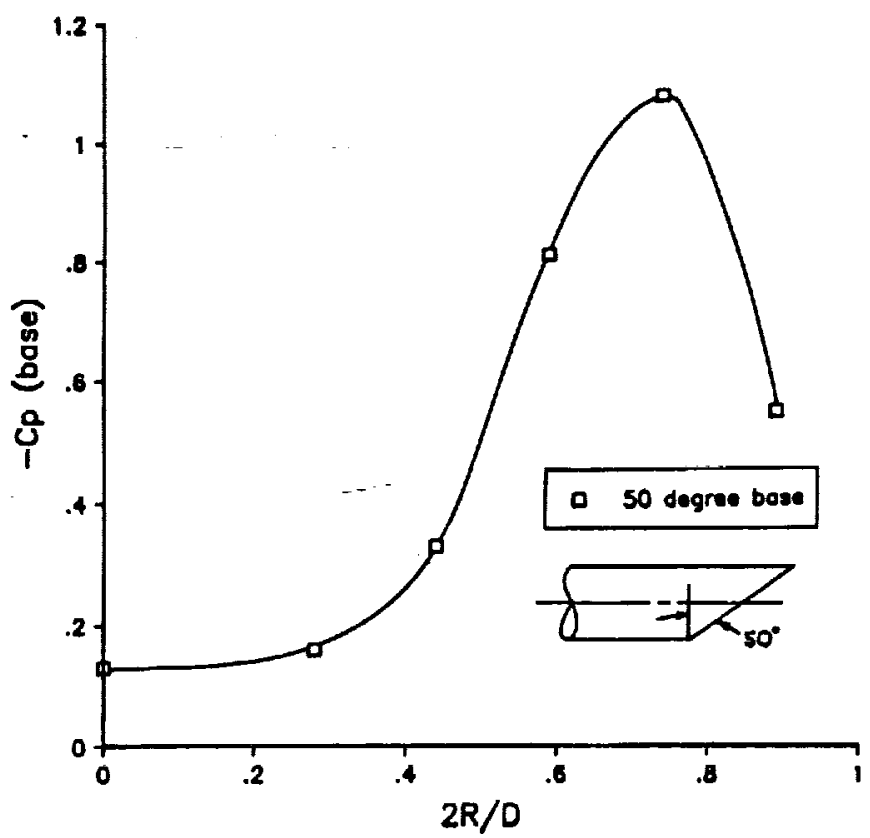

2. Pressure distribution $\left(50^{\circ}\right.$ base).

Fig. 20b Flow visualization on $50^{\circ}$ base (Liquid crystals). 


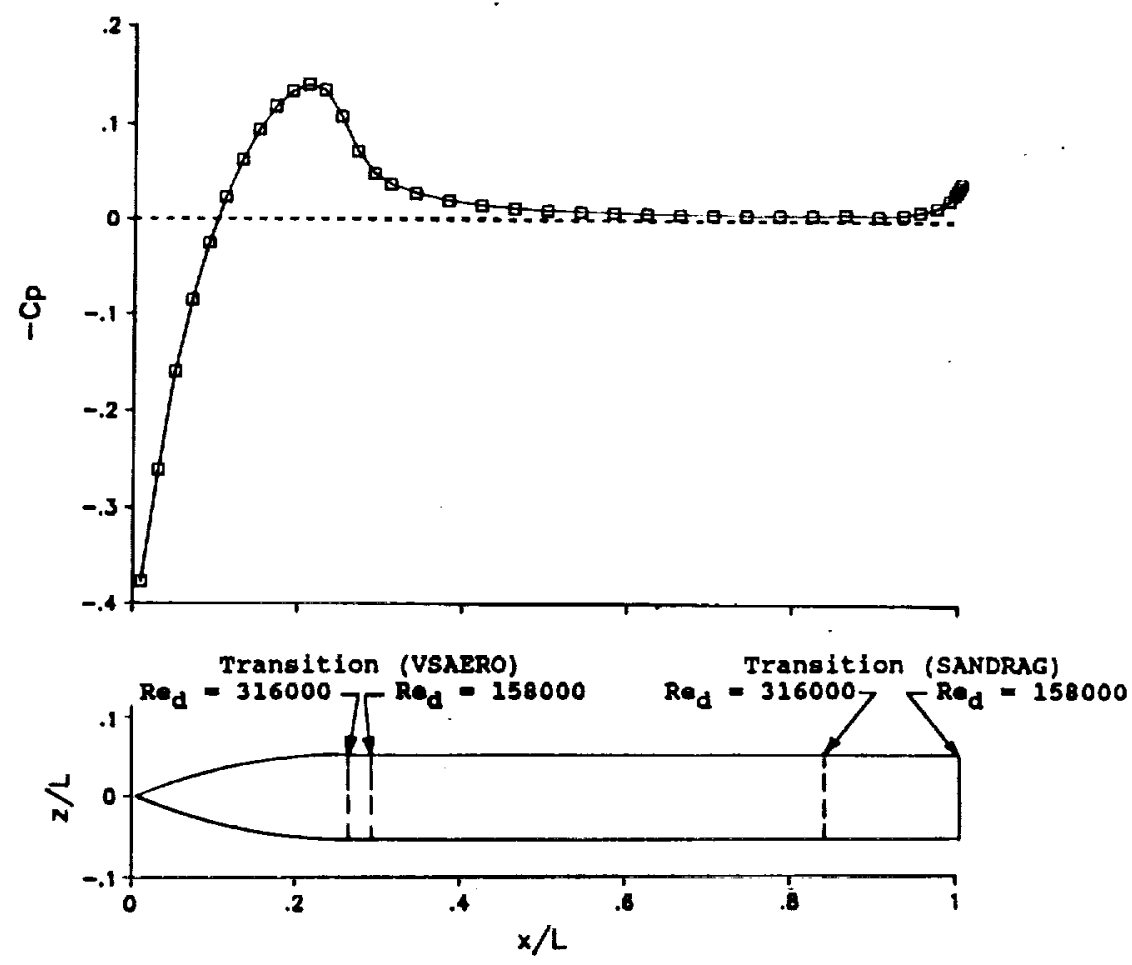

Fig. 21 Pressure distribution (VSAERO) and predicted transition locations ( $0^{\circ}$ base).

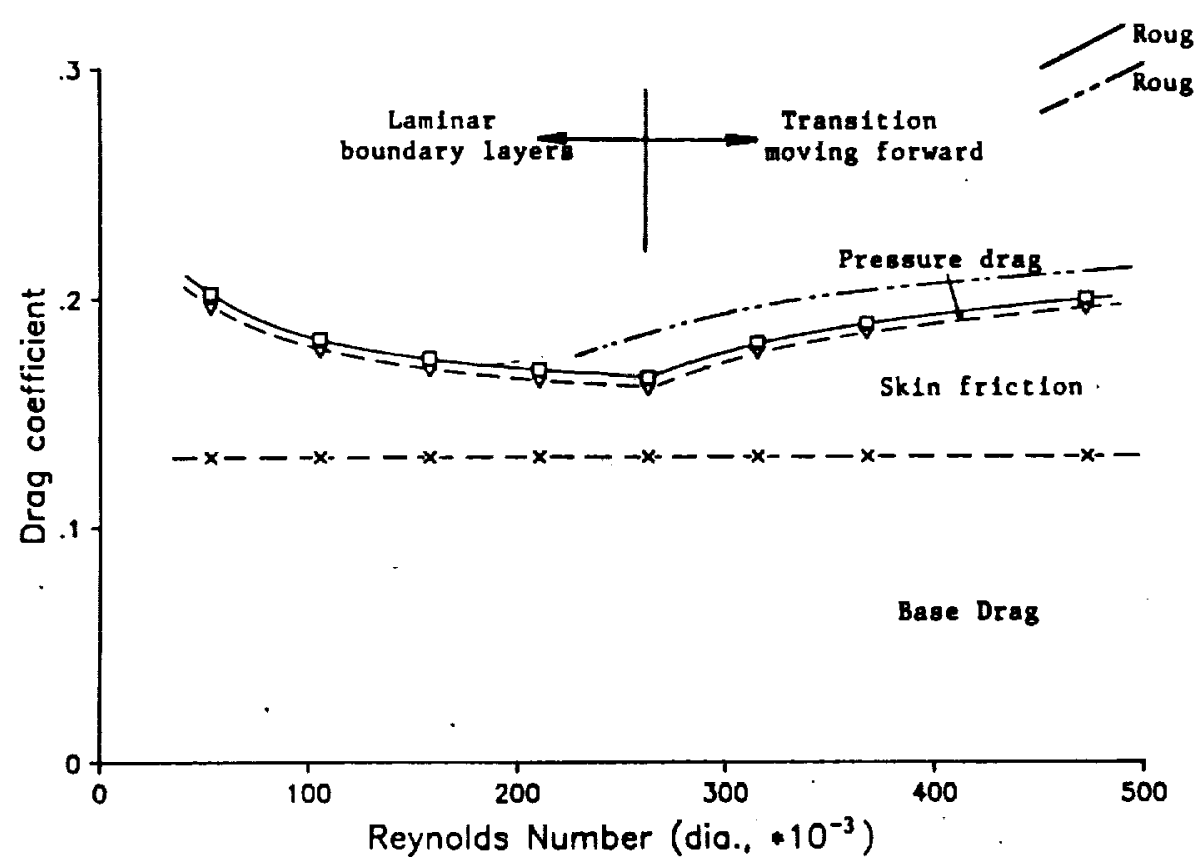

Fig. 22 Details of SANDRAG computations. 


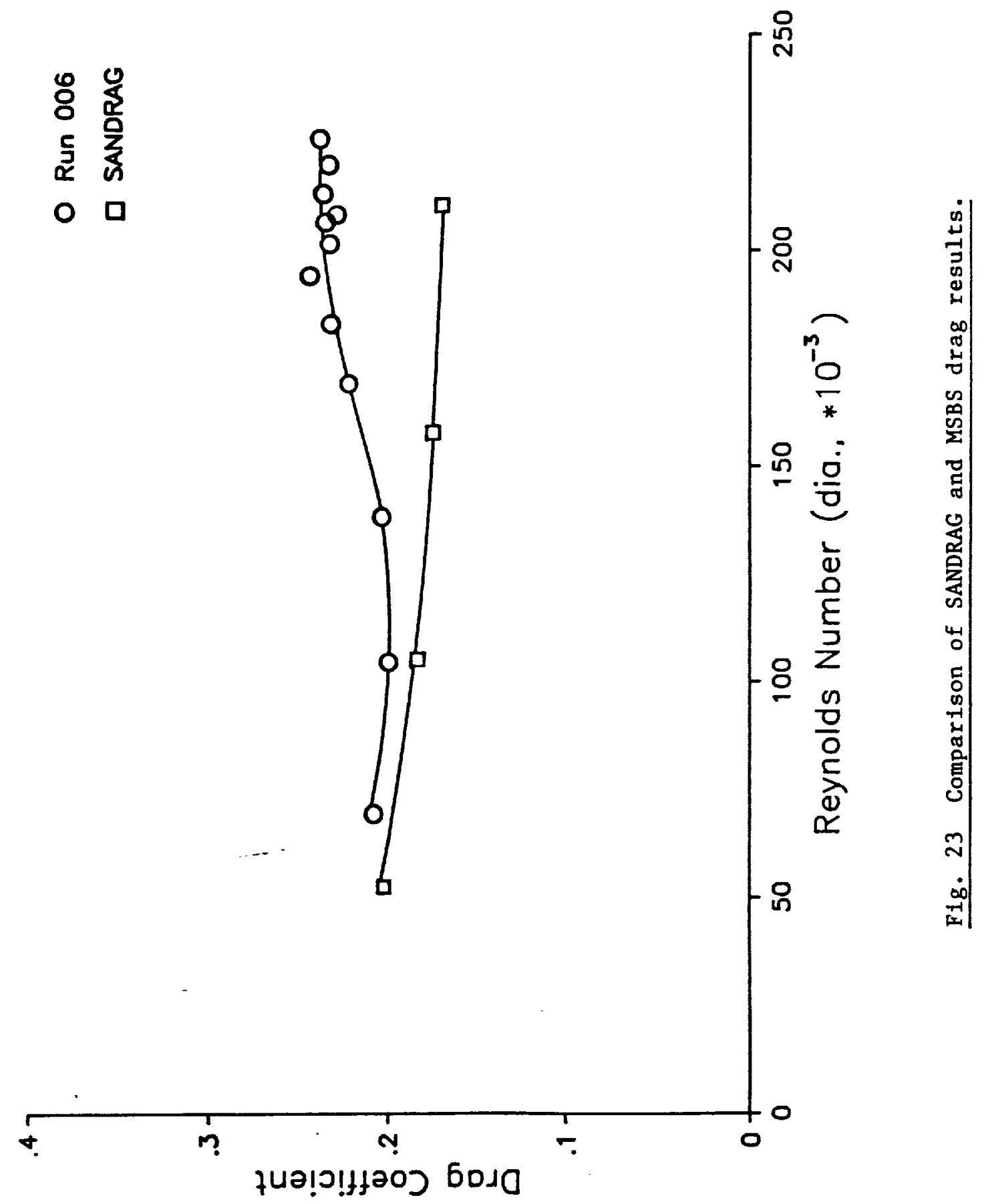




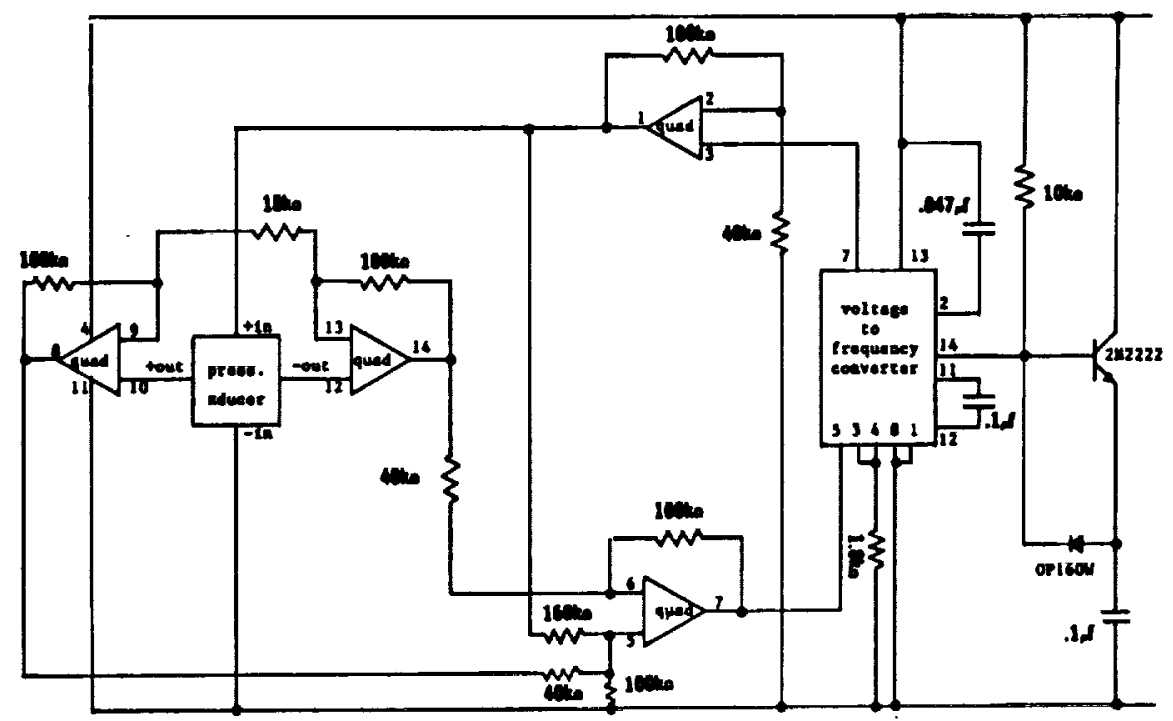

Fig. 24 Schematic of pressure telemetry system.

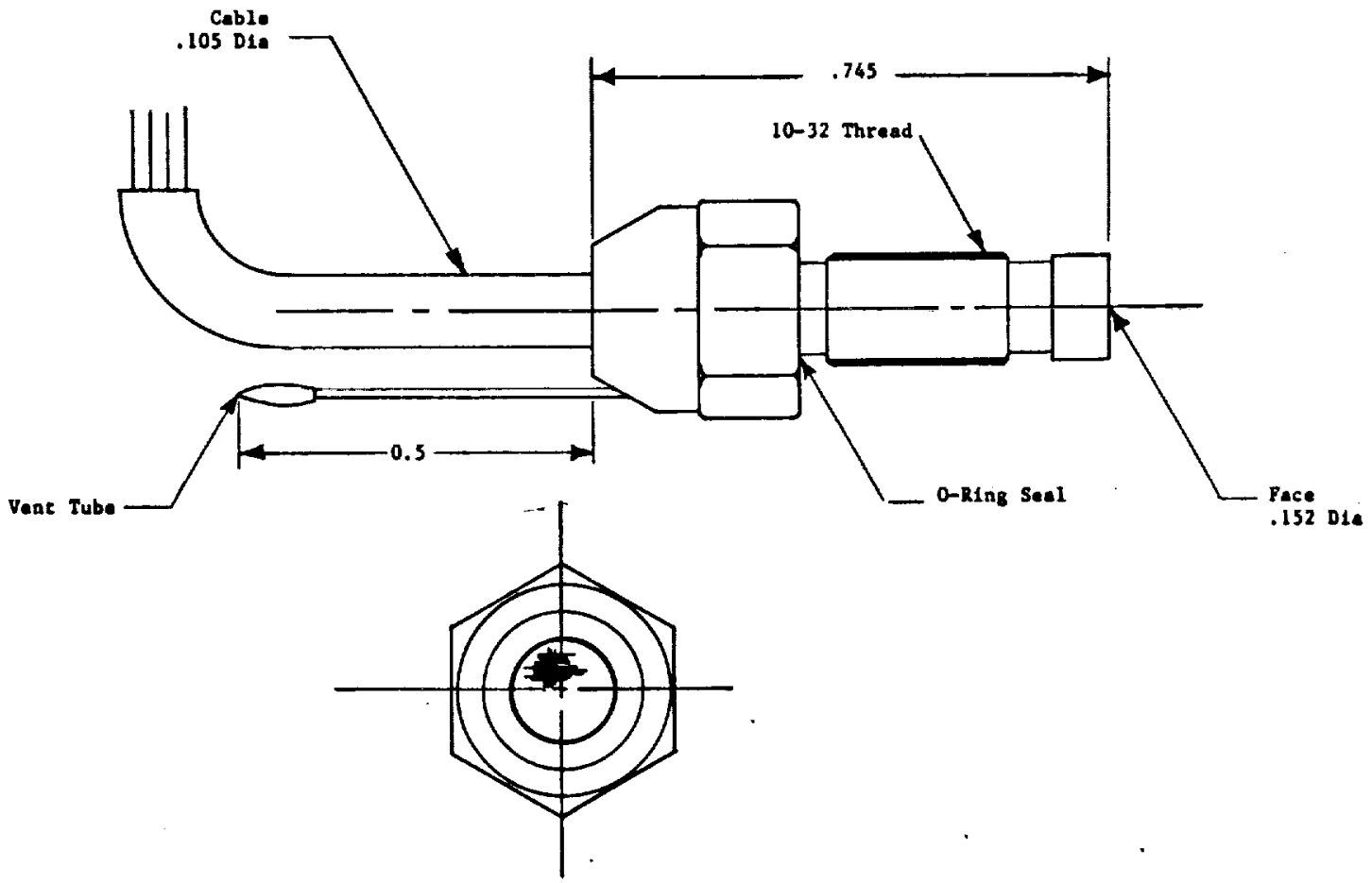

Fig. 25 Detalls of pressure transducer. 

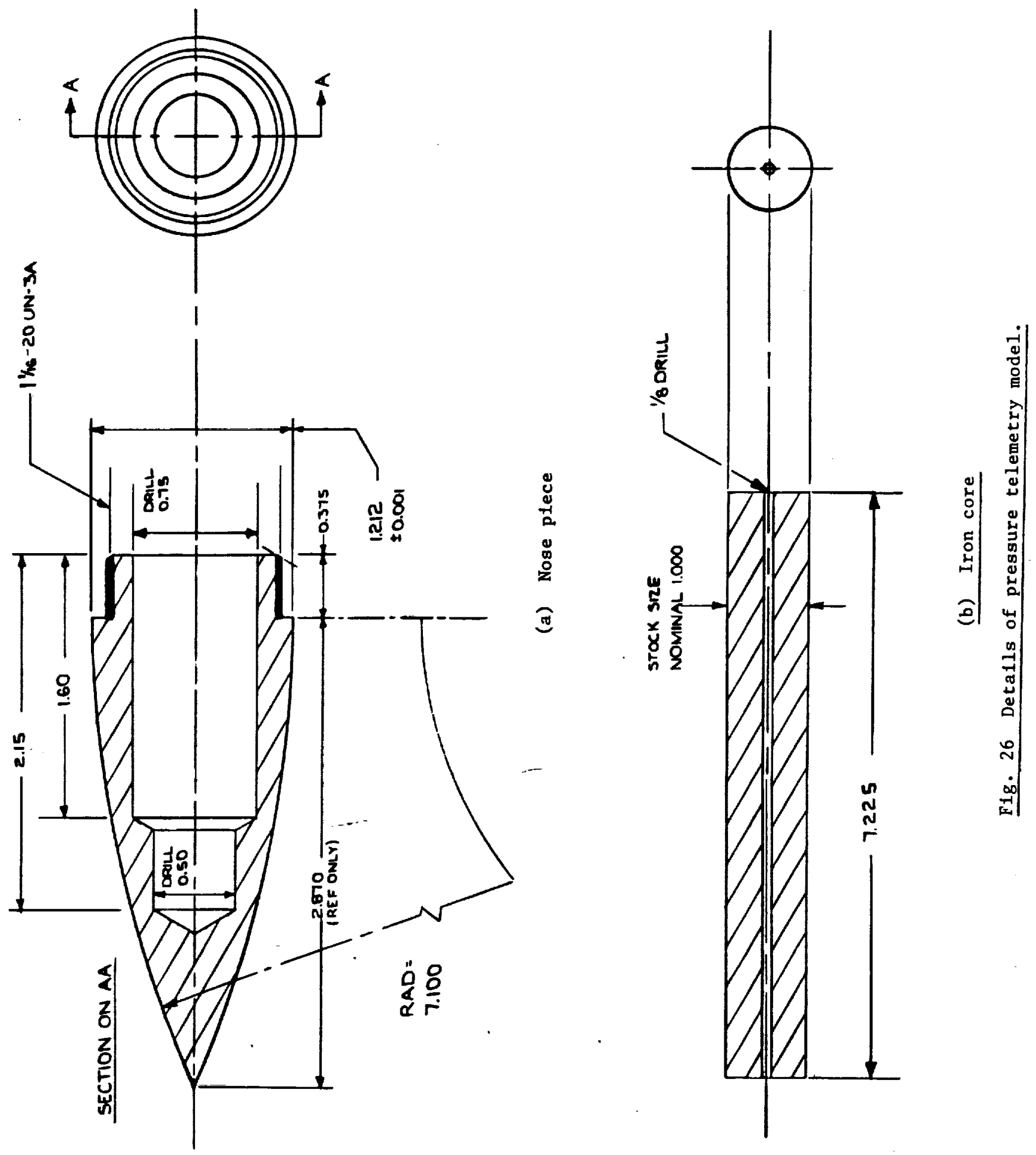


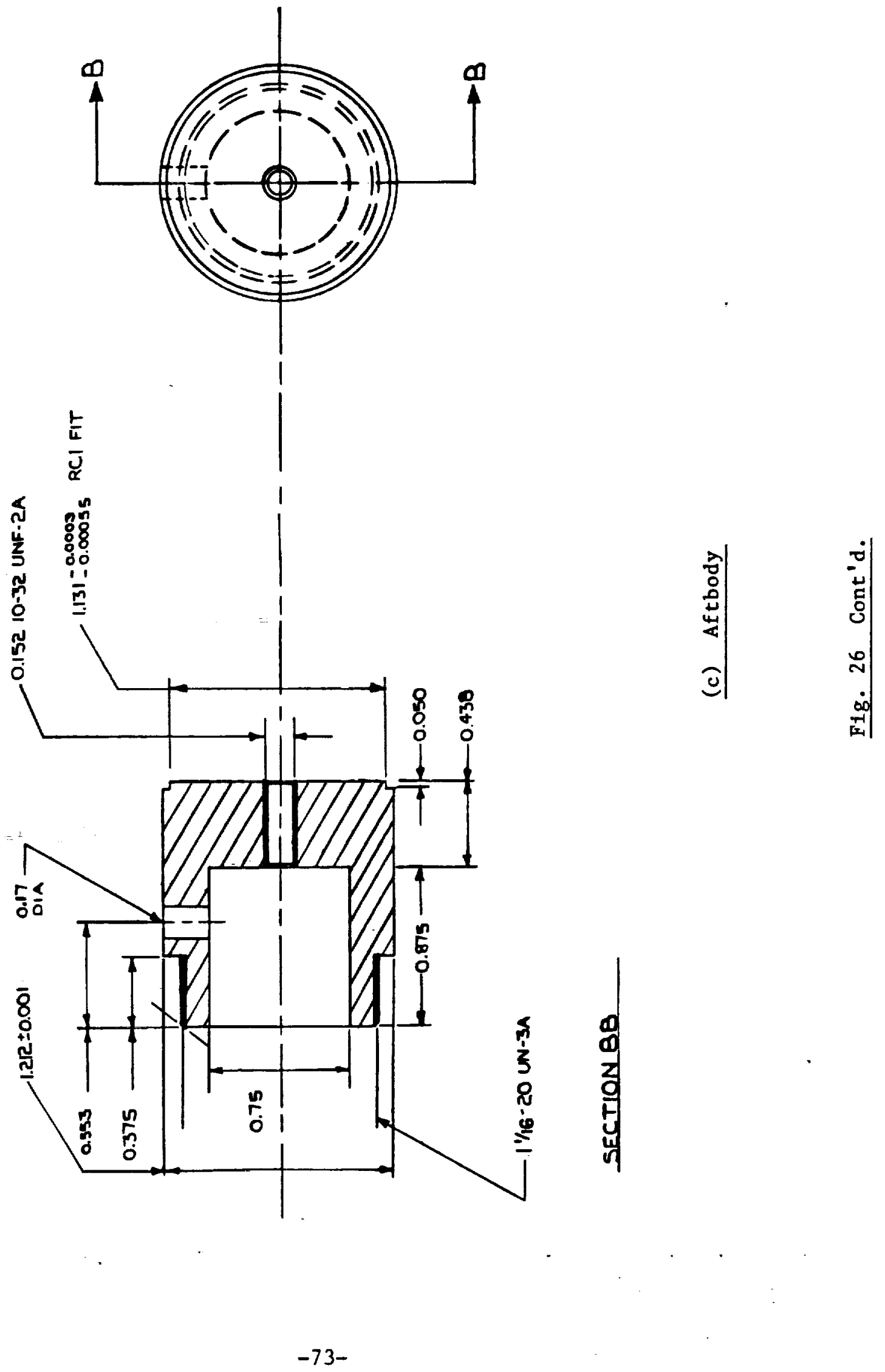



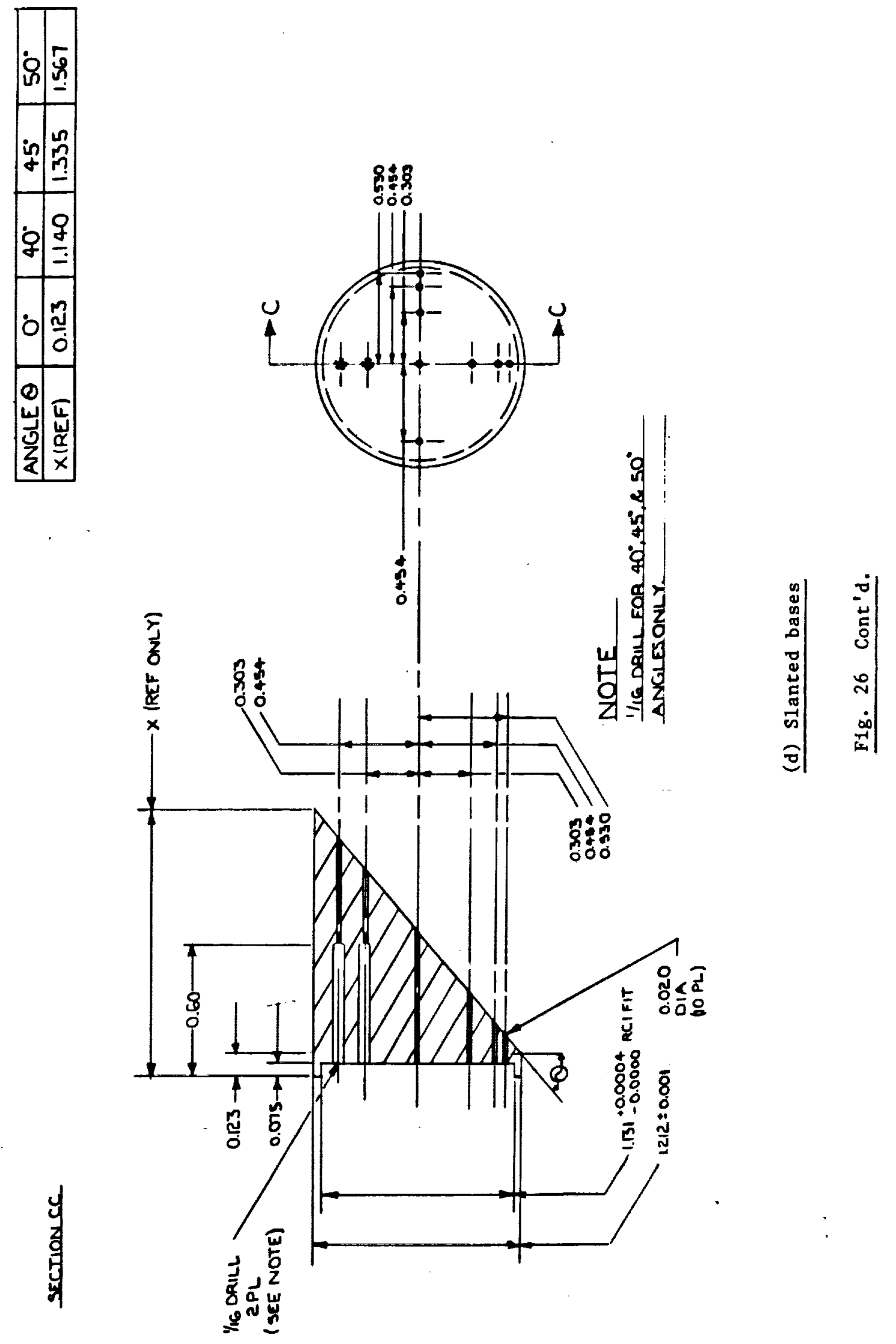


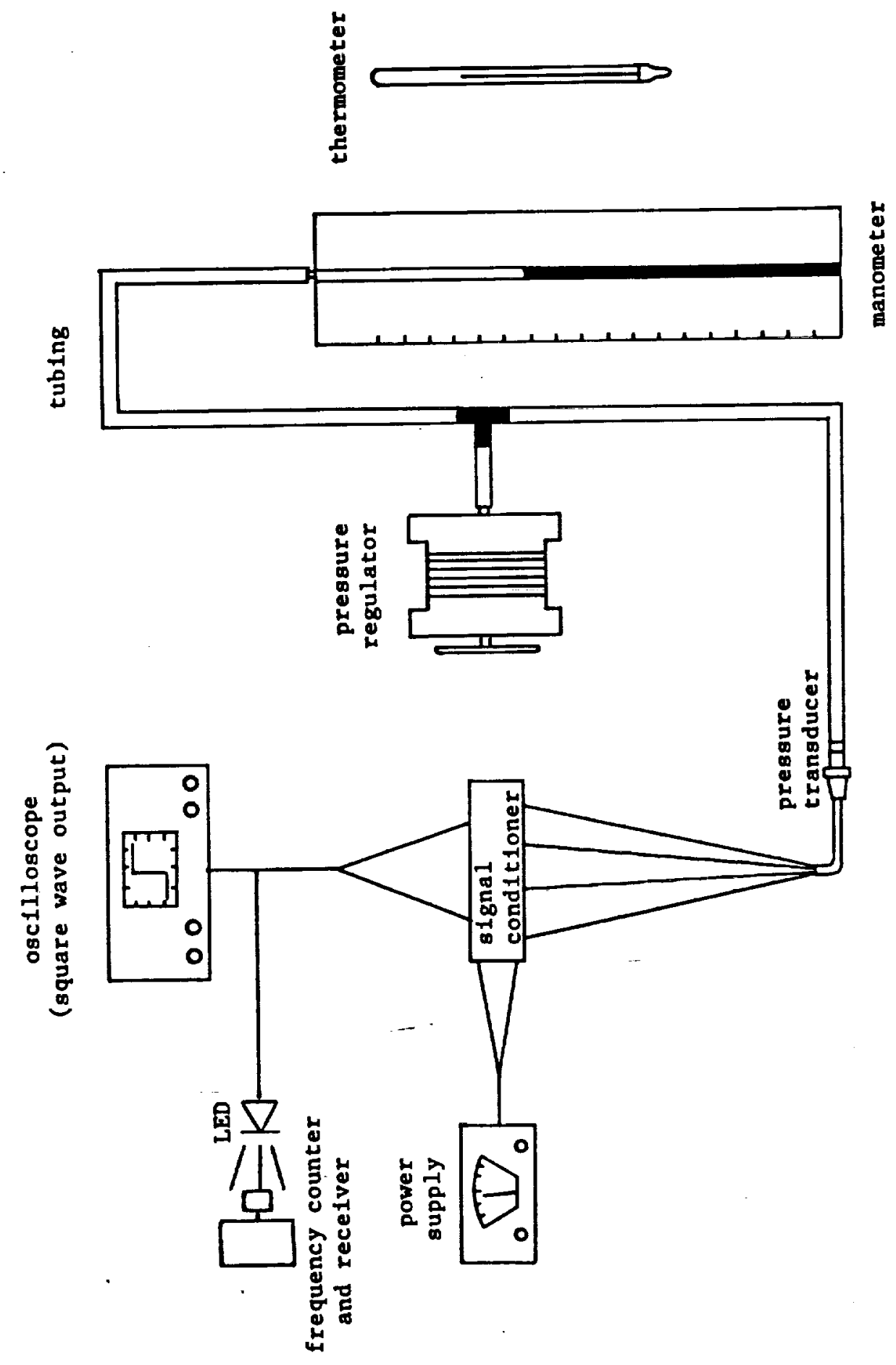

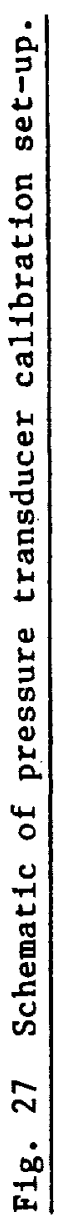




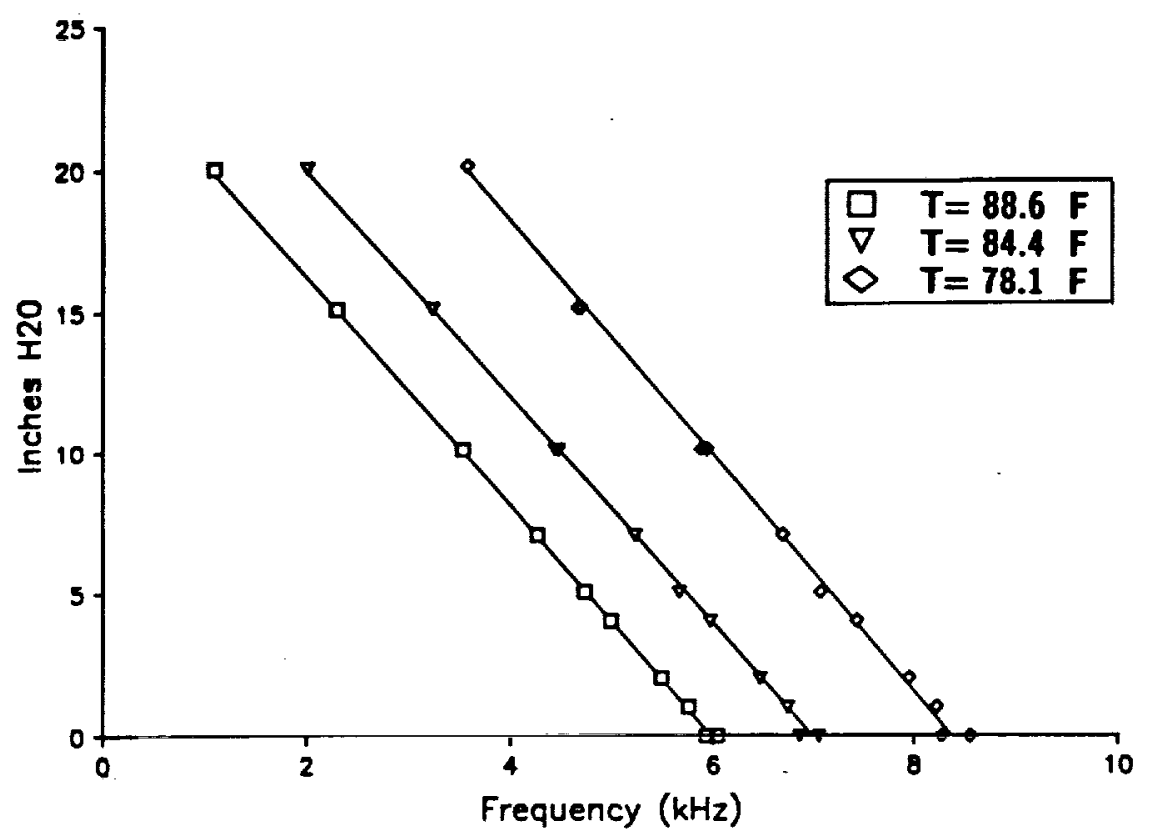

Fig. 28 Pressure transducer calibration curves.

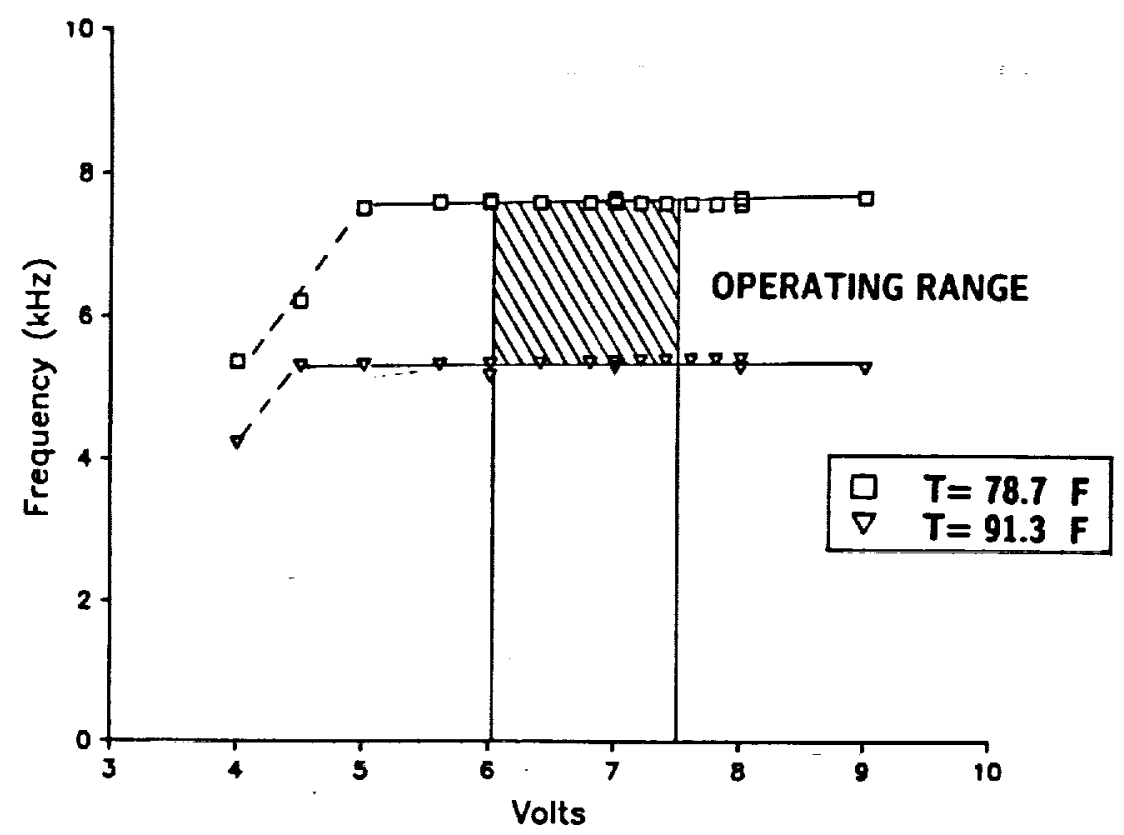

Fig. 29 Effects of input voltage on output frequency. 


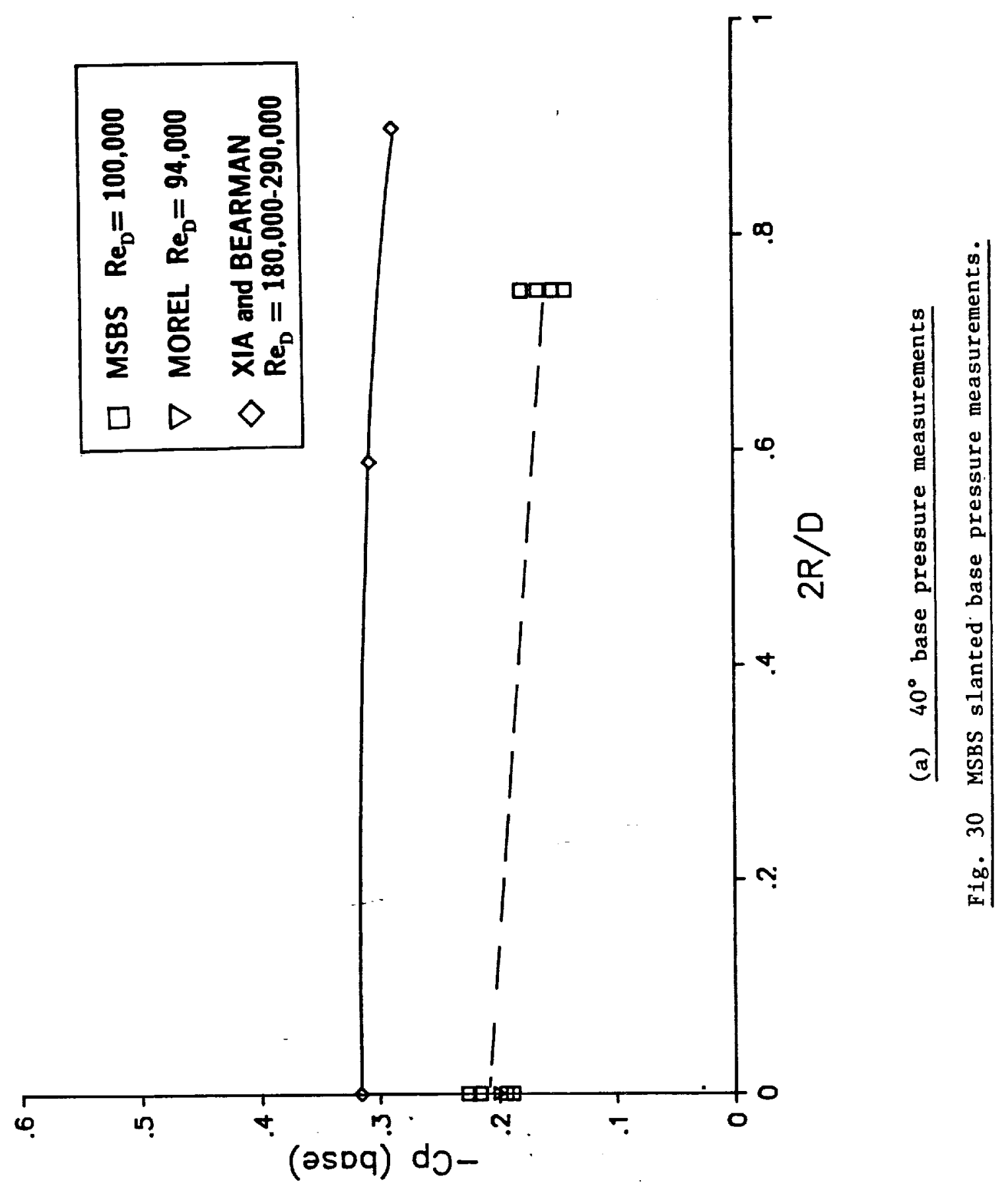




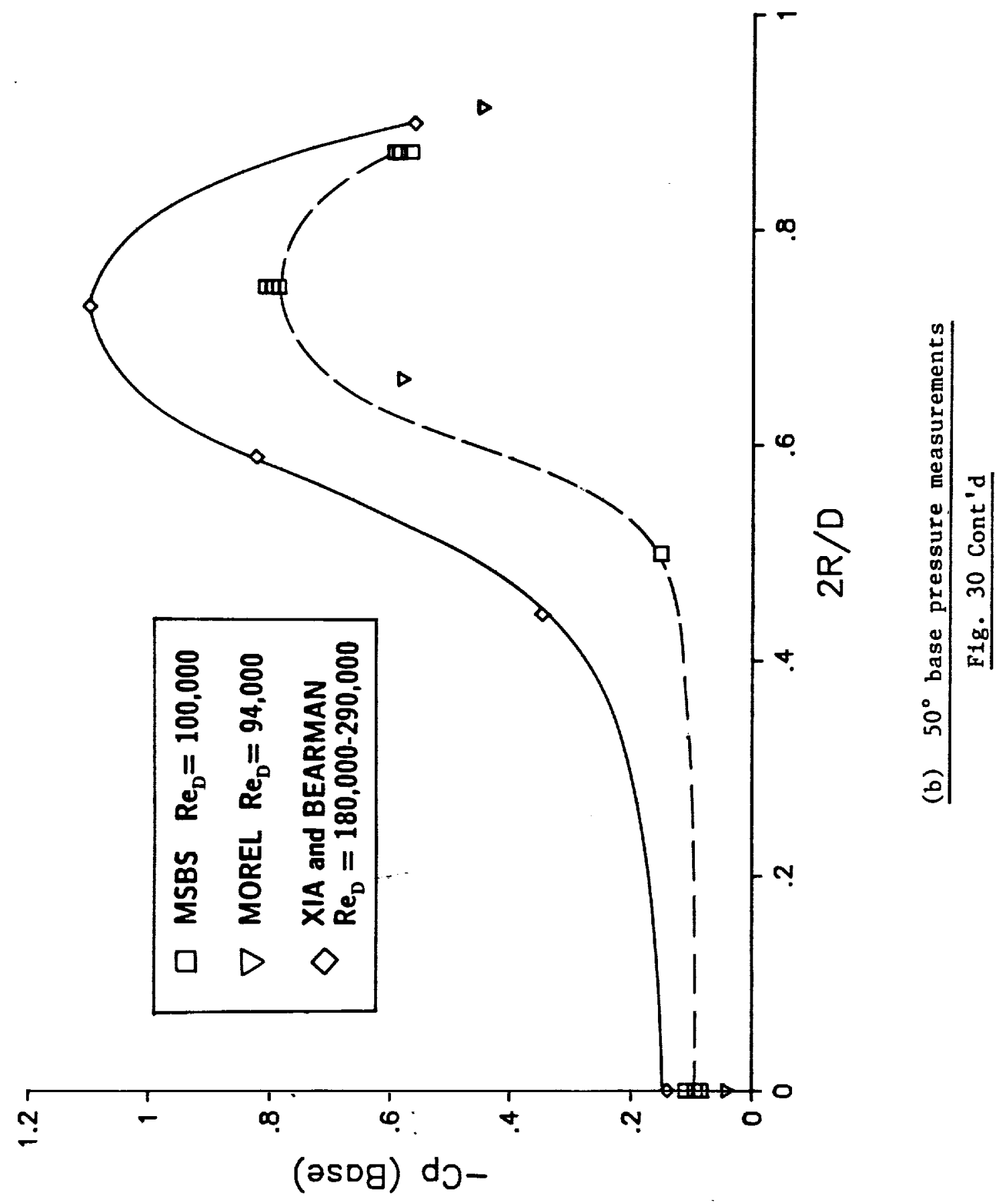




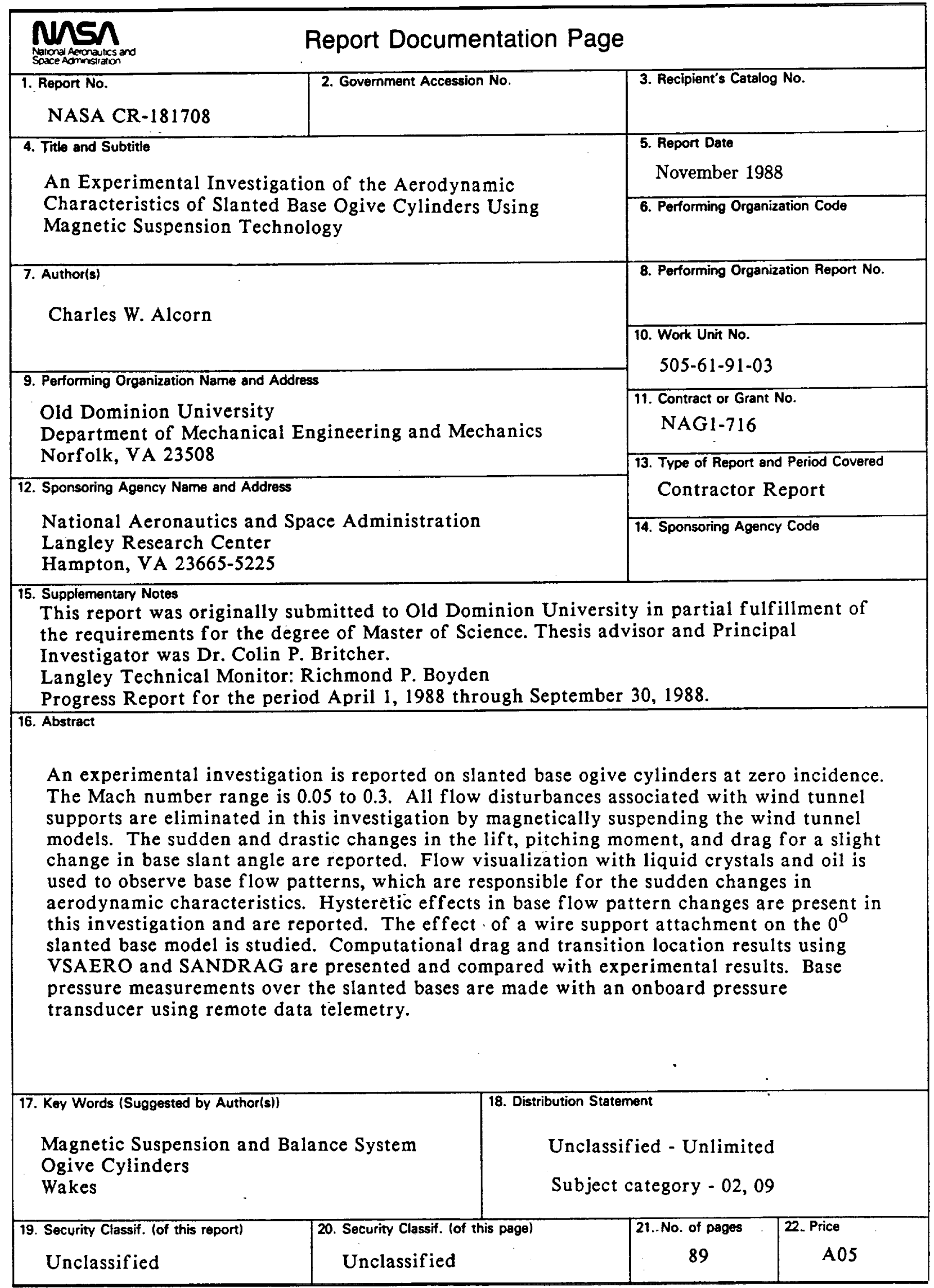


